Volkswirtschaft und Theater: Ernst und Spiel, Brotarbeit und Zirkus, planmäßige Geschäftigkeit und Geschäftlichkeit und auf der anderen Seite Unterhaltung und Vergnügen! Und doch hat eine jahrhundertelange Entwicklung ein Band, beinahe eine Kette zwischen beiden geschaffen, gehämmert und geschmiedet.

Max Epstein ${ }^{1}$

The public has for so long seen theatrical amusements carried on as an industry, instead of as an art, that the disadvantage of applying commercialism to creative work escapes comment, as it were, by right of custom.

William Poel ${ }^{2}$

\title{
4. Theatergeschäft
}

Theater als Geschäft - das scheint heute zumindest in Deutschland, wo fast alle Theater vom Staat subventioniert werden, ein Widerspruch zu sein. Doch schon um 1900 waren für die meisten deutschen Intellektuellen Geschäft und Theater, Kunst und Kommerz unvereinbare Gegensätze. Selbst für jemanden, der so intensiv und über lange Jahre hinweg als Unternehmer, Anwalt und Journalist mit dem Geschäftstheater verbunden war wie Max Epstein, schlossen sie einander letztlich aus. Obwohl er lange gut am Theater verdient hatte, kam er kurz vor dem Ersten Weltkrieg zu dem Schluss: „Das Theatergeschäft hat die Bühnenkunst ruiniert“. 3 In Großbritannien hingegen, wo Theater seit der Zeit Shakespeares als private, kommerzielle Unternehmen geführt wurden, war es völlig selbstverständlich, im Theater eine Industrie zu sehen. Der Schauspieler, Direktor und Dramatiker William Poel bezeugte diese Haltung und war zugleich einer der ganz wenigen, der sie kritisierte.

Wie auch immer man den Prozess bewertete, Tatsache war, dass Theater in der Zeit der langen Jahrhundertwende in London wie in Berlin überwiegend kommerziell angeboten wurde. Zwar gilt dies teilweise bereits für die frühe Neuzeit, erst im Laufe des 19. und frühen 20. Jahrhunderts aber entwickelte sich das Theater zu einer Industrie, die in Form von GmbHs und Aktiengesellschaften organisiert war, Interessenvertretungen besaß und große Gewinne, aber auch spektakuläre Pleiten verzeichnete. Unter all den Umwälzungen, die das Theater im Laufe des 19. Jahrhunderts, insbesondere seit seinem letzten Drittel erlebte, war seine Kommerzialisierung die auffälligste und die einschneidendste. Das folgende Kapitel spürt dieser Entwicklung nach, indem es nach ökonomischen Akteuren, Praktiken und Strukturen fragt. Sie sind der Gegenstand des ersten Unterkapitels, das den Unternehmern und Unternehmen, den Einnahmen und Ausgaben, der zunehmenden Konzentration der Theaterindustrie und der Konkurrenz

1 Epstein, Theater und Volkswirtschaft, S. 3.

2 Poel, What is Wrong with the Stage, S. 9.

3 EPSTEIN, Theater und Volkswirtschaft, S. 17. 
von Kino und Radio nachgeht. Das folgende Unterkapitel behandelt dann, ausgehend von der um 1900 verbreiteten Vorstellung einer ,Industrialisierung des Theaters, die Veränderungen auf der Ebene der Produkte (der Texte und Aufführungen) sowie den internationalen Austausch von Stücken und Inszenierungen. Das Theater ,erlitt' die Kommerzialisierung aber nicht; es war aktiv an ihr beteiligt, war selbst ein Motor für die Transformation von Unterhaltung in eine marktförmige Ware und bildete so die Ökonomisierung der Gesellschaft ab. Darauf geht das letzte Kapitel ein, das die Repräsentation von Kommerz und Konsum in Form von Reklame, Warenhaus und Mode auf der Bühne zum Gegenstand hat. 
Die meisten Schauspielunternehmer [...] werden von der Spekulation getrieben, $[\ldots]$ das materielle Interesse ist die Haupttriebfeder ihrer Unternehmungen.

C. A. I. Gesell ${ }^{4}$

I am, first and of all, a business man. I am out to make money for my old age, if I am spared.

Sir George Alexander 5

\subsection{Unternehmen}

Wie unterschiedlich die Sichtweisen auf das Geschäftstheater in Berlin und London waren, lässt sich auch daran ablesen, dass deutsche Theaterunternehmer nicht selten als geldgierige Spekulanten verunglimpft wurden, während ein angesehener britischer actor-manager wie Sir George Alexander sich offen dazu bekannte, dass er sich als ein Geschäftsmann verstand, der mit Unterhaltung Geld verdiente, ohne dass die Öffentlichkeit daran Anstoß nahm. Tatsächlich stand der „Betrieb eines größeren Theaters [...] an Kompliziertheit und Vielgestaltigkeit keinem industriellen nach".6 Insofern sie nach Gewinn strebten, gehorchten die Theaterbetriebe dem Prinzip der Gewinnmaximierung; insofern sie einer natürlichen oder juristischen Person gehörten dem Prinzip des Privateigentums; insofern sie selbstständig und unabhängig wirtschaftlich tätig waren dem Autonomieprinzip - und damit den drei Elementen, die definitionsgemäß ein Unternehmen konstituieren. ${ }^{7}$ Überdies waren sie organisiert wie andere Unternehmen auch, beschäftigten Arbeiter und Angestellte und produzierten Unterhaltung für eine wachsende Zahl von Konsumenten. Auf der Ebene der Unternehmer ist allerdings zwischen verschiedenen Funktionen zu unterscheiden: zwischen dem Besitzer eines Theaters (owner oder proprietor), dem Mieter (lessee), dem Konzessionär (licence holder), dem Direktor (manager) und dem Regisseur (stage manager, später director). ${ }^{8}$ Alle diese Funktionen konnten sich in einer Person vereinigen und taten dies bis ins 20. Jahrhundert hinein häufig, vor allem in Großbritannien, wo der actor-manager zugleich Hauptdarsteller, Regisseur und Geschäftsführer war. Mit der Zeit jedoch gingen diese Funktionen auf verschiedene Personen über. An die Stelle von Familienbetrieben traten erst GmbHs und Aktiengesellschaften, später Theaterkonzerne, die mehrere Bühnen gleichzeitig bespielten und die sich nach dem Ersten Weltkrieg oft zu Trusts zusammenschlossen, womit die Kommerzialisierung ihren Höhepunkt erreichte. Diese Entwicklung zeichnet das

4 GeSELL, Die Übelstände, S. 16.

5 Sir George Alexander, The Referee, 17.3. 1918, zit. nach CARTer, The New Spirit, S. 19.

6 Engel-Reimers, Die deutschen Bühnen, S. 42.

7 Vgl. Pierenkemper, Unternehmensgeschichte, insbes. S. 13-54; Berghoff, Moderne Unternehmensgeschichte, insbes. S. 7-12.

8 Vgl. Davis, The Economics, S. 166. 
folgende Kapitel nach, indem es Unternehmer, Besitzverhältnisse, Unternehmensformen und die Konkurrenz durch neue Medien in den Blick nimmt.

\section{Unternehmer}

Das britische Theater der edwardianischen Zeit war immer noch dominiert von der Institution des actor-manager. Sie lässt sich zurückverfolgen bis in die zweite Hälfte des 18. Jahrhunderts, als mit David Garrick der erste Starschauspieler die Leitung eines Theaters übernommen hatte. Der Schritt vom Schauspieler zum Direktor war in den meisten Fällen ökonomisch motiviert, denn als Mitglied eines Ensembles hatte ein Schauspieler nur begrenzten Einfluss auf seine Rollen und sein Gehalt. Nur wenn er sich als Manager selbstständig machte, konnte er selbst die Stücke auswählen, in denen er auftreten wollte, sich die besten Rollen sichern und seinen Gewinn maximieren. ${ }^{9}$ Mit der Zeit entwickelte sich das System dann zum Selbstläufer. Wollte ein Schauspieler zur ersten Garde seiner Profession gehören, blieb ihm gar nichts anderes übrig, als ein Theater zu übernehmen, wie Johnston Forbes-Robertson in seinen Memoiren berichtet: „several actors, younger than I, had taken up management very much earlier in their careers, and there was nothing for it but to take a theatre if I was to maintain my place" 10 Die Vorzüge dieses Systems waren zugleich seine Nachteile, denn die Leistung des Ensembles konnte unter der Dominanz seiner Stars leiden. ${ }^{11}$ An ihr Ende kam die Herrschaft der actor-manager spätestens mit der ökonomischen Krisenphase der Zwischenkriegszeit: „The days of the great actor-managers had gone for ever, and a new financial spirit had come into being“, beklagte 1934 Daphne du Maurier, die Tochter eines der letzten Repräsentanten des alten Systems. ${ }^{12}$

Die Kombination von Hauptdarsteller, Regie und Direktion in einer Person war in erster Linie ein britisches Phänomen. Selbst in den USA erlangte der actormanager nie die Bedeutung, die er in London besaß. In Deutschland, wie überhaupt auf dem Kontinent, sucht man eine vergleichbare Institution vergeblich; nicht einmal eine passende Übersetzung des Begriffs steht zur Verfügung. Dennoch führte der Weg zur Leitung eines Theaters auch in Berlin in den allermeisten Fällen über die Ausbildung zum Schauspieler und die mehrjährige Ausübung dieses Berufes. So hatten die meisten der zwischen 1880 und 1930 in Berlin tätigen Theaterdirektoren ihre Karriere als Schauspieler begonnen, wie etwa Richard Schultz, Max Reinhardt, Victor Barnowsky, Leopold Jessner, Rudolf Bernauer und Erwin Piscator - aber für sie alle war der Wechsel von den Bühnenbrettern in den Direktorensessel ein endgültiger.

\footnotetext{
${ }^{9}$ Vgl. Bоотн, Theatre, S. 31; zum actor-manager siehe ebd. S. 55-57; sowie PEARSON, The Last Actor-Managers; DonALDSON, Actor-Managers.

10 Forbes-RoberTson, Player, S. $164 \mathrm{f}$.

11 Vgl. Nicoll, English Drama, S. 48.

12 Du Maurier, Gerald, S. $205 \mathrm{f}$.
} 
Einem actor-manager noch am ähnlichsten war Ludwig Barnay. Nachdem er seinen Abschied vom Meininger Hoftheater genommen hatte, beteiligte er sich an der Gründung des Deutschen Theaters, ehe er 1888 das Berliner Theater baute, das er bis 1894 führte. Im Gegensatz zum Gros seiner Kollegen trat er auch dann noch als Schauspieler auf. ${ }^{13}$ Dasselbe gilt für die Gebrüder Herrnfeld, die nicht nur die Stücke für ihr eigenes Theater schrieben, sondern auch die Hauptrollen in diesen verkörperten. ${ }^{14}$ Eine dritte Ausnahme war Bernhard Rose, der 1906 das Ostend-Theater übernommen und in Rose-Theater umbenannt hatte. Er führte sein Theater als Familienbetrieb, in dem alle Familienmitglieder mitarbeiteten und dem er selbst als Direktor, Regisseur und Schauspieler vorstand. ${ }^{15}$

Ein anderer Weg zum Theaterunternehmer führte über die Tätigkeit als Bühnenautor oder den Journalismus, insbesondere die Theaterkritik. Paul Lindau, von 1900 bis 1903 Direktor des Berliner Theaters, danach für eine Saison Direktor des Deutschen Theaters, vereinigte in sich alle drei Funktionen: Er war Kritiker, Dramatiker und Theaterleiter. ${ }^{16}$ Oscar Blumenthal, von 1888 bis 1897 Direktor des Lessing- Theaters, war ebenfalls zugleich Bühnenautor und Theaterkritiker. ${ }^{17}$ Auch Otto Brahm hatte, ehe er am Deutschen Theater den Naturalismus durchsetzte, als Journalist und Theaterkritiker gearbeitet. ${ }^{18}$ Jean Kren, der 1899 die Direktion des Thalia-Theaters übernahm, war zuvor mehrere Jahre „erster Dramaturg des angesehenen deutschen Vertriebshauses Felix Bloch Erben“ gewesen, weshalb er „mit allen Zweigen des Theaterlebens auf's Innigste vertraut“ zu sein meinte. ${ }^{19}$ Auch in London gab es Direktoren, die über den Journalismus zum Theater gekommen waren. John Hollingshead beispielsweise hatte seine Karriere als Buchhalter begonnen und sich später als Textilkaufmann selbstständig gemacht. In seiner Freizeit gab er eine Zeitschrift heraus, um schließlich ganz in den Journalismus zu wechseln. In den 1860er Jahren begann er abermals eine neue Karriere als Inspizient (stage manager) am Alhambra Theatre, einer Music Hall am Leicester Square. Mit der Hilfe finanzstarker Investoren gelang es ihm 1868, das Gaiety Theatre zu eröffnen, dessen Leitung er 1885 an George Edwardes abtrat. $^{20}$

Edwardes' Karriere als Theaterunternehmer verlief ebenso wenig stromlinienförmig wie die von Hollingshead. Als Sohn eines aus Irland stammenden Zollbe-

13 Vgl. BARNAY, Erinnerungen, Bd. 1, S. 269-290.

14 Vgl. SPRengel, Populäres jüdisches Theater, S.55, 95, 106; siehe auch Riss, Ansätze; ОтTE, Jewish Identities; KRIVANEC, Jüdisches Unterhaltungstheater.

15 Vgl. Krull und Rose (Hrsg.), Erinnerungen; Heinrichs, Rose-Theater; Freydank, Entstehungsgeschichte eines Vorstadttheaters; BAumeIsTER, Theater und Metropolenkultur, S.211213.

16 Vgl. Gertraude Wilhelm, Lindau, Paul, Neue Deutsche Biographie, 14. Bd., S. 573-575.

17 Vgl. KiauleHn, Berlin, S. 427 f.; RÜHLE, Theater, S. 75, 121.

18 Vgl. Hubert Kulick, Brahm, Otto, Neue Deutsche Biographie, 2. Bd., S. 506-508.

19 Vgl. Krens Lebenslauf in LAB, A Pr. Br. Rep. 030-05-1954.

${ }^{20}$ Vgl. Hollingshead, My Lifetime; ders., Gaiety Chronicles, insbes. S. 18-30; ders., , Good Old Gaiety', insbes. S. 2-8; MACQueEn-Pope, Gaiety, insbes. S. 7, 22-32, 215; HyMan, The Gaiety Years, S. 1-40. 


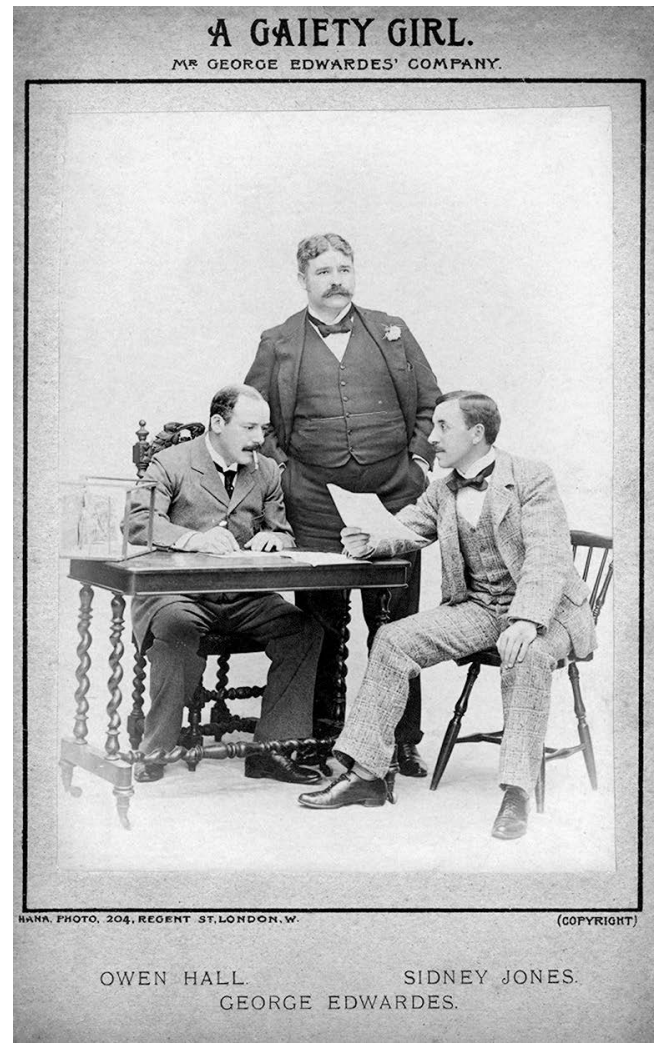

Abbildung 21: Die Erfinder der Musical Comedy: Theaterdirektor George Edwardes mit Librettist James Davis und Komponist Sidney Jones.

amten 1855 in Lincolnshire zur Welt gekommen, hatte er ursprünglich eine militärische Laufbahn angestrebt. ${ }^{21}$ Während er sich in London auf die entsprechende Prüfung vorbereitete, half er einem Cousin bei der Durchführung einer Theatertournee, woraufhin er die Armee mit dem Theater vertauschte. Sein Cousin verschaffte ihm eine Anstellung bei Richard D'Oyly Carte, der Edwardes erst zum Manager der Opera Comique, dann des Savoy Theatre machte, wo seine Aufgaben zu gleichen Teilen aus Geschäfts- und Regieführung bestanden. 1885 wechselte Edwardes dann ans Gaiety Theatre, dessen Leitung er im folgenden Jahr übernahm. Wie Hollingshead vor ihm leitete er zwischenzeitlich noch andere Theater im West End, so das Empire Theatre of Varieties am Leicester Square. In den neunziger Jahren führte er sogar Gespräche über eine mögliche Verbindung mit dem Theater Unter den Linden. ${ }^{22}$ Fotografien aus dieser Zeit zeigen einen

${ }^{21}$ Dazu und zu allem Folgenden siehe SHORT, Ring up the Curtain, S. 30, 96-119; FORBESWinslow, Daly's; MACQueEn-PoPe, Gaiety, S. 215; ders., Shirtfronts, S. 121-123; BLOOM, Curtain Call; Hyman, The Gaiety Years, insbes. S.17-21; GÄnzL, The Encyclopedia, S.398f.; Donohue, Fantasies of Empire, S. 14-23.

22 Vgl. Gaiety Theatre Company, Limited, The ErA, 3.9.1892, S. 9. 
Abbildung 22: Richard Schultz (Mitte) mit Hauskomponist Victor Hollaender (links) und Hausautor Julius Freund (rechts).

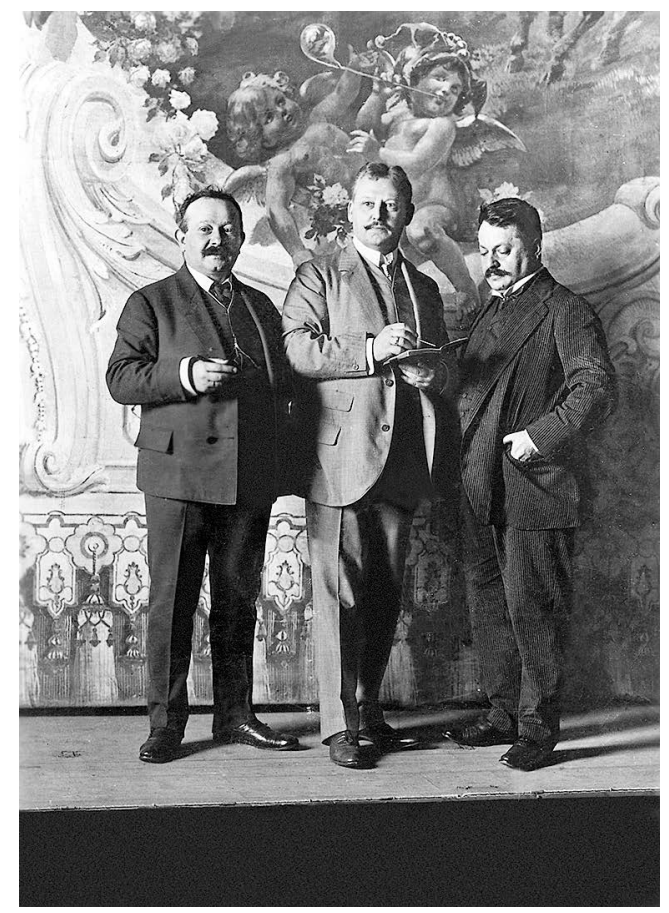

korpulenten, sorgfältig gekleideten Mann, den Mittelscheitel und Schnurrbart eher wie einen pensionierten Offizier aussehen lassen (Abbildung 21). Dank des Erfolgs seiner Produktionen war Edwardes so vermögend, dass er neben einem Anwesen am Regent's Park einen Reitstall auf dem Land unterhalten konnte. Als der Erste Weltkrieg ausbrach, hielt er sich gerade zur Kur in Deutschland auf. Nur mit Schwierigkeiten gelang ihm die Rückkehr in die Heimat, wo er im folgenden Jahr kurz vor seinem dreiundsechzigsten Geburtstag verstarb. ${ }^{23}$ Von der Zugkraft seines Namens zeugt der Umstand, dass noch fast ein Jahrzehnt nach seinem Tod neue "George Edwardes productions“ herauskamen. ${ }^{24}$ Unter dem Titel Gaiety George wurde 1946 sein Leben sogar verfilmt. ${ }^{25}$

Richard Schultz, der in der Berliner Theaterlandschaft eine vergleichbare Position einnahm, glich Edwardes bereits optisch (Abbildung 22). Ähnlich wie dieser gehörte Schultz als katholischer Österreicher in der preußischen Hauptstadt einer Minderheit an. Sein Weg zum Theater war dagegen klassisch. 1863 in Wien als Sohn eines Seidenhändlers geboren, besuchte er - gegen den Wunsch seines Vaters, der ihn lieber in einem kaufmännischen Beruf gesehen hätte - das Kon-

${ }^{23}$ Vgl. Forbes-Winslow, Daly's, S. 121; MacQueEn-Pope, Shirtfronts, S. 148; Hyman, Sullivan, S. 203.

${ }^{24}$ Vgl. GänZL, The British Musical Theatre, S. 87.

25 Vgl. ST. PIERre, Music Hall Mimesis, S. 99-102. 
servatorium für Musik und darstellende Kunst. ${ }^{26}$ Mit 16 Jahren debütierte er in Wien und trat dann an verschiedenen österreichischen Bühnen auf. In der Folge wurde er für das Meininger Hoftheater engagiert, eine der führenden Bühnen der Zeit. Von 1883 an spielte er am Stadttheater in Wien und nach Ableistung seiner militärischen Dienstzeit am Deutschen Theater in Berlin, am Hoftheater in St. Petersburg und am Berliner Theater.

Ähnlich wie Edwardes leitete auch Schultz zunächst eine Theatertournee, ehe er 1890 am Tivoli-Theater in Bremen seine erste Direktion übernahm. Schon drei Jahre später wechselte er nach Berlin ans Central-Theater. Hier lernte er den Komponisten Victor Hollaender und den Autor Julius Freund kennen, womit das Triumvirat beisammen war, das in der Folgezeit die Jahresrevuen in Berlin etablierte. Nach fünf erfolgreichen Jahren am Central-Theater übernahm Schultz 1898 das Metropol-Theater. Um sich ganz auf die künstlerische Leitung des Hauses zu konzentrieren, trat Fritz Paul Jentz als sein Kompagnon in die Geschäftsführung des Theaters ein. ${ }^{27}$ Diese Partnerschaft war für beide äußerst einträglich, denn zusammen machten sie die größten Gewinne, „welche beim Theater in Berlin überhaupt erzielt worden sind“; so war Schultz bei Ausbruch des Ersten Weltkrieges „ein doppelter Millionär“. ${ }^{28}$ Max Epstein charakterisierte ihn als einen „Mann von Uebersicht und geschäftlichtem Verständnis“ beziehungsweise als den „tüchtigsten Direktor“ Berlins. ${ }^{29}$

Obwohl Schultz erst 1928 starb, spielte er in der Weimarer Zeit keine Rolle mehr. Nach dem Tod seines Hauptdarstellers Josef Giampietro 1913 und seines Hausautors Julius Freund 1914 gab er nach dem Weltkrieg die Leitung des Metropol-Theaters ab. So deckte sich die Ära Schultz am Metropol-Theater fast genau mit jener von George Edwardes am Gaiety Theatre. Mit seinem zeitigen Rückzug vom Theatergeschäft bewies Schultz ein weiteres Mal Gespür für die Zeitläufte, denn im veränderten ökonomischen Klima der Weimarer Zeit war die Leitung eines Theaters riskanter als je zuvor. Nach Jahren des Auf und Ab musste sein ehemaliger Kompagnon Fritz Paul Jentz 1927 Bankrott anmelden. ${ }^{30}$

In London erodierte nach dem Ersten Weltkrieg nicht nur die Institution des actor-managers, auch Unternehmer wie Edwardes wurden seltener. Ein Theater im West End, einst die Verkörperung des sozialen Aufstiegs und Ausgangsbasis

${ }^{26} \mathrm{Zu}$ seiner Biographie siehe seinen Lebenslauf in einem Brief seines Anwalts Michaelis an das Berliner Polizeipräsidium vom 24.7.1893, LAB, A. Pr. Br. 030-05-3061 sowie Ludwig Eisenberg's Großes Biographisches Lexikon, S.937; ÖsTERREICHISCHES BIOGRAPHISCHES LEXIKON, Bd. 11, S. 351 f.; OTTE, Jewish Identities, S. 219-226.

27 Vgl. Hinter den Kulissen, Berliner Börsen-Courier, 19. 1. 1909; zu Jentz siehe LAB, A Pr. Br. Rep. 030-05 Nr. 2375.

28 Epstein, Das Theater als Geschäft, S. 42; FriedegG, Millionen und Millionäre, S. 160.

29 EpsTEIn, Theater als Geschäft, S. 70.

30 Vgl. Das Metropol-Theater und Geschäftsaufsicht, BERLINER BÖRSEN-COURIER, 28. 12. 1926; Metropol-Theater geschlossen, Berliner Morgenpost, 5. 8.1927; Alois Munk, Der Niedergang des Metropol-Theaters, Berliner LoKal-AnZeiger, 6. 8. 1927; Der Konkurs des Metropoltheaters, Berliner Tagesspiegel, 26.11.1927; Die neuen Streiche der Brüder Rotter, DAS Kleine Journal, 18. 12.1927. 
für weitere künstlerische und geschäftliche Unternehmungen, entwickelte sich immer mehr zu einer schwerwiegenden finanziellen Belastung. Das lässt sich schon daran ablesen, dass die Leitung des Gaiety Theatre nach dreißig Jahren unter der Führung von George Edwardes nun sehr häufig wechselte. Kaum eine Direktion blieb länger als drei, vier Jahre im Amt. ${ }^{31}$ Ähnlich erging es dem Daly's Theatre, das seit 1920 von verschiedenen Managern geführt wurde. ${ }^{32}$

An die Stelle der actor-manager und Theaterdirektoren alten Schlages traten nun zwei neue Typen: Der Theaterunternehmer, der in erster Linie Geschäftsmann war und der die künstlerische Leitung an angestellte Regisseure abtrat, und der Impresario, der sich nicht an ein festes Haus band, sondern Inszenierungen für wechselnde Aufführungsorte entwickelte. Den ersten Typus verkörperte Alfred Butt, der zwar den Theaterbetrieb von der Pike auf erlernt hatte, sich aber völlig auf die Tätigkeit als Geschäftsführer verlegte. ${ }^{33}$ Stellvertretend für den zweiten Typus steht Charles Blake Cochran, einer der erfolgreichsten und kreativsten britischen Theatermacher der Zwischenkriegszeit. Als das Ringen populär wurde, organisierte er Ringkämpfe, als das Rollschuhfahren in Mode kam, gründete er Rollschuhbahnen in London, Paris, Hamburg und Berlin, um wenig später als Ausrichter von Boxkämpfen $\mathrm{zu}$ reüssieren. Cochran verstand sich selbst als „Showman“, der nicht zwischen einzelnen Sparten oder Genres unterschied. ${ }^{34}$ Der Theaterkritiker Huntly Carter beschrieb ihn treffend als „caterer of novelties“. 35 Cochran war ebenso geschickter Geschäftsmann wie experimentierfreudiger Theatermacher und verdiente so viel Geld mit seinen Shows, dass er in einem Buch über Kings of Commerce neben Thomas Lipton, George Eastman, Gordon Selfridge und John D. Rockefeller aufgeführt wurde. ${ }^{36}$ Wie andere ,Wirtschaftskönige' häufte er immer wieder große Vermögen an, um bei seinem nächsten Experiment alles zu riskieren - und oft genug zu verlieren.

Für das Berliner Geschäftstheater bedeutete der Erste Weltkrieg zunächst keinen so großen Einschnitt. Dies hatte auch damit zu tun, dass bereits vor dem Krieg ein umfassender Generationswechsel eingesetzt hatte. An die Stelle erfahrener Direktoren wie L'Arronge, Lindau und Brahm war nach der Jahrhundertwende die Generation der zwischen 1870 und 1880 Geborenen getreten: Max Reinhardt am Deutschen Theater, Victor Barnowsky am Lessing-Theater sowie

31 George Grossmith und Edward Laurillard (1920-1921), Thomas Francis Dawe und William Cooper (1922-1924), Horace Fry und William Copper (1924-1926), William Clifford Gaunt (1926-1931), George Brinton McLellan (1931-1932) und Thomas Henry Bostock (19331939), vgl. TNA, BT 31/31087/25934; HowARD, London Theatres, S. 89.

32 Vgl. Howard, London Theatres, S. 62f.; Forbes-Winslow, Daly's.

33 Vgl. Carter, New Spirit, S. 19; Sir Alfred Butt Politics, Racing and The Theatre, The Times, 10.12.1962, S. 14 .

34 Vgl. Cochran, The Secrets of a Showman; ders., I Had Almost Forgotten, ders., A Showman Looks On; HePPNER, Cockie; Graves, Cochran Story; HARDIng, Cochran; SHORT, Ring Up the Curtain, S. 252-270.

35 CARTER, New Spirit, S. 21.

36 Vgl. BRIDGES, Kings of Commerce, S. 33-46. 
Rudolf Bernauer und Carl Meinhard am Berliner Theater. ${ }^{37}$ Diese Generation gab in der Zeit der Weimarer Republik weiterhin den Ton an. Am ehesten zum Zug kamen jüngere Direktoren und Regisseure im Bereich des populären Theaters, beispielsweise die Brüder Alfred und Fritz Rotter, die in der Weimarer Zeit den größten deutschen Theaterkonzern errichteten. ${ }^{38}$ James Klein hatte 1908 mit nur 24 Jahren als jüngster Theaterdirektor Deutschlands die Leitung des Neuen Walhalla Theaters in Berlin übernommen, mit dem er aber schon 1913 Bankrott gemacht hatte. Während des Krieges leitete er das Apollo-Theater und die Komische Oper, häufte aber in der Nachkriegszeit derartige Schulden an, dass ihm 1925 die Konzession entzogen wurde. Doch schon 1926 meldete er sich an der Komischen Oper mit opulenten Revue-Inszenierungen zurück. ${ }^{39}$ Darin konkurrierte er mit Hermann Haller, dessen Karriere viele Parallelen zu der von Charles Cochran aufweist. Auch Haller hatte als Schauspieler begonnen, sich dann aber auf die Organisation von Ausstellungen und Massenspektakeln verlegt, über die er dann zur Revue kam. ${ }^{40}$ Der dritte Regisseur spektakulärer Revuen war Erik Charell, der als Choreograph bei Max Reinhardt begonnen hatte. Nachdem Reinhardts Projekt fehlgeschlagen war, im Großen Schauspielhaus seinen Traum von einem ,Theater der Fünftausend' zu realisieren, übergab er dessen Leitung an Charell, der dort mit Revuen und Operetten jenes schichtübergreifende Massenpublikum erreichte, das Reinhardts Klassikerinszenierungen versagt geblieben war. ${ }^{41}$

Wie diese Lebensläufe zeigen, lässt sich nur auf theoretischer Ebene zwischen dem Unternehmer, dem Direktor und dem Regisseur unterscheiden, in vielen Fällen fielen alle drei Funktionen in einer Person zusammen. Mitunter war unklar, wer bei einem Theater welche Funktion innehatte, da nach außen hin meist nur eine einzelne Person wie George Edwardes, Max Reinhardt oder Richard Schultz auftrat. Obschon diese als Inhaber der Theaterkonzession die Verantwortung trugen, verfügten sie immer über einen Stab von Mitarbeitern. Oft gab es einen Geschäftsführer, der für die wirtschaftlichen Belange zuständig war. Reinhardt und Edwardes inszenierten überdies keineswegs alle Stücke selbst, sondern beauftragten damit mitunter angestellte Regisseure. Fast immer aber führte der Weg zur Theaterleitung über die Schauspielerei, denn eine systematische Ausbildung zum Direktor gab es nicht und nur wenige arbeiteten sich wie George Edwardes über verschiedene Tätigkeiten im Management eines Theaters langsam nach oben vor.

37 Vgl. RÜHLE, Theater in Deutschland.

38 Vgl. Weniger, Zwischen Bühne und Baracke, S. 298-300; Riss, Ansätze, S. 183-190; KAMBER, Der Zusammenbruch; ders., Zum Zusammenbruch.

39 Vgl. Biographisches Handbuch der deutschsprachigen Emigration, 2. Bd., S. 628; Kothes, Die theatralische Revue, S. 143; SCHNeIDEReIT, Berlin, wie es weint und lacht, S. 222-240; JANSEN, Glanzrevuen.

40 Vgl. Biographisches Handbuch Der DeUtschsprachigen Emigration, 2. Bd., S. 452; Kothes, Die theatralische Revue, S.140; SCHNEIDEREIT, Berlin, wie es weint und lacht, S.222-240; JANSEN, Glanzrevuen.

${ }^{41}$ Vgl. Jansen, Glanzrevuen, S. 128-134; Dömeland, Grosses Schauspielhaus; BerG, ,Det Jeschäft ist richtig!'; CLARKE, Im Rausch der Genüsse. 
Von einer Professionalisierung der Theaterunternehmer, wie sie für die Schauspieler konstatiert wurde, kann daher kaum gesprochen werden. Allerdings kam es zu einer zunehmenden Ausdifferenzierung des Berufsfeldes. In Großbritannien wurde der actor-manager des 19. Jahrhunderts durch den neuen Typus des producer abgelöst. Mit der Zeit überließ dieser dann die Regie immer häufiger Mitarbeitern, die verwirrender Weise zunächst auch producer genannt wurden und erst später director. ${ }^{42}$ Dieser Begriff stammte aus Deutschland, wo die Bühnenleiter bereits seit dem 18. Jahrhundert als Direktoren bezeichnet wurden. ${ }^{43}$ Verwirrenderweise aber war der britische director gerade nicht identisch mit dem deutschen Direktor, sondern mit dem Regisseur - ein Beruf, der sich ebenfalls zuerst in Deutschland entwickelte. ${ }^{44}$ Nach der Jahrhundertwende übernahm das Theater in anderen Ländern zunehmend dieses Prinzip. ${ }^{45}$ Bis zum Ersten Weltkrieg hatten sich dann weitgehend jene Bezeichnungen herausgebildet, wie sie bis heute in Theater und Film verwendet werden.

Der bereits für die Schauspieler konstatierte soziale Aufstieg war bei den Theaterunternehmern noch ausgeprägter. Actor-manager wie Henry Irving, George Alexander, Charles Wyndham und Herbert Beerbohm Tree gehörten zur Elite der Londoner Gesellschaft, verkehrten auf einer Augenhöhe mit Intellektuellen, Unternehmern, Politikern, Adeligen und dem Königshaus. Der actor-manager wusste um seine Bedeutung und stellte sie selbstbewusst zur Schau: „He was exclusively West End; he was not seen about all over the place. His was the dignity of distance and aloofness - you had to pay to see him and that gave him much value".46 Sichtbarer Ausdruck der neu erworbenen Stellung war die Erhebung in den Ritterstand, eine Auszeichnung, die den actor-managern nicht nur aufgrund ihrer schauspielerischen Leistungen zuteilwurde, sondern auch wegen ihres fortgesetzten Bemühens um das Ansehen des Theaters. Dazu bedurfte es jedoch der Bühnenpräsenz als Ausweis künstlerischer Leistung, denn George Edwardes erhielt nie den Ritterschlag, obwohl das Gaiety Theatre das Lieblingstheater Edwards VII. war. ${ }^{47}$ Auch in Deutschland wurden bedeutende Schauspieler wie Ludwig Barnay mit Ehrungen bedacht und sogar Richard Schultz wurde in Sachsen-Coburg zum Hofrat ernannt. ${ }^{48}$ Und schließlich erfuhren die Theaterdirektoren auch als Unternehmer Anerkennung. So finden sich ihre Namen nicht nur im Green Room Book und im Who's Who in the Theatre, sondern auch im Dictionary of Business Biography. ${ }^{49}$

Wenn bislang ausschließlich von Männern die Rede war, dann weil diese das Theaterleben der Zeit dominierten. Allerdings war die Leitung eines Theaters

\footnotetext{
42 Vgl. Godfrey, Back-Stage, S. 142; Nicoll, English Drama, S. 97; Kennedy, British Theatre, S. 6.

43 Vgl. MeHLIN, Fachsprache, S. 138-153.

44 Vgl. ebd., S. 408-414.

45 Vgl. InNES, The Rise of the Director, S. 172.

46 MacQueEn-Pope, Carriages at Eleven, S. $10 \mathrm{f}$.

47 Mac-QueEn-Pope, Gaiety, S. 135, 468.

48 Danziger Zeitung, 20. 8. 1911.

49 Vgl. DAVIs, The Economics, S. 185.
} 
"one of the very few occupations in which a woman could compete on equal terms with a man and even control him economically by taking him into her employment ". ${ }^{50}$ So gab es in London bereits in der ersten Hälfte des 19. Jahrhunderts einige wichtige Direktorinnen. An erster Stelle ist dabei Lucia Elizabeth Vestris zu nennen, die als Opernsängerin so wohlhabend wurde, dass sie 1831 das Olympic Theatre mieten konnte. Von 1839 bis 1842 leitete sie mit Covent Garden das bedeutendste Londoner Opernhaus. Noch einflussreicher war Effie Bancroft, die zwischen 1865 und 1880 das Prince of Wales Theatre leitete. ${ }^{51} \mathrm{Zu}$ nennen sind außerdem Madge Kendal, Sarah Lane, Mrs. Patrick Campbell, Lillie Langtry und Ellen Terry. ${ }^{52}$ Trotz dieser zum Teil sehr erfolgreichen Direktorinnen blieb das Londoner Theater fest in der Hand von Männern. Auch in der Zwischenkriegszeit gab es mit Violette Melnotte, Gladys Cooper und vor allem Lilian Baylis wichtige, aber doch vergleichsweise wenige Theaterdirektorinnen. ${ }^{53}$

In Berlin war die Zahl der Direktorinnen noch geringer, obwohl es in Deutschland mit Friederike Caroline Neuber durchaus ein historisches Vorbild für eine einflussreiche Direktorin gab. ${ }^{54}$ Während der langen Jahrhundertwende aber bekleideten nur wenige Frauen den Direktorenposten. Nationale Bekanntheit erlangte eigentlich nur Louise Dumont, die gemeinsam mit ihrem Mann, dem Schauspieler Gustav Lindemann, das Düsseldorfer Schauspielhaus führte, das sich unter ihrer Leitung „zur führenden Bühne Westdeutschlands und zu einer vorbildlichen Kunst- und Lehranstalt Deutschlands und der europäischen Welt" entwickelte. ${ }^{55}$ Nur wenige Jahre jünger als Dumont war Olga Wohlbrück, die in allen Bereichen des Theaters reüssierte: als Schauspielerin, Schriftstellerin und Direktorin. 1894 spielte sie am Berliner Theater die Hauptrolle in ihrem ersten Schauspiel. Zu dieser Zeit leitete sie bereits eine Berliner Kleinkunstbühne. Darüber hinaus ging sie als erste weibliche Filmregisseurin in die Geschichte ein. ${ }^{56} \mathrm{Zu}$ ihrer Generation gehörte auch Gertrud Eysoldt, die heute vor allem als Mitglied des Reinhardt-Ensembles in Erinnerung ist, obwohl sie von 1920 bis 1922 das Kleine Schauspielhaus in Charlottenburg leitete, an dem sie auch Regie führte. ${ }^{57}$

Wie der Vergleich zeigt, gelang es in beiden Städten nur sehr wenigen Frauen, die Direktion eines Theaters zu übernehmen, wobei dies in London immerhin

50 Bоотн, Theatre, S. 45.

51 Vgl. BANCROFT und BANCROFT, Mr. \& Mrs. Bancroft; BoOTH, Theatre, S. 52-54.

52 Vgl. DAVIS, The East End, S. 218, Anm. 33; BROwn, The Oxford Illustrated History of Theatre, S. 362; Holroyd, A Strange Eventful History; Powell, Women and Victorian Theatre; siehe auch allgemein DAVIS, Female Managers.

53 Vgl. Gale, West End Women; dies. Errant Nymphs, insbes. S. 125-130.

54 Vgl. Fischer-Lichte, Kleine Geschichte, S. 98-107.

55 Vgl. Hermann Sinsheimer, Louise Dumont, Die Deutsche BüHne 24 (1932), Nr. 7, S, 101f., hier S. 101; Carl Niessen, Dumont, Louise, Neue Deutsche Biographie, 4. Bd., S. $141 \mathrm{f}$.

56 Wininger, National-Biographie, 1. Bd., S.494; BudKE und Schulze, Schriftstellerinnen, S. 380-390.

57 Vgl. Reichshandbuch, Bd. 1, 1930, S. 398; Kiaulehn, Berlin, S. 473; MarX, Max Reinhardt, S. 58-60; RÜHLE, Theater in Deutschland, S. 111. 
noch häufiger der Fall war als in Berlin. ${ }^{58}$ Die Zwischenkriegszeit brachte diesbezüglich wenig Neues. Direktorinnen blieben weiterhin unterrepräsentiert und leiteten allenfalls kleine Bühnen. Die großen Unterhaltungstheater hingegen wurden allesamt von Männern geführt. Daran hat sich auch bis in unsere Gegenwart wenig geändert. Obwohl ebenso viele Frauen wie Männer die Regieklassen der Schauspielschulen absolvierten, stellten sie 2011 gerade einmal 15 Prozent der deutschen Intendanten. ${ }^{59}$ Kaum besser sieht es in Großbritannien aus, wo im selben Jahr nur 19 Prozent der Theaterdirektoren Frauen waren. ${ }^{60}$ Die Führungsetage des Theaters ist bis heute eine Männerbastion.

\section{Besitzverhältnisse}

Ein Theaterunternehmen wird oft mit dem Theatergebäude gleichgesetzt, dabei gehörte dieses in den wenigsten Fällen dem Unternehmer, der es betrieb. In London galt das nur für das Daly's Theatre. Stolz teilte George Edwardes einem Reporter des Sketch mit: „I am the actual and sole proprietor of Daly's Theatre, which has cost me from first to last about $\mathfrak{E} 70000$ “61 In Berlin gehörte zunächst nur das Deutsche Theater seinem Direktor. Adolph L'Arronge hatte zwar zunächst eine Gesellschaft gegründet, um den Bau zu finanzieren, mit den erwirtschafteten Gewinnen dann aber seine Sozietäre ausbezahlt. Nachdem er sich 1894 von der Direktion zurückgezogen hatte, vermietete er es an Otto Brahm, unter dessen Leitung das Haus zu einer der bekanntesten Bühnen Deutschlands avancierte. Dennoch kündigte L'Arronge Brahm 1905. Als das Theater nach einem kurzen Zwischenspiel wieder freigeworden war, gelang Max Reinhardt, aus den Erfahrungen seiner Vorgänger schlau geworden, 1905 L’Arronge zu überzeugen, ihm das Theater zu verkaufen. Die Kaufsumme von 2450000 Mark konnte er allerdings nur aufbringen, indem er eine Kapitalgesellschaft gründete. ${ }^{62}$ Etwa zur selben Zeit kaufte Bernhard Rose das Ostend-Theater und benannte es in Bernhard-Rose-Theater um. ${ }^{63}$

Das waren jedoch Ausnahmefälle. Meistens pachtete ein Unternehmer ein Grundstück, um darauf ein Theater zu bauen, das er dann an einen Theaterunternehmer weitervermietete, der eine Theaterkonzession beantragte. So verhielt es sich im Fall des Gaiety Theatre: Lionel Lawson pachtete 1868 das Grundstück, auf

${ }^{58}$ Zur unterschiedlichen gesellschaftlichen Situation von Frauen in Großbritannien und Deutschland siehe: Voget, Patriarchale Herrschaft.

${ }^{59}$ Eva Behrendt, Vorhang auf für das F-Wort, TAGESzeitung, 25. 05. 2011; dies., Erfolgsgeschichten hinter dem Vorhang, ebd., 25.05.2011.

60 Vgl. Lyn Gardner, ,It's time we got angrier', THE Guardian, 11.9. 2011, http://www.guardian. co.uk/ world/2007/apr/04/ gender.theatre [21.2.2012]; Krystina Nellis Monday, Women in Theatre. Let's Get Rid of the Equality Myth, The Guardian, 18.6.2011, http://www.guardian. co.uk/ world/ 2007/apr/04/gender.theatre [21.2.2012].

${ }^{61}$ Mr. George Edwardes, The SKetch, 12.9.1894, S.360; Forbes-Winslow, Daly's.

62 Vgl. Huesmann, Welttheater, S. 16.

${ }^{63}$ Vgl. LAB, A Pr. Br. Rep. 030-05 Nr. 579; Heinrichs, Das Rose-Theater; Baumgart und FreyDANK (Hrsg.), Das Rose-Theater. 
dem die bankrotte Strand Music Hall stand, ließ sie abreißen und baute an ihrer Stelle für 15000 Pfund ein Theater, das er dann an John Hollingshead vermietete. ${ }^{64}$ Als Lawson 1881 starb, fiel das Gebäude an seine Erben, die den Mietvertrag auf weitere 21 Jahre verlängerten. Das zweite Gaiety Theatre gehörte zwar der Gaiety Theatre Company Ltd., das Grundstück, auf dem es stand, befand sich aber im Besitz der Stadt London. ${ }^{65}$ Kaum anders verhielt es sich beim Metropol-Theater, das ebenso wie das Grundstück, auf dem es stand dem Aktien-Bau-Verein Unter den Linden gehörte, von dem es die Metropol-Theater $\mathrm{GmbH}$ anmietete. ${ }^{66}$

Noch komplizierter waren die Pachtverhältnisse, wenn der Besitzer des Theaters dieses nicht in seiner Gesamtheit, sondern Bühne, Restaurant, Bars und Garderoben an je unterschiedliche Subunternehmen verpachtete. Auch lagen der Besitz und Betrieb eines Theaters oft nicht bei einer einzelnen Person, sondern bei einer $\mathrm{GmbH}$, einem Konsortium oder einer Aktiengesellschaft. ${ }^{67}$ Wer bei einem Theater welche dieser Rollen zu einem bestimmten Zeitpunkt innehatte, lässt sich heute oft kaum noch rekonstruieren. Manchmal wurden Theater und Konzession so oft von einer Partei an die andere weitervermietet, dass am Ende niemand mehr wusste, wem ein Theater eigentlich gehörte und wer es betrieb. Mitunter schoben sich vier oder fünf Zwischenhändler zwischen den Besitzer eines Theaters und dessen Direktor. ${ }^{68}$ Zurecht meinte deshalb ein britischer Beobachter: „It would puzzle the ingenuity of economists to unravel the tangle of stage finance, particularly that relating to the West End theatre“.69 Ganz ähnlich hatte schon 1902 die Berliner Morgenpost festgestellt: „Man sieht, es giebt [sic!] gar manche Theater, die recht verzwickte Besitz- und Pachtverhältnisse haben " ${ }^{70}$ Dabei war zu diesem Zeitpunkt die Lage zumindest in Berlin noch recht überschaubar, denn die überwiegende Zahl der Berliner Theater gehörte damals einer einzelnen Person. ${ }^{71}$

Die Besitzer waren die einzige an einem Theater beteiligte Partei, die mit einiger Sicherheit davon ausgehen konnte, Gewinn zu machen - und das selbst dann noch, wenn das Theatergeschäft schlecht lief. John Hollingshead zufolge gab es um 1900 kaum eine risikolosere und einträglichere Geldanlage:

There is no pounds, shillings and pence investment known to ,those in the trade that can equal the building of the right theatre at the right time and in the right place [...] theatrical bricks and mortar, far from being speculation, are something more than what is called a,dead certainty. They are, in the language of to-day, a Klondyke - a living treasure. ${ }^{72}$

${ }^{64}$ Vgl. HollingShead, Gaiety Chronicles, S. 22-24; MACQueEn-PoPe, Gaiety, S. 36, 208; SHORT, Ring Up the Curtain, S. 23; HyMan, The Gaiety Years, S. 6.

65 Vgl. MacQueen-Pope, Gaiety, S. 382.

66 Vgl. LAB, A. Pr. Br. Rep. 030-50-709; Wagner, Die Dorotheenstadt, S. $389 \mathrm{f}$.

67 Vgl. für London: SANDISON, Theatre Ownership, S.3; PICK, West End, S.77; DAVIS, The Economics, S. 164-166; für Berlin: EpsTeIN, Theater als Geschäft.

68 Vgl. NiCOLL, English Drama, S. 34.

${ }^{69}$ Barbour, The Theatre, S. 32 .

70 Die Besitzverhältnisse der Berliner Theater, BerLIner Morgenpost, 20.7. 1902.

${ }^{71}$ Vgl. ebd.

72 Hollingshead, Gaiety Chronicles, S. 50. 
Hollingshead zufolge war die Position des Theaterbesitzers einzigartig: Stets bekäme er seine Miete drei Monate im Voraus, während sein Mieter ihm die sorgenvolle Aufgabe abnähme, für Abgaben, Steuern und Versicherung aufzukommen. Einem Maximum an Sicherheit stehe somit ein Minimum an Risiko gegenüber. Wenn der Mieter seinen Vertrag beende oder Bankrott anmelde, hinterlasse er seinem Nachfolger nicht nur die Maschinerie, sondern auch genug Bühnenbilder, Kostüme und Requisiten, sodass dieser sofort die Arbeit aufnehmen könne. Deshalb stehe ein Theater auch selten länger als wenige Wochen oder Monate leer und diese Zeit könne durch Rücklagen bestens überbrückt werden. ${ }^{73}$

Diese Beobachtung lässt sich eins zu eins auf Berlin übertragen. Hugo Baruch, dessen Ausstattungsfirma fast alle Berliner Theater mit Bühnenbildern, Requisiten und Kostümen versorgte und der Anteile an mehreren von ihnen hielt, brachte es auf die treffende Formel: „Theater bauen ist gut, Theater betreiben ist gefährlich “ 74 Auch Max Epstein zufolge rentierten sich die meisten Theaterbauten als Grundstücke ausgezeichnet, da die Eigentümer fast alle Lasten auf ihre Pächter abwälzten. ${ }^{75}$ Deshalb blieben die Besitzverhältnisse relativ konstant - vor allem im Vergleich zu den häufig wechselnden Mietern. Seit Mitte der zwanziger Jahre begann dann die Zahl der Theater, die im Besitz von GmbHs und Aktiengesellschaften waren, schrittweise zuzunehmen, bis zu Beginn der dreißiger Jahre nur noch wenige Theater einer einzelnen Person oder Familie gehörten. ${ }^{76}$ Das Gaiety Theatre wurde Mitte der zwanziger Jahre von der Associated Theatre Properties, Ltd. aufgekauft. ${ }^{77}$ Ähnlich erging es dem Daly's Theatre, das Edwardes' Erben 1929 an British Amalgamted Theatres Ltd. verkauften. ${ }^{78}$ Damit war das Theatergebäude selbst zu einer Ware geworden, die nicht mehr gleichbedeutend mit einem bestimmten Direktor, Regisseur, Ensemble oder Genre war. Als bloßer Veranstaltungsort wurde es an den höchsten Bieter vermietet.

\section{Unternehmensformen}

Wie Tracy Davis für London gezeigt hat, fand in der Theaterindustrie im 19. Jahrhundert analog $\mathrm{zu}$ anderen Branchen eine Entwicklung vom Familienbetrieb über Partnerschaften und GmbHs (limited liability companies) bis hin zu börsennotierten Unternehmen (publicly traded companies) statt. ${ }^{79}$ Das Gaiety Theatre und das Metropol-Theater sind hierfür wiederum gute Beispiele. Als John Hol-

${ }^{73}$ Vgl. ebd., S. 27-29.

74 Epstein, Das Theater als Geschäft, S. 30.

75 Vgl. ebd.

76 Für London siehe SANDISON, Theatre Ownership; für Berlin siehe die Angaben zu den Theaterbesitzern im DeUTSCHEN BÜHNENJAHRBUCH dieser Jahre.

77 Vgl. Special Resolution of Gaiety Theatre Company Limited, 30th day of March, 1939 und Extraordinary Resolution of Gaiety Theatre Company Limited (in Voluntary Liquidation) passed the 20th day of June, 1944, TNA, BT 31/31087/25934; siehe auch SANDISON, Theatre Ownership, S. 13; HowARD, London Theatres, S. 89.

78 Vgl. HOWARD, London Theatres, S. 62 f.; Forbes-WinsLow, Daly's.

79 Vgl. DAvis, The Economics, S. 170-176. 
lingshead das Gaiety Theatre 1868 pachtete, verfügte er lediglich über 200 Pfund. Um das notwendige Betriebskapital aufzubringen, gründete er eine Gesellschaft mit beschränkter Haftung, die New Theatres Company, Ltd., mit einem Kapital von 5000 Pfund. ${ }^{80}$ Diese Gesellschaft überführte er Anfang der 1880er Jahre in eine kleine Kapitalgesellschaft (small joint-stock company), in der er das Gaiety Theatre vorübergehend mit der Empire Music Hall zusammenschloss. ${ }^{81}$ Die Gaiety Theatre Company Limited gab 5000 Aktien aus, jede zu zehn Pfund, die nur elf Anteilseignern gehörten und von denen Hollingshead mit 1625 Aktien ein Drittel hielt. ${ }^{82}$

Nachdem George Edwardes die Leitung des Theaters übernommen hatte, erhöhte er die Zahl der Aktien von 5000 auf 60 000, wobei nun jede Aktie ein Pfund wert war, sodass das Stammkapital von 50000 auf 60000 Pfund stieg. Diese Summe wurde von 187 Aktionären aufgebracht, wobei die Beteiligung bei einer Aktie begann und bis zu fast 7000 Aktien reichte. Edwardes selbst hielt mit 20050 Aktien ein Drittel aller Aktien, brachte also ein Drittel des Kapitals auf. Später hielt er nur noch einen geringen Teil der Aktien, blieb aber weiterhin Direktor. ${ }^{83}$ Die Betreibergesellschaft des Gaiety Theatre war eine GmbH im Sinne des Company Acts und ihr Direktor ein Geschäftsführer, der der Generalversammlung rechenschaftspflichtig war. ${ }^{84}$

Auch das Metropol-Theater wurde von einer Gesellschaft mit beschränkter Haftung betrieben, denn als Richard Schultz das Haus 1897 übernahm, besaß er nicht genügend Kapital, um das Theater auf eigene Rechnung zu führen. Deshalb gründete er eine $\mathrm{GmbH}$, in deren Auftrag er das Theater leitete. Technisch gesehen war Schultz also bloß ein Angestellter dieser Gesellschaft. Ihr gehörten neben ihm selbst noch 19 weitere Personen an, drei Kaufmänner, drei Bankiers, zwei Fabrikbesitzer, zwei Rechtsanwälte und fünf Rentiers. Von dem Stammkapital von 400000 Mark zeichneten Schultz und drei weitere Beteiligte je 40000 Mark, einer 30 000, sechs 20000 Mark und neun 10000 Mark. ${ }^{85} 1899$ trat Schultz von der kaufmännischen Leitung des Theaters zurück und gab diese an seinen Mitdirektor Fritz Paul Jentz ab. ${ }^{86}$

Von 1905 bis 1911 führte die Metropol-Theater GmbH zusätzlich das Walhalla-Theater. ${ }^{87}$ Auf dem Zenit ihres Erfolgs gründeten Schultz und Jentz 1909 die

${ }^{80}$ Vgl. Hollingshead, My Lifetime, 1. Bd., S. 234f.; MaCQueEn-Pope, Gaiety, S. 29 f.

${ }^{81}$ Vgl. Hollingshead, My Lifetime, 1. Bd., S.211f.; ders., Gaiety Chronicles, S.430; MACQueEn-Pope, Gaiety, S.214.

82 Vgl. List of Persons holding Shares in the Gaiety Theatre Company Limited, 9.2.1885, TNA, BT 31/3386/20253.

${ }^{83} \mathrm{Vgl}$. Summary of Capital and Shares of the Gaiety Theatre, 2.7.1888, TNA, BT 31/31087/ 25934; siehe auch DAVIS, The Economics, S. $175 \mathrm{f}$.

${ }^{84} \mathrm{Vgl}$. Articles of Association of The Gaiety Theatre Company Limited, 23.2.1888, TNA, BT 31/31087/25934.

${ }^{85}$ Notarielle Verhandlung vom 19. Oktober 1897 über die Errichtung einer Gesellschaft, LAB, A. Pr. Br. 030-05-306; siehe auch HANDBUCH DER DEUTSCHEN GESELLSCHAFTEN MIT BESCHRÄNKTER HAFTUNG, S. 378.

${ }^{86}$ Vgl. Der Schauspiel-Unternehmer Richard Schultz, LAB, A. Pr. Br. 030-05-3061, Bl. 115.

${ }^{87}$ Vgl. ebd. 
Metropol-Theater Aktiengesellschaft Berlin mit einem Stammkapital von einer Million Mark, die Aktie zu 1000 Mark. ${ }^{88}$ Während bei der GmbH der Kreis der Gesellschafter auf gerade einmal 20 Personen beschränkt gewesen war, konnte nun die Zahl der Aktionäre beliebig vergrößert werden. Schultz und Jentz blieben die Geschäftsführer des neuen Unternehmens mit einem Jahresgehalt von 50000 Mark und 15 Prozent Gewinnbeteiligung. ${ }^{89}$ Wie bei den Gründungen der meisten Aktiengesellschaften ging es auch bei der Umwandlung des Metropol-Theaters von einer $\mathrm{GmbH}$ in eine Aktiengesellschaft darum, frisches Kapital zu akquirieren. Dafür spricht, dass zur selben Zeit der Gagenetat auf 540000 Mark und der Ausstattungsetat auf 150000 Mark erhöht wurden und dass die Gesellschaft wenig später auf dem Nachbargrundstück den Metropol-Palast eröffnete. ${ }^{90}$ Drei Jahre später gelang Schultz und Jentz bereits den nächsten Coup: die Gründung einer englischen Aktiengesellschaft unter dem Namen Metropole Palace Company Ltd. mit einem Aktienkapital von sechs Millionen Schilling (etwas über sechs Millionen Mark). Der Grund dafür lag „in der Verschiedenheit der Aktiengesetze in England und Deutschland und in der Eigenart des Betriebes, der bei verhältnismäßig geringem Anlagekapital einen verhältnismäßig hohen Nutzen abwirft“.91 Allerdings verkauften Schultz und Jentz schon im folgenden Jahr das Grundstück des Metropol-Palastes an den Aktienbauverein Unter den Linden, dem bereits das Grundstück des Metropol-Theaters gehörte, und liquidierten ihre englische Aktiengesellschaft. ${ }^{92}$ Verantwortlich dafür war wahrscheinlich die wirtschaftlich schlechte Lage des Theaters in dieser Zeit: Mit Chauffeur - in's Metropol! war zum ersten Mal eine Jahresrevue beim Publikum durchgefallen. ${ }^{93}$ Dennoch zeigt die Episode, in welch internationalen Dimensionen Berliner Theaterunternehmer dachten.

Während des Ersten Weltkriegs ging es nach anfänglicher Flaute für das Metropol-Theater wieder aufwärts, sodass es zusätzlich Gastspiele im Central-Theater gab. ${ }^{94}$ Im ersten Friedensjahr setzte sich dann Richard Schultz zur Ruhe. Sein Kompagnon Fritz Paul Jentz blieb weiter Geschäftsführer der Metropol-Theater AG und setzte den Theaterautor Fritz Friedmann-Frederich als künstlerischen Leiter ein. ${ }^{95}$ Im folgenden Jahr mietete die Metropol-Theater AG erneut zusätzlich das Central-Theater an, das sie jedoch noch im selben Jahr abstieß, um dann von 1921 bis 1927 neben dem Metropol-Theater noch das Theater in der Kom-

88 Eine Theatergründung, Vossische ZeITUNG, 1. 12. 1909.

89 Vgl. LAB, A. Pr. Br. 030-05-3061.

90 Ebd.

${ }^{91}$ Kassenerfolg im Metropol. Die Gründung des Metropolpalastes, BerLiner MorgenPost, 2.5.1912; siehe auch Ladon, Kaiserhof-Passage, Die ZuKunft 79 (1912), S.303-306; HaHN, Metropol-Theater, S. 101.

92 Eine neue Metropolpalast-Transaktion, DAS Organ DER VARIÉTÉwelt, 20. 12. 1913, S. 11f.; Der Ankauf des Berliner Metropolpalastes, ebd., 28. 12.1913, S. 13.

93 Vgl. Max Epstein, Das Theatergeschäft, Die SchaubüHne 8 (1912), Nr. 5, S. 117-120.

94 Vgl. Eine interessante Theaterbilanz, Die Deutsche Bühne 6 (1914), Nr. 13, S. 194f.; Max Epstein, Drei Theaterbilanzen, Die SChaubühne (1917), S. 320-323; LAB, A. Pr. Br. 030-05-3061.

95 Vgl. LAB, A Pr. Br. Rep. 030-05 Nr. 2375. 
mandantenstraße zu betreiben. ${ }^{96} 1927$ meldete sie Bankrott an, woraufhin das Metropol-Theater von Fritz und Alfred Rotter übernommen wurde. ${ }^{97}$

Das Metropol-Theater war eines der ersten deutschen Theater, das als Aktiengesellschaft betrieben wurde. Nur wenige Geschäftsheater folgten diesem Beispiel. Häufiger kamen Aktiengesellschaften bei dem Betrieb von gemeinnützigen Theatern zum Einsatz. So im Fall des 1893/94 gegründeten Schiller-Theaters und des 1911/12 eröffneten Deutschen Opernhauses. Das Schiller-Theater wurde als eine Gesellschaft betrieben, der es nicht um finanziellen Gewinn ging, sondern die volkstümliche Stücke zu volkstümlichen Preisen bot. ${ }^{98}$ In ganz Deutschland gab es 1919 nur 21 Theater und Opernhäuser, die von Aktiengesellschaften unterhalten wurden. Davon befanden sich 90 Prozent im Besitz eines Einzelinhabers. Keine von ihnen war an der Börse notiert. ${ }^{99}$ Die überwiegende Zahl der Berliner Theater wurde auch nach dem Ersten Weltkrieg weiterhin von GmbHs betrieben.

Obwohl es also durchaus eine Entwicklung vom Familienbetrieb über die $\mathrm{GmbH}$ zur Aktiengesellschaft gab, verlief diese keineswegs linear. So gab es auch im frühen 20. Jahrhundert durchaus noch einige Theater, die als Familienbetrieb geführt wurden, wobei diese jedoch auch als $\mathrm{GmbH}$ s organisiert waren. $\mathrm{Zu}$ diesem Instrument griffen die Theaterdirektoren aus denselben Motiven wie andere Unternehmer auch, nämlich um Kapital zu akquirieren und ihr Risiko zu limitieren. Wenn der Direktor Bankrott anmelden musste, haftete er nicht mit seinem Privatvermögen, sondern lediglich in der Höhe seiner Einlage. Wie die Kurzlebigkeit vieler Theaterunternehmen belegt, war die Leitung eines Theaters ein äußerst riskantes Geschäft. Ohne die Beschränkung der persönlichen Verbindlichkeit in Form der $\mathrm{GmbH}$ hätte sich daher kaum jemand zur Übernahme eines Theaters bereitgefunden. Die Transformation einer $\mathrm{GmbH}$ in eine Aktiengesellschaft diente dann primär der Expansion des Unternehmens und bereitete bereits die nächste Stufe in der Entwicklung des Geschäftstheaters vor: die Herausbildung von Theaterkonzernen.

\section{Theaterkonzerne}

Mit dem Zusammenschluss der Unternehmen von Edward Moss und Oswald Stoll entstand in Großbritannien 1898 der erste große Theaterkonzern, der über eine Vielzahl von Bühnen gebot. Beide Unternehmen verfügten über eine Reihe

96 Vgl. die Angaben zu den Besitzern im DeuTsChen-BüHnENJAHRBuCH dieser Jahre.

${ }^{97}$ Vgl. Das Metropol-Theater unter Geschäftsaufsicht, BERLINER BÖRSEN-COURIER, 28. 12. 1926; Das Metropoltheater unter Geschäftsaufsicht, BERLINER LOKAL-ANZEIGER, 28. 12. 1926; Metropol-Theater geschlossen, MorgenPost, 5.8.1927; Schließung des Metropol-Theaters, ebd., 5. 8. 1927; Alois Munk, Der Niedergang des Metropol-Theaters, ebd., 6.8.1927; Der Konkurs des Metropoltheaters, BerLiner Tagesspiegel, 26.11.1927; Die neuen Streiche der Brüder Rotter, Das KLeINe JournaL, 18.12.1927.

98 Vgl. Max Epstein, Drei Theaterbilanzen, Die SchaubÜhne 13 (1917), 1. Bd., S. 320-323; siehe auch Heringdorf, Das Charlottenburger Opernhaus; LitTMAnn, Das Charlottenburger Schiller-Theater.

99 Vgl. PAssow, Aktiengesellschaft, S. 24, 28, 56. 
von Music Halls, Moss vor allem in Schottland, Stoll in Nordengland. Durch die Vereinigung entstand die größte Kette von Music Halls in Großbritannien, die von anfangs 20 auf 35 im Jahr 1906 wuchs. Fast jede größere Stadt besaß entweder ein Empire oder ein Coliseum. Am Verkehrswert gemessen rangierte Moss Empires 1905 an 44. Stelle der größten Unternehmen Großbritanniens. Der Konzern fungierte als Dachgesellschaft für eine Fülle von Subunternehmen, die zum Teil als Familienbetriebe weitergeführt wurden. ${ }^{100}$ Zeitgleich zu Moss Empires entstand, ebenfalls ausgehend von Schottland, Howard \& Wyndham Theatres Ltd., ein Zusammenschluss der Unternehmen von John B. Howard und Frederick Wyndham. ${ }^{101}$ Bei der Gründung beider Konzerne ging es nicht primär um Theaterbesitz, sondern um Rationalisierung durch die gemeinsame Verpflichtung von Künstlern und, mehr noch, die Zusammenlegung des Kartenverkaufs. Zu demselben Zweck vereinigten sich 1932 Moss Empires und Howard \& Wyndham. Die Manager des neuen Unternehmens waren H. M. Tennent und Hugh Beaumont, die ihre Karriere in den beiden Unternehmen begonnen hatten. Nach dem Ende dieses Arrangements gründeten sie 1936 die in London ansässige und auf die Produktion von Theaterstücken spezialisierte Firma H. M. Tennent, Ltd. ${ }^{102}$

Der erste in London ansässige Theaterkonzern entstand 1925 mit Associated Theatre Properties Limited, dem acht West End-Theater angehörten, darunter das Gaiety Theatre. Anfangs stand der Konzern unter der Leitung von William Clifford Gaunt, einem Textilunternehmer aus Yorkshire. Ebenfalls beteiligt an dem Konzern war mit Lee Shubert der Miteigentümer eines der größten Theaterkonzerne der USA. ${ }^{103}$ Auch Charles Frohman, der bedeutendste Konkurrent Shuberts, hatte 1897 mit dem Duke of York's Theatre ein Theater in London angemietet, um dort amerikanische Stücke herauszubringen. ${ }^{104}$ Dieses Engagement amerikanischer Produzenten in London stieß jedoch auf Ablehnung. Viele Kritiker warnten vor der Etablierung von Theaterkonzernen nach amerikanischem Vorbild und der Amerikanisierung des britischen Theaters. ${ }^{105}$ Sie sahen in der Vertrustung des Theaters ein amerikanisches Phänomen, obwohl die Anfänge in der britischen Music Hall gelegen hatten. Der Theaterdirektor Oscar Asche machte die „American ,perdoocers“", wie er sie abschätzig nannte, für die wirtschaftlichen Schwierigkeiten der Theaterindustrie verantwortlich. ${ }^{106}$ Daphne du Maurier gab der „American invasion“ die Schuld an der Kommerzialisierung des Theaters:

100 Vgl. SANDISON, Theatre Ownership, S. 7, 14; Davis, The Economics, S. 176-178.

101 Vgl. ebd., S. 19-22; Davis, The Economics, S. 178.

102 Vgl. ebd., S. 22.

103 Vgl. TNA, BT 31/31087/25934; Graves, The Price of Pleasure, S. 16; SAndison, Theatre Ownership, S. 12; zum Theaterkonzern der Shuberts siehe HiRSCH, The Boys from Syracuse.

104 Vgl. Daly, Life, S. 567f., 578, 630, 638-640; Forbes-Winslow, Dalys's; MarCossen, Charles Frohman, S.230-236; MACQUEen-PoPe, Carriages at Eleven, S.134-141; Postlewait, The London Stage, S. 41-49.

105 B. W. Findon, The American Trust. Its Prospects in England, Play Pictorial 10 (1907), Nr.61, S. 12.

106 Asche, His Life, S. 231. 
„American methods were introduced, and their influence was felt in every quarter; box-office returns were of sole importance in this trade that was no longer an art or a profession". 107 Ähnlich sah es der Theaterkritiker Huntly Carter, der gar eine amerikanische Verschwörung ausmachte: „One after the other Frohman, Shubert, Klaw, Erlanger, Keith, Proctor, Hammerstein came to London with the set purpose of drawing the English theatre into the American net“. ${ }^{108}$ Tatsächlich waren jedoch nur wenige amerikanische Unternehmer in London tätig und langfristig sollten sie sich alle wieder auf ihr Kerngeschäft in den USA beschränken.

Die Tendenz zur wirtschaftlichen Konzentration setzte sich in der Zwischenkriegszeit ungebrochen fort. In London erreichte sie ihren Höhepunkt 1942, als Prince Littler, Direktor von Howard \& Wyndham und Anteilseigner an sechs Theatern, erst Stoll Theatres Corporation, dann Associated Theatre Properties und schließlich auch Moss' Empires übernahm. Damit war ein gemeinhin als, The Group ' bezeichneter Zusammenschluss entstanden, der weniger als ein einheitlicher, durchrationalisierter Konzern vorzustellen ist, denn als ein undurchsichtiges Konglomerat von Beziehungen und Abhängigkeiten in Form von Verträgen, Mietverhältnissen, Aktienanteilen und Aufsichtsratsposten. Um die Theater in ihrem Besitz zu bespielen, waren, The Group 'verschiedene Produktionsfirmen, wie unter anderem H. M. Tennent Ltd., angeschlossen. Allerdings produzierten diese Firmen auch Stücke an Theatern, die nicht zu, The Group' gehörten, wie diese umgekehrt ihre Theater auch an unabhängige Produktionsfirmen vermietete. ${ }^{109}$ Die zunehmende Konzentration war keine Eigenheit der Theaterindustrie, vielmehr gehorchte diese denselben Entwicklungen wie andere Branchen in der Zwischenkriegszeit. ${ }^{110}$ Die Entstehung großer Theaterkonzerne nahm ähnliche Entwicklungen in verschiedenen Bereichen der Unterhaltungsindustrie vorweg, wie beispielsweise im Filmgeschäft, und blieb folgenreich für das britische Theater im gesamten 20. Jahrhundert. Der Stoll-Moss-Konzern etwa, dem 10 West EndTheater gehörten, existierte bis 1999, als er von Andrew Lloyd Webbers Really Useful Group übernommen wurde. ${ }^{111}$ Nach Umstrukturierungen gehörten dieser 2011 noch sieben West End-Bühnen, womit sie neben der Delfont Mackintosh Theatre Group, mit ebenfalls sieben Bühnen, der größte Theaterbesitzer Londons ist. ${ }^{112}$ Die heute im West End zu beobachtende Konzentration von Theaterbesitz markiert das vorläufige Ende eines Prozesses, der um 1900 begann.

107 Du Maurier, Gerald, S. 206.

108 CARTER, New Spirit, S. 23.

109 Vgl. Armstrong, The Playwright and his Theatre, S. 19f.; Elsom, Post-War, S. 12 f.; RebellaTO, 1956, S. 53-57; PRIOR, Dreams and Reconstruction, S. 87-94.

110 Vgl. Eichengreen, The Inter-war Economy; BoOTH und GlynN, Modern Britain, S. 71-73.

111 Vgl. Lloyd Webber Buys London Theatres, BBC NEws, 9. 1.2000, http://news.bbc.co.uk/2/hi/ uk_news/596495.stm [19.6.2011]; Warren Hoge, A Major New Role As Theater Mogul For Lloyd Webber, THE New YORK TIMES, 12.1.2000, http://www.nytimes.com/2000/01/10/arts/ a-major-new-role-as-theater-mogul-for-lloyd-webber.html? pagewanted $=$ all $\& \mathrm{src}=\mathrm{pm}$ [19.6.2011].

112 Vgl. http://www.reallyuseful.com; http://www.delfontmackintosh.co.uk [19.6.2011]. 
Auch in Berlin bildeten sich nach dem Ersten Weltkrieg mehrere Theaterkonzerne heraus. Einer der größten von ihnen unterstand Max Reinhardt, dessen Karriere als Direktor an einem der kleinsten Theater Berlins begonnen hatte, bevor er 1903 das Neue Theater am Schiffbauerdamm übernahm. Dieses gab er 1905 für das Deutsche Theater wieder auf, zu dem 1906 noch die nebenan gelegenen Kammerspiele hinzukamen. ${ }^{113}$ Schon vor dem Ersten Weltkrieg betätigte er sich als Regisseur und Produzent außerhalb von Berlin, vor allem im Rahmen großer Gastspiele in München, Wien und London. ${ }^{114}$ Nach dem Krieg expandierte der Reinhardt-Konzern weiter, vor allem durch die Übernahme des Großen Schauspielhauses, das als eigenständige Aktiengesellschaft verwaltet wurde. ${ }^{115}$ Als er 1921 Berlin vorübergehend den Rücken kehrte, gab er das Deutsche Theater in die Obhut von Felix Hollaender und das Große Schauspielhaus in die von Erik Charell.

Nach seiner Rückkehr zwei Jahre später begann eine neue Phase der Expansion mit der Übernahme der Komödie am Kurfürstendamm und des Theaters in der Josefstadt in Wien. ${ }^{116}$ An seinem Höhepunkt bespielte der Reinhardt-Konzern zehn Theater in Berlin und Wien gleichzeitig. ${ }^{117}$ Aber auch andere Unternehmer leiteten gleichzeitig mehrere Theater: Carl Meinhard und Rudolf Bernauer das Berliner Theater, das Komödienhaus, das Theater in der Königgrätzer Straße und das Theater am Nollendorfplatz; Victor Barnowsky das Lessing-Theater und das Deutsche Künstler-Theater; Eugen Robert Die Tribüne und das Theater am Kurfürstendamm. Im Laufe der zwanziger Jahre kam es immer wieder zu ruckartigen Verschiebungen in der Berliner Theaterlandschaft, die jedes Mal in einer noch größeren Konzentration endeten. Nachdem erst Meinhard und Bernauer, dann Eugen Robert aufgegeben hatten, gingen ihre Häuser an Victor Barnowsky, der über drei, und an Heinz Saltenburg, der über fünf Bühnen gebot. ${ }^{118}$

Nun schlug die Stunde von Alfred und Fritz Rotter, deren Karriere als Theaterleiter bereits vor dem Ersten Weltkrieg begonnen hatte, die sich aber Mitte der zwanziger Jahre von ihrer Direktorentätigkeit zurückgezogen hatten. 1927 meldeten sie sich mit einem Paukenschlag zurück: Sie übernahmen das Pleite gegangene Metropol-Theater. ${ }^{119}$ Außer diesem betrieben sie das Central-Theater, das Lustspielhaus, den Admiralspalast, das Theater des Westens und das Lessing Theater, von denen ihnen allein das letztgenannte auch gehörte, wobei aber jede

113 LAB, A Pr. Br. Rep. 030-05 Nr. 2836 und Nr. 2837; HuesmanN, Welttheater.

114 Vgl. Leisler, Max Reinhardt; Fuhrich-Leisler, Max Reinhardt; Huesmann, Welttheater.

115 Vgl. Hostetter, Grosses Schauspielhaus.

116 Vgl. LEISLER, Max Reinhardt; HUESMANN, Welttheater.

117 Vgl. ReinhaRdT, Der Liebhaber, S. 31; siehe auch Huesmann, Welttheater.

118 Barnowsky über das Theater in der Königgrätzer Straße, Die Tribüne und das Komödienhaus; Saltenburg über das Deutsche Künstlertheater, das Theater am Kurfürstendamm, das Theater am Schiffbauerdamm, das Lustspielhaus und das Wallner-Theater; vgl. THEATERAlmanach 1926; Trask C. Hooper, The Berlin Stage, The Stage Year Book 1927, S. 87-98; Bernauer, Das Theater, S.380; Huesmann, Welttheater, S.59; Rühle, Theater in Deutschland, S. 470-475.

119 Die neuen Streiche der Brüder Rotter, DAS KLEINE JOURNAL, 18. 12. 1927. 
dieser Bühnen von einer eigenständigen $\mathrm{GmbH}$ geführt wurde. ${ }^{120}$ Hinzu kamen außerdem das Schauspielhaus in Breslau, das Bellevue-Theater in Stettin sowie das Residenz- und das Central-Theater in Dresden. ${ }^{121}$ Wie die Deutsche Allgemeine Zeitung meinte, war es selbst „Eingeweihten [...] so gut wie unmöglich zu erfahren, wer wirklich zur Zeit geschäftlich verantwortlich hinter einem Theater steht: Der sogenannte Hauseigentümer, der Pächter, ein Unterpächter oder einer der zahllosen Strohmänner“.122 Die Theaterpolizei verfolgte die Entwicklung der Rotter-Bühnen genau, sah aber keinen Grund zum Einschreiten. ${ }^{123}$

Später gelangte die Staatsanwaltschaft dann zu dem Schluss, die Rotters hätten zunächst alle Theater auf eigene Verantwortung beziehungsweise als Aktiengesellschaft geführt. Erst als „die finanzielle Lage [...] im Jahre 1931 sich so verschlechterte, dass eine Pfändung der Kasseneinnahmen der Theater drohte“, wurde für „jedes der von ihnen bespielten Theater eine besondere Betriebsgesellschaft in der Rechtsform der Gesellschaft mit beschränkter Haftung“ gegründet. ${ }^{124}$ Mit den zunächst noch reichlich fließenden Gewinnen verschafften sich die Rotters neue Kredite, die es ihnen erlaubten, weitere Theater zu übernehmen. Solange diese Gewinne abwarfen, funktionierte ihr Schneeballsystem. Als jedoch ausgerechnet in den wirtschaftlich katastrophalen frühen dreißiger Jahren gleich mehrere aufwändige Inszenierungen scheiterten, brach es in sich zusammen. Im Januar 1933 waren die Rotter-Brüder zahlungsunfähig und setzten sich ins Ausland ab. Die Berliner Staatsanwaltschaft erließ einen Haftbefehl, konnte ihrer aber nicht mehr habhaft werden. ${ }^{125}$ Der neuen, nationalsozialistischen Regierung kam der Zusammenbruch des Rotter-Konzerns sehr gelegen. Sofort wurde er als Beleg für die zwielichtigen Machenschaften jüdischer Unternehmer ausgeschlachtet. Die Polizei versuchte sogar, Fritz und Alfred Rotter aus Liechtenstein, wohin sie geflohen waren, zu entführen. Eine Verfolgungsjagd endete mit dem tödlichen Autounfall von Alfred Rotter und seiner Frau. Fritz Rotter gelang die Flucht nach Frankreich, wo er untertauchte. ${ }^{126}$ Trotz der Abwesenheit der Angeklagten kam es in Berlin zu einem Schauprozess. ${ }^{127}$

Auch in Deutschland schlossen sich die Theaterkonzerne zu Kartellen zusammen. Der größte von ihnen war die 1926 als Antwort auf die Vorherrschaft der

120 Vgl. Brief Rechtsanwalt Castro an Amtsgericht Berlin-Mitte vom 7.9.1931 und Brief der Industrie- und Handelskammer Berlin an Amtsgericht Berlin-Mitte vom 18.4. 1932, LAB, A Pr. Br. Rep. 030-05 Nr. 2966; siehe auch Rotter-Konzern, Der AuTOR 8 (1932), Nr. 12, S. 4 f.

121 Vgl. DAIBER, Schaufenster, S. 36.

122 Deutsche Allgemeine Zeitung, 18. 1. 1933.

123 Vgl. LAB, A Pr. Br. Rep. 030-05 Nr. 2967.

124 Generalstaatsanwalt bei dem Landgericht I, 19. Juni 1933, Anklageschrift, LAB, A Rep. 35802 Nr. 108611.

125 Konkursantrag gegen die Brüder Rotter. Das Ende des Theater-Konzerns, VossisCHE ZEITUNG, 18. 1. 1933; Die Berlin Theater-Katastrophe, TäGliche RundsCHAU, 18. 1. 1933; RotterKonzern verkracht!, VORWÄRTS, 18.1.1933; Strafanzeige gegen Gebrüder Rotter, BERLINER LoKal-AnZeiger, 20.1. 1933; Rotters verduftet, Deutsche Tageszeitung, 21. 1. 1933.

126 Das Attentat auf die Brüder Rotter, B.Z. AM MitTAG, 6.4. 1933; Jews Murdered in Liechtenstein, The Times, 6.4.1933, S. 13; siehe auch KAMBER, Der Zusammenbruch.

127 Vgl. die Prozessakten, LAB, A Rep. 358-02 Nr. 108611 bis Nr. 108614. 
Rotters gegründete Theaterabonnement $\mathrm{GmbH}$, besser bekannt unter dem Namen Reibaro. Sie war eine Vereinigung der Bühnen Max Reinhardts, Victor Barnowskys und Eugen Roberts zum Zweck des gemeinsamen Abonnement- und Kartenverkaufs. Nach außen zielte sie darauf ab, „für die Theater selbst die künstlerische und wirtschaftliche Stabilität; für die Schauspieler die Erfüllung ihrer Postulate nach festem Ensemble und langfristigen Verträgen; für das Publikum eine entscheidende Verbilligung des Theaterbesuchs“ zu schaffen. ${ }^{128}$ In Wirklichkeit ging es den beteiligten Unternehmern jedoch schlicht um die Sanierung ihrer ins Schlingern geratenen Konzerne. Die Konkurrenz nahm die Reibaro von Anfang an als Bedrohung wahr. Rudolf Bernauer bezeichnete sie abschätzig als „Billettverschleuderungsstelle“. ${ }^{129}$ Die Revue Die fleißige Hetäre von Friedrich Hollaender und Marcellus Schiffer aus dem Jahr 1927 wartete mit einer personifizierten Reibaro auf: „Ich bin die Theater Hydria / Wir fressen billige Abonnenten / die wir den andern nicht gönnten". ${ }^{30}$

Vorübergehend erfüllte die Reibaro die in sie gesetzten Hoffnungen und umfasste bald sogar die Staatstheater. In der Zeit der äußersten wirtschaftlichen Anspannung jedoch, der steigenden Kosten und sinkenden Einnahmen, denen schon so viele Theaterunternehmen zum Opfer gefallen waren, wurde die Konkurrenz zwischen den Berliner Theatern immer unerbittlicher, Herbert Ihering sprach nicht ganz unzutreffend von einem „Krieg der Direktoren“. ${ }^{131}$ Um der gegen sie gerichteten Reibaro etwas entgegenzusetzen, schlossen die Rotters Verträge mit der Gesellschaft der Funkfreunde mbH, einer anderen Abonnementsgesellschaft. $\mathrm{Zu}$ Beginn der dreißiger Jahre standen sich damit nur noch zwei große Kartelle gegenüber, die die Berliner Theater unter sich aufgeteilt hatten. Um ihren Konzern am Laufen zu halten, ließen die Rotters sich immer wieder Vorschüsse von der Gesellschaft der Funkfreunde zahlen, die im Gegenzug niedrigere Kartenpreise verlangte. Ihr Leiter Heinz Hentschke nahm den Rotters täglich 1000 Karten ab, die er mit einem Aufschlag von einer Mark an seine Mitglieder weitergab. Allerdings behielt er dabei 4 bis 5000 Mark täglich zur Tilgung der Schulden zurück. Durch die Abgabe von Theaterkarten unter Preis und eines Teils des Gewinns machte der Rotter-Konzern gleich zweifach Verlust. ${ }^{132}$ Das Kleine Journal gab Hentschke deshalb eine Mitschuld am Ruin des Konzerns, denn er habe einen „Zwischengewinn beim Billettverkauf eingestrichen, der so horrend ist, daß die Theater selbst bei gutem, von Herrn Hentschke inspiriertem Besuch nicht existieren können “' ${ }^{133}$ Zum Jahreswechsel 1932/33 entzog er dann den Rotters plötzlich jede Unterstützung und ließ sich die Gewinne aus der Operette Ball im Savoy

128 Berliner Tageblatt, 16.4. 1926; siehe auch Bab, Theater der Gegenwart, S. 189; Kiaulehn, Berlin, S. 473; DAIBER, Schaufenster, S. 38; RÜHLE, Theater, S. 631.

129 BERnAUER, Das Theater, S. 386.

130 Marcellus Schiffer, Hetärengespräche, AAdK, NL Marcellus Schiffer, 4.

131 IHERING, Theaterkrise? Geistige Krise!, S. 380-385, hier S. 381.

132 August Herman Zeiz, Berliner Tageblatt, 27. 1. 1931.

133 Das Berliner Theater-Chaos, Das Kleine Journal, 20.1.1933; siehe auch Riss, Ansätze, S. 190-192; KAMBER, Der Zusammenbruch; ders., Zum Zusammenbruch. 
überschreiben, mit der diesen nach langer Durststrecke wieder ein Erfolg gelungen war. Damit war der Rotter-Konzern am Ende. Hentschke aber, der im Mai 1933 in die NSDAP eingetreten war, übernahm im folgenden Jahr im Auftrag des Propagandaministeriums die Leitung des Metropol-Theaters. ${ }^{134}$

\section{Ausgaben und Einnahmen}

Als Aktiengesellschaften waren das Gaiety Theatre und das Metropol-Theater zur Veröffentlichung ihrer Bilanzen verpflichtet. Diese geben einen Einblick in die wirtschaftliche Arbeitsweise der Theater. Der größte Posten unter den Ausgaben waren stets die Gehaltskosten. Die Gaiety Theatre Company Ltd. zahlte $1891 \mathrm{Ge}-$ hälter in Höhe von 28772 Pfund an die Schauspieler, Sänger, Musiker und Bühnenarbeiter sowie 4909 Pfund an das Personal vor dem Haus. An zweiter Stelle stand der Posten für Bühnenbilder, Ausstattung und Kostüme in Höhe von 8446 Pfund, für Miete und Steuern fielen 4810 Pfund und für Werbung 3843 Pfund an. ${ }^{135}$ Diesen Ausgaben standen Einnahmen aus dem Kartenverkauf, Lizenzgebühren und den Tourneen durch die Provinz und nach Übersee in Höhe von 58229 Pfund gegenüber. Ein knappes Jahrzehnt später waren die Ausgaben gewachsen: Der Gagenetat umfasste 190032338 Pfund, die Ausstattung 8738 Pfund und Miete und Steuern 6040 Pfund, so dass sich die Ausgaben die auf 71440 Pfund belifen; ihnen standen Einnahmen gegenüber die sich um 20 Prozent auf 84755 Pfund gesteigert hatten. ${ }^{136}$

Bis zum Ersten Weltkrieg florierte die Gaiety Theatre Company. Unter der Leitung von John Hollingshead machte sie jährlich einen Umsatz von zwischen 30000 und 55000 Pfund, in den Jahren von 1869 bis 1885 insgesamt 672777 Pfund. ${ }^{137}$ Nachdem George Edwardes das Theater übernommen hatte, sank der Umsatz zunächst stark. Mehrfach konnten zu Beginn der neunziger Jahre keine Dividenden ausgeschüttet werden. Die Aktionäre warfen Edwardes vor, sich aufgrund seiner Beteiligung an anderen Theatern nicht genügend um das Gaiety Theatre zu kümmern und verpflichteten ihn zur Aufgabe dieser Nebentätigkeiten. ${ }^{138}$ Seit Mitte der neunziger Jahre hatten sie dann kaum noch Grund zur Beschwerde. Mit Ausnahme des Jahres 1907, in dem das Theater nur 1279 Pfund Gewinn machte und keine Dividende zahlen konnte, schüttete es fast jedes Jahr eine Dividende von 20 Prozent aus. Bereits vor dem Krieg geriet das Gaiety Theatre in schwierigeres Fahrwasser. So konnte es 1913 nur noch 10 Prozent Dividende zahlen. Nach 1914 brachen die Einnahmen dann komplett zusammen, um sich erst gegen Ende des Krieges wieder zu erholen. ${ }^{139}$ Der Krieg war dafür

\footnotetext{
134 Vgl. Kamber, Zum Zusammenbruch, S. 78-80.

135 Vgl. Gaiety Theatre Co., Limited, The ErA, 8. 8. 1891, S. 8.

136 Vgl. Gaiety Theatre, Limited, THE ERA, 6. 10. 1900, S. 11.

137 Vgl. Hollingshead, My Lifetime, Bd. 2, S. 215.

138 Vgl. Gaiety Theatre Company, Limited, The Era, 3.9. 1892, S. 9; City Notes, National OBSERVER, 3.11.1894, S. 634.

139 Vgl. The Stage Year Book 1917, S. 67; Economist 29.9. 1917, S. 480 und 30. 8. 1919, S. 378.
} 
nur partiell verantwortlich, denn zur selben Zeit spielte die Musical Comedy Chu Chin Chow am His Majesty's Theatre bei Produktionskosten in Höhe von 5300 Pfund binnen fünf Jahren 700000 Pfund ein - mehr als das Gaiety Theatre in den 18 Jahren unter der Leitung von John Hollingshead. ${ }^{140}$

Wie die Gaiety Theatre Company wendete auch die Metropol-Theater GmbH am meisten für Personalkosten auf. Der Gagenetat der Schauspieler, des Orchesters, Balletts und des technischen Personals wurde 1897 auf 360000 Mark veranschlagt. Danach folgte die Pacht an den Aktien-Bau-Verein Unter den Linden in Höhe von 222000 Mark, die das Theater zu dem mit Abstand teuersten von Berlin machte. Sie reduzierte sich allerdings erheblich durch die Unterverpachtung einzelner Bereiche an Subunternehmen. So brachte die Verpachtung des Restaurants 75000 Mark ein, der Garderobe 50000 Mark, der Theaterzettel 9000 Mark, des Reklamevorhangs 3000 Mark, des Verkaufs von Blumen im Theater 4000 Mark, der Kantine 5000 Mark und der Zigarren-Buffets 1000 Mark. Zusammengenommen ergaben die Unterpachten 147000 Mark, sodass sich die Pacht für das Theater auf 75000 Mark reduzierte, womit sie gerade einmal so viel betrug wie die des Restaurants. Der drittgrößte Posten in Höhe von 70000 Mark wurde für die Ausstattung wie Bühnenbilder und Kostüme aufgewandt, gefolgt von 50000 Mark für Tantiemen, 40000 Mark für Beleuchtung, 30000 Mark für Reklame, 24000 Mark für die Leitung des Theaters, 12000 Mark für Verwaltungskosten, Reisen und Steuern und 4000 Mark für die Heizung. ${ }^{141}$

Während die Pacht bis zum Ersten Weltkrieg nur relativ mäßig stieg, auf 235000 Mark im Jahr 1902 und auf 257464 Mark 1910, verdoppelten sich die Ausgaben für Gagen und Gehälter auf 626078 Mark und verdreifachten sich die Ausgaben für Tantiemen auf 150224 Mark. ${ }^{142}$ Dennoch erzielte das MetropolTheater so hohe Einnahmen, dass es nach der Umwandlung in eine Aktiengesellschaft jährlich Dividenden in Höhe von 20 bis 22 Prozent ausschütten konnte. ${ }^{143}$ Es war damit ebenso profitabel wie das Gaiety Theatre in London. Nach mehreren Misserfolgen sank die Dividende 1914 auf vier Prozent, obwohl das Metropol-Theater mit Die Reise um die Erde in achtzig Tagen nach nur hundert Aufführungen bereits eine dreiviertel Million Mark verdient hatte. ${ }^{144}$ Der Erste Weltkrieg bescherte auch dem Berliner Geschäftstheater zunächst eine Flaute, die jedoch schnell in eine Hochkonjunktur mündete, die bis 1920 anhielt. ${ }^{145}$ Auf diese folgte

140 Vgl. SHORT, Theatrical Cavalcade, S. 15.

141 Vgl. Aufstellung der Jahresspesen für das Metropol-Theater, LAB, A. Pr. Br. 030-05-3061.

142 Vgl. Die Besitzverhältnisse der Berliner Theater, BerLiner MorgenPost, 20. 7. 1902; Generalversammlung der Metropoltheater-Aktiengesellschaft, BERLINER TAGEBLATT, 12. 12. 1910.

143 Vgl. Deutsche Tageszeitung, 17.10.1910; Generalversammlung der Metropoltheater-Aktiengesellschaft, BERLINER TAGEBLATT, 12.12.1910; Metropol-Theater Aktiengesellschaft in Berlin, BerLiner BörSen-Courier, 3.11.1911; 20 Prozent Dividende des Metropol-Theaters, BERLINER BÖRSEN COURIER, 28.11.1912.

144 Vgl. Berliner LoKalanzeiger 16.3.1914; Die Zukunft des Metropoltheaters, Deutscher KURIER, 12.1.1914.

145 Bernard Weller, The After-War Stage, The Stage Year Book 1920, S.33-40. 
aufgrund sinkender Zuschauerzahlen und steigender Ausgaben allerdings eine schwerwiegende Depression.

In London erhöhten die Theater die Eintrittspreise nach dem Krieg um 50 Prozent. Dem Anstieg der Produktionskosten um 600 Prozent, der Mieten zeitweise sogar um 1000 Prozent wurden sie damit dennoch nicht Herr. ${ }^{146}$ Die Produzentin Edyth Goodall klagte 1920:

The cost of production is enormous, and it is impossible to take the same risk as before the war. One theatre which cost $£ 50$ to rent in 1913 costs $£ 500$ a week to-day, and lighting, heating and the salaries of people engaged - apart from the actors and actresses - in connection with the production of a play have gone up enormously. The price of seats has been raised, but the difference, which seems considerable to the public, has no effect in balancing the budget, as it is only a government tax. ${ }^{147}$

$\mathrm{Zu}$ den steigenden Kosten kam noch die zur Finanzierung der Kriegsanstrengungen eingeführte Vergnügungssteuer (entertainment tax), die ein Theater selbst dann zu bezahlen hatte, wenn es Verluste machte. Manche Inszenierung warf aufgrund der Vergnügungssteuer gar keinen Gewinn mehr ab. ${ }^{148}$ Im letzten Kriegsjahr bescherte sie dem Fiskus Einnahmen in Höhe von drei Millionen, 1919 sogar in Höhe von fünf Millionen Pfund. ${ }^{149}$ Während des kriegsbedingten Theaterbooms hatte sich die 1916 eingeführte Vergnügungssteuer zunächst kaum ausgewirkt, zumal die Theater sie über verteuerte Eintrittskarten an ihr Publikum weitergereicht hatten. Bei den allgemein steigenden Kosten in der Nachkriegszeit war dies jedoch nicht mehr möglich. ${ }^{150} \mathrm{Mehr}$ als alle anderen Faktoren war die Kostenexplosion die treibende Kraft hinter der Umstrukturierung der Londoner Theaterlandschaft, sie trieb ganz wesentlich die Konzentration voran. Anstatt sich mit dem Unterhalt eines Theaters und eines festen Ensembles zu belasten, schufen Impresarios wie Charles Cochran Inszenierungen, für die sie dann ein passendes Theater mieteten und ein Ensemble zusammenstellten.

In Berlin war die Situation ähnlich. Auch hier strömte während des Weltkrieges „eine bisher ungewöhnte Fülle von Besuchern" in die Theater. ${ }^{151}$ Mit seinen populären Operetten machte das Metropol-Theater bald wieder glänzende Geschäfte: 1917/18 ergab der Erlös aus Karten und Unterpachten fast zwei Millionen Mark. Dem stand allerdings ein Gagenetat gegenüber, der sich in den zwanzig Jahren seines Bestehens auf 700000 Mark verdoppelt hatte. Max Epstein prophezeite schon damals die kommende Krise, sollte der Publikumsstrom eines Tages

146 Vgl. Barbor, The Theatre, S. 32; Findlater, Unholy Trade, S. 35.

147 The Arts and Letters, The Living Age 305 (1920), S. 244-247, hier S. 244.

148 Vgl. Graves, The Price of Pleasure, S. 17.

149 Vgl. Bernard Weller, The Theatrical Year. The War and the Stage, The Stage Year Book 1918, S. 11-22, hier S. 14; ders., The War-Time Stage, The Stage Year Book 1919, S. 23-30, hier S. 27; siehe auch GALE, West End Women, S. 45-48.

150 Vgl. Bernard Weller, The After-War Stage, The Stage Year Book 1920, S.33-40; Findlater, Unholy Trade, S. 15, 33, 35; GALE, The London Stage, S. 148.

151 Hermann Levy, Gedanken über Theater und Wirtschaft, DAs Junge Deutschland 3 (1920), Nr. 5/6, S. 177-185, hier S. 178; siehe auch Wolfgang Lenk, Die Theaterkrisis, Die DeuTsChe BüHNe 23 (1931), Nr. 10, S. 198-202 und Nr. 11, S. 221-226. 
abreißen. ${ }^{152}$ Bereits im letzten Kriegsjahr sanken die Besucherzahlen dann tatsächlich, nicht zuletzt aufgrund der spanischen Grippe. ${ }^{153}$

Nach Kriegsende setzte sich dieser Trend fort, denn die Bevölkerung musste sparen und sie sparte „zuerst am Theaterbesuch“. ${ }^{154}$ Das Theater in der Königgrätzer Straße verzeichnete von 1918 auf 1919 einen Besucherrückgang von zwischen 67 und 80 Prozent, das Wallner-Theater von 75 Prozent, das Lessing Theater von 70 Prozent und das Kleine Theater von 86 Prozent. ${ }^{155}$ Dem Journalisten Felix Pinner zufolge hatte während des Krieges die Zahl der Sitzplätze in Berlin um zwischen 10 bis 12000 zugenommen, nach dem Krieg jedoch eine „Anpassung der Produktion an die gesunkene Kaufkraft des Konsums nicht stattgefunden“. 156 Den sinkenden Einnahmen stand eine „fabelhafte Erhöhung der Unkosten“ gegenüber, aus „bagatellhafte[n] Ausgaben früherer Zeiten“ wurden „Riesensummen“.157 Auch der Theaterdirektor Ludwig Spannuth-Bodenstedt beklagte die „ins Riesenhaft gewachsenen Preise“, Beträge, die früher keine Rolle gespielt hatten, „bekunden heute durch mehrstellige Zahlen, daß sie die Macht haben, dem Etat wesentlich zu schaffen zu machen“.158 Vor allem hätten die Lohnsteigerungen „die Betriebsunkosten der deutschen Theater auf eine ungeahnte Höhe“ getrieben. ${ }^{159}$ Sein Kollege Felix Hollaender, der die ehemaligen Reinhardt-Theater nach dessen Weggang aus Berlin unter eigenem Namen weiterführte, verwahrte sich 1922 gegen die Forderung nach weiteren Gagenerhöhungen und stellte der Not der Schauspieler die Not der Bühnenleiter gegenüber. ${ }^{160}$ Dass die Theaterdirektoren nicht übertrieben, zeigt das Beispiel des Reinhardt-Konzerns, dessen Gesamtjahresetat von 800000 Mark kurz vor dem Krieg auf über drei Millionen stieg. Allein die Ausgaben für Gagen und Gehälter wuchsen von 96000 auf 1640000 Mark. ${ }^{161}$ Als Reaktion auf die gestiegenen Kosten wurden die Eintrittspreise „unsinnig hinaufgesetzt“ und damit „das Publikum verjagt“.162 Nach der Stabilisierung der Mark kam es zum Chaos, als manche Theater Eintrittspreise von 30 Mark verlangten, was sich allenfalls eine Minderheit leisten konnte. Daraufhin schlug das Pendel in die gegenteilige Richtung aus,

152 Vgl. Max Epstein, Die drei Theater-Aktiengesellschaften, Die WeltbüHne 14 (1918), Bd. 1, S. 369-372, hier S.372.

153 Vgl. Theaterkurssturz, Die WeltbÜhne 14 (1918), Bd. 2, S. 392.

154 Levy, Gedanken über Theater und Wirtschaft, Das Junge Deutschland 3 (1920), Nr. 5/6, S. 177-185, hier S. 178.

155 Schultze, Untersuchungen, Bd. 1, S. 350.

156 Felix Pinner, Die Krise der Theaterwirtschaft, Die Deutsche Bühne 17 (1925), Nr. 1/2, S. 2-6, hier S.3.

157 Schultze, Untersuchungen, Bd.1, S.350; Levy, Gedanken über Theater und Wirtschaft, S. 178.

158 Ludwig Spannuth-Bodenstedt, Theaternot, Die Deutsche Bühne 11 (1919), Nr.21/22, S. 369-371, hier S.369.

159 Ebd.

160 Vgl. Felix Hollaender, Theaterelend, Die Deutsche Bühne 14 (1922), Nr. 6, S. 75-77.

161 Vgl. Huesmann, Welttheater, S. 34.

162 Vgl. Schultze, Untersuchungen, Bd. 1, S. 350; siehe auch Siegfried Nestriepke, Das deutsche Theater 1922/23, DAs DeuTsche TheATer 2 (1923/24), S. 161-174, hier S. 162. 
denn nun begannen die Theater, durch Niedrigpreise um die Gunst des Publikums zu buhlen. 163

Verschlimmert wurde die Lage noch durch die Lustbarkeitssteuer, die in Berlin schon 1910 eingeführt worden war, nach mehr als fünfjähriger Diskussion und gegen den heftigen Widerstand der Theaterunternehmer. ${ }^{164}$ Das Metropol-Theater hatte bereits vor dem Krieg jährlich 290000 Mark an den Staat abführen müssen und damit eine Unterbilanz von bis zu 90000 Mark eingefahren. ${ }^{165}$ In dem ohnehin ökonomisch angespannten Klima der zwanziger und dreißiger Jahre stellte die Lustbarkeitssteuer, die 10 Prozent der Einnahmen betrug, eine noch größere Belastung der Theaterunternehmen dar. In regelmäßigen Abständen suchten die Theaterunternehmer bei der Politik um ihre Abschaffung nach. ${ }^{166}$ Selbst neutrale Beobachter machten die „Besteuerungsleidenschaft, die bei Staat und Gemeinde herrscht", für die Notlage der Theater mitverantwortlich. ${ }^{167}$ Seit 1926 gab es zwar für „künstlerisch hochstehende Veranstaltungen“ eine Ermäßigung oder Befreiung von der Steuer, die aber nur die Staatstheater, nicht die kommerziellen Unterhaltungstheater beanspruchen konnten. ${ }^{168}$

\section{Organisation}

Noch vor den Schauspielern organisierten sich im 19. Jahrhundert die Theaterdirektoren in Deutschland wie in Großbritannien. Bereits 1846 gründete sich der Deutsche Bühnenverein (DBV), der ursprünglich den Anspruch erhob, alle Bühnenangehörigen zu vertreten. In den folgenden Jahrzehnten entwickelte er sich jedoch mehr und mehr zu einem „Kartellverband gegen Kontraktbrüche“. ${ }^{169}$ Der Zusammenschluss der Direktoren entsprang dem Wunsch, überzogene Gagenforderungen von Starschauspielern abzuwehren und zu verhindern, dass diese vertragsbrüchig wurden. ${ }^{170}$ Bis 1918 wurde der DBV von den Hoftheatern und deren Intendanten dominiert, so war der Intendant der Königlich Preußischen

163 Vgl. C. Hooper Trask, The Berlin Stage, The Stage Year Book 1927, S. 87-98.

164 Vgl. LAB, A Pr. Br. Rep. 030-05 Nr. 203; Walter Turszinsky, Lustbarkeitssteuer, DiE SCHAUBÜHNE 6 (1910), Bd. 1, S.646-648; Gegen die Lustbarkeitssteuer. Protest der Berliner Theaterdirektoren, Berliner Morgenpost, 1.6.1910; Otto Brahm, Die Lustbarkeitssteuer, DiE DEUTSCHE BüHne 3 (1911), Nr.7, S.98-100; Joachim Bellachini, Lustbarkeitssteuer, ebd., Nr. 18, S. 424.

165 Ein Monat Lustbarkeitssteuer, BERLINER BÖrSEN COURIER, 9.5. 1913.

166 Vgl. Reichsvergnügungssteuer, DiE DEUTSCHE BüHNE 11 (1919), Nr. 16, S. 178-181; Zur Lustbarkeitssteuer, ebd. 12 (1920), Nr.31/32, S. 463-465; Wolff, Der Kampf gegen die Lustbarkeitssteuer, ebd. 17 (1925), H. 1/2, S. 1 f.; An die Mitglieder des Reichstags, ebd. 18 (1926), Nr. 4, S. 55-58.

167 SChultze, Untersuchungen, Bd. 1, S. 349.

168 Vgl. MARKULL, Vergnügungssteuer; siehe auch BOETZKES und QUECK, Die Theaterverhältnisse, S. 700 .

169 SCHWANBECK, Sozialprobleme, S.72f.; zur Frühzeit des DBV siehe Carl Niessen, Der Deutsche Bühnen-Verein. Ein Rückblick, Die Deutsche Bühne 27 (1935), S. 240-256.

170 Vgl. Martersteig, Das deutsche Theater, S. 741; BAB, Theater der Gegenwart, S. 61; SCHÖNDIENST, Geschichte, S. 37, 166-168; LENNARTZ, Theater, S. 32-39. 
Schauspiele fast immer zugleich Vorsitzender des DBV. ${ }^{171}$ Noch vor dem Ersten Weltkrieg traten einige nichthöfische Theater aus dem Bühnenverein aus, weil sie sich nicht länger von dessen Vorsitzenden bevormunden lassen wollten. ${ }^{172}$

Nach dem Krieg entstanden neue Friktionen innerhalb des DBV. Erst gründete sich 1920 der Verband der deutschen gemeinnützigen Theater, in dem die Kommunen und Länder organisiert waren, die Staats- und Stadtheater betrieben. Doch schon wenig später kam es zu einer Fusion der beiden Verbände, sodass die Intendanten der Theater und die Kommunen als Träger im selben Verband organisiert waren. ${ }^{173}$ Anstatt adeliger Hoftheater-Intendanten stellten nun Staatsräte und Ministerialdirektoren den Vorsitz des DBV. Noch 1918 vereinte dieser nahezu sämtliche Bühnenleiter, doch veränderte die zunehmende Dominanz der Theater in öffentlicher Trägerschaft die Struktur des Verbandes. Die Vertreter der Geschäftstheater fühlten sich erneut benachteiligt und gründeten 1926 einen eigenen Unterverband, die Gruppe der freien Mitglieder des Deutschen Bühnenvereins. ${ }^{174}$ Wie Edmund Reinhardt im Berliner Tageblatt erklärte, fühlten sich die privatwirtschaftlich geführten Theater nicht länger vom DBV repräsentiert, da in diesem die städtischen und staatlichen Bühnen überwogen, „die Subventionen erhalten und Steuerfreiheit genießen“; diese würden den „Kampf der Privatbühnen um eine Herabsetzung der Vergnügungssteuer" nicht unterstützen, da sie die Steuer nicht betraf. ${ }^{175}$

Dieser Widerstand hatte allerdings keinerlei Einfluss auf die Politik des DBV, der sich nun fest in der Hand von Beamten befand. 1930 zählte er 645 Mitglieder, darunter 90 Institutionen wie die Stadtverwaltung Aachen oder die Städtische Oper Berlin, und 555 Personen (darunter gerade einmal neun Frauen), die zumeist wiederum Institutionen repräsentierten. ${ }^{176}$ Trotz ihrer Enttäuschung über die Verbandspolitik blieben fast alle Direktoren der noch verbliebenen Berliner Privattheater Mitglied im DBV, so etwa Ernst Josef Aufricht, Hermann Haller, Max Reinhardt, Alfred und Fritz Rotter und Heinz Saltenburg. Doch Initiativen zur Rettung des Privattheaters waren vonseiten des Verbandes nicht zu erwarten. Mit dem Einrücken von Nationalsozialisten in die Kultusministerien, Stadtverwaltungen und Theater ging die Selbstgleichschaltung des Bühnenvereins einher. Seit 1934 wurden dessen Geschicke nicht mehr von seinen Mitgliedern gestaltet, sondern von der Reichstheaterkammer diktiert, in die der DBV 1935 dann end-

${ }^{171}$ Karl Theodor von Küstner von 1846 bis 1851, Botho von Hülsen von 1865 bis 1886, Bolko Graf von Hochberg von 1886 bis 1902 und Georg Graf von Hülsen-Haeseler von 1903 bis 1920; siehe dazu LÖsCHE, Verbände, S. 142.

172 Hochdorf, Deutsche Bühnengenossenschaft, S. 173.

173 Vgl. LENNARTZ, Theater, S. 47.

174 Vgl. Dussel, Ein neues, ein heroisches Theater?, S. 34; SCHÖNDIENST, Bühnenverein, S. 275277.

175 Edmund Reinhardt, Berliner TAgeblatt, 9.6.1926.

176 Vgl. Mitgliederverzeichnis des Deutschen-Bühnenvereins, Deutsches BüHnEN-JAHRBUCH 41 (1930), S. 128-142. 
gültig überführt wurde. Nach dem Zweiten Weltkrieg wiederbegründet, besteht er bis heute fort. ${ }^{177}$

Das britische Äquivalent zum Deutschen Bühnenverein war die 1894 gegründete Theatrical Managers Association, die 129 Theater in ganz Großbritannien repräsentierte. Zwar waren die Londoner Manager zahlenmäßig in der Minderheit, doch der Vorstand spiegelte dies nicht wieder, denn in ihm saßen neben dem Vorsitzenden Henry Irving mit Herbert Beerbohm Tree und Richard D'Oyly Carte noch zwei weitere West End-Manager und nur zwei Manager aus der Provinz. Zweck der Vereinigung war die Wahrnehmung der Interessen der Theaterdirektoren gegenüber der Regierung, der Konkurrenz und den Schauspielern. ${ }^{178}$ Obwohl die West End-Manager im Leitungsgremium des Verbandes überrepräsentiert waren, gründeten sie 1908 unter der Führung des actor-manager Charles Wyndham die Association of West End London Managers, die sich kurze Zeit später in Society of West End Theatre Managers umbenannte. Vor dem Ersten Weltkrieg hatte die Theatrical Managers Association 90 Mitglieder, die etwa 250 Theater repräsentierten. Die Society of West End Theatre Managers umfasste 22 Mitglieder, darunter die actor-manager Herbert Beerbohm Tree, Charles Wyndham und George Alexander; auch George Edwardes gehörte ihr an. ${ }^{179}$ Eine weitere Vereinigung, die 1924 gegründete Stage Guild schrieb sich auf die Fahnen, alle am Theater beteiligten Gruppen wieder zu vereinen, existierte aber nur vier Jahre. Die älteren Verbände dagegen bestehen als Theatrical Management Association und The Society of London Theatres bis heute fort. ${ }^{180}$

Obwohl der Deutsche Bühnenverein und die Theatrical Managers Association beide die Funktion einer Interessenvertretung der Theater und ihrer Direktoren wahrnahmen, unterschieden sie sich voneinander auf eine Weise, die generelle Differenzen in den beiden Theaterlandschaften verdeutlicht. Während die Theatrical Management Association und die Association of West End London Managers Vereinigungen der kommerziellen Theaterunternehmer waren und deren Interessen vertraten, war der DBV gespalten. Den kommerziellen Theaterunternehmern standen erst die Intendanten der Hoftheater, dann die der Staatstheater gegenüber. Diese nutzten den Verband für ihre eigenen Zwecke und booteten die Unternehmer aus, denen es nicht gelang, einen eigenen, schlagkräftigen Verband zu gründen. Die Spaltung in Staats- und Geschäftstheater setzte sich folglich bis in die Interessenvertretungen fort.

177 Vgl. LEnNARTZ, Theater, S. 50-57; Dussel, Ein neues, ein heroisches Theater?, S. 67-69, zur Einrichtung der Reichstheaterkammer siehe auch LAB, A Pr. Br. Rep. 030-05 Nr. 3786.

178 Vgl. Nicoll, English Drama, S. 38 f.; Pick, West End, S. 105 f.; JefFries, Henry Irving, S. 69.

179 The Stage Year Book 1914, S. 115, siehe auch Pick, West End, S. 105 f.

180 Vgl. NiCOLL, English Drama, S.38f.; siehe auch die Websites von TMA und SOLT: http:// www.tmauk.org/About/ history.aspx und http://www.solt.co.uk/ [29.4.2011]. 


\section{Kino und Radio}

„Dem Theater ist ein gefährlicher Feind erstanden: der Kinematograph. Alle seine wirklichen und möglichen Verdienste in Ehren, daß er viele Menschen vom Theaterbesuch ablenkt, kann doch nicht mehr geleugnet werden", schrieb der Theaterkritiker Hermann Kienzl 1911. Bis dahin war der Film in den Augen vieler eine exzentrische Attraktion gewesen, die sich auf Varietés, Jahrmärkte und bescheidene Ladenkinos beschränkte. Nun begann der Aufstieg zu einer Industrie, die immer längere und aufwändigere Filme produzierte, Anleihen bei der Hochkultur nahm, eigenständige Vorführräume errichtete und wachsende Teile der Bevölkerung unterhielt. ${ }^{181}$ Der Schriftsteller Paul Ernst beobachtete 1912, wie in Berlin „die meisten Theater zu den verzweifelsten Kunststücken ihre Zuflucht nehmen müssen, um Zuschauer zu bekommen, indessen beim Kinematographen sich die Menge derartig an der Kasse drängt, daß mancher traurig abziehen muß, ohne eine Eintrittskarte gelöst zu haben".182

Nirgends schien die Konkurrenz ausgeprägter als in Berlin, das sich nun rasch „zum Zentrum der deutschen Filmproduktion“ entwickelte. ${ }^{183}$ In der Schaubühne rechnete Richard Treitel nach, dass in Deutschland 1911 bereits 32 Theater an der Konkurrenz durch das Kino zugrunde gegangen seien. ${ }^{184}$ In der Folge kam es zu einem „erbitterten Ringen zwischen Theater und Kino“. 185 In den Eisenacher Beschlüssen von 1913 untersagte der Deutsche Bühnenverein seinen Vereinsmitgliedern, ,irgendwelche künstlerische oder geschäftliche Unterstützung der Kinos und Filmfabrikanten" zu leisten. ${ }^{186}$ Auch viele Kritiker und Intellektuelle stimmten in den Chor der Kinogegner ein, da sie das neue Medium als künstlerisch minderwertig betrachteten. ${ }^{187}$ „Handfeste wirtschaftliche Interessen überschnitten sich mit gängigen kulturellen Vorbehalten“, fasst Jörg Schweinitz den Tenor der Debatte zusammen. ${ }^{188}$

181 Zur Frühgeschichte des Kinos siehe Channan, The Dream That Kicks; Burrows, Legitimate Cinema; Múller und Segeberg (Hrsg.), Die Modellierung des Kinofilms; Müller, Frühe deutsche Kinematographie; dies., Der frühe Film; Elsaesser und Wedel (Hrsg.), Kino der Kaiserzeit; BAKKER, Entertainment Industrialised.

182 Zit. nach Schweinitz (Hrsg.), Prolog vor dem Film, S. 234 (zuerst als Paul Ernst, Kinematograph und Theater, DER TAG, 8.3.1912).

183 BAB, Das Theater der Gegenwart, S. 163; zu Berlin als Filmstadt siehe auch HANISCH, Auf den Spuren der Filmgeschichte.

184 Vgl. Richard Treitel, Pseudo-Varietés, Die Schaubühne 8 (1912), 1. Bd., S.664-666, hier S. 663; ähnlich: WolfF, Denkschrift betreffend die Kinematographentheater, S. 7, 10.

185 Zit. nach SchweINITZ (Hrsg.), Prolog vor dem Film, S. 248 (zuerst als Emilie Altenloh, Theater und Kino, BILD UND FILM 2 (1912/13), Nr. 11/12, S. 264f.).

186 Zit. nach SCHÖNDIENST, Geschichte des deutschen Bühnenvereins, S. 236; LENNARTZ, Theater, Künstler und die Politik, S. 214; siehe auch die Beiträge in der Verbandszeitung des DBV wie Alfons Fellner, Die Kinofrage, Die Deutsche Bühne 4 (1912), Heft 8, S. 117 f.

187 Siehe die Textsammlung KaEs (Hrsg.), Kino-Debatte; SchweInItZ (Hrsg.), Prolog vor dem Film; zur Kritik am frühen Film siehe LichTwITZ, Die Auseinandersetzung um den Stummfilm; JELAVICH, ,Darf ich mir hier amüsieren?'; MưlLER, Der frühe Film.

188 SchweInitz (Hrsg.), Prolog vor dem Film, S. 223. 
In Großbritannien fiel der Widerstand der Theaterindustrie gegen das Kino zunächst nicht so stark aus. Die Zahl der Kinos nahm aber auch hier von Jahr zu Jahr weiter zu: Hatte es 1911 in London bereits 94 Kinos mit 55000 Sitzplätzen gegeben, war ihre Zahl 1931 auf 258 mit 344000 Sitzplätzen angewachsen. ${ }^{189}$ In der Zwischenkriegszeit wuchs dann auch in Großbritannien bei den Theaterbetreibern die Furcht vor dem neuen Medium: „Will the Film outdo the Footlights?", fragte die Branchenzeitung immer wieder besorgt. ${ }^{190}$ Vor allem die Umstellung zum Tonfilm wurde von den Theaterschaffenden als Bedrohung wahrgenommen.

Die Vorstellung, das Kinos habe den Untergang des Theaters herbeigeführt, findet sich auch bei Historikern. Konrad Dussel etwa macht das Kino für die vielbeschworene ,Theaterkrise ' der Weimarer Republik verantwortlich. ${ }^{191}$ Aus heutiger Sicht erscheint diese Diagnose jedoch wenig stichhaltig, denn die „Sorge vieler Kritiker, das Kino gefährde die Existenz des Theaters, erwies sich langfristig als unbegründet“. 192 Auch die Annahme, den Konsumenten habe nur ein begrenztes Budget an Geld und Zeit zur Verfügung gestanden, das sie entweder für Kino oder Theater ausgeben konnten, ist irrig. Tatsächlich schlossen die beiden Freizeitvergnügen einander nicht aus. Wie Carlo Mierendorff zu Beginn der zwanziger Jahre beobachtete, waren „die Kinos [...] gestopft voll und die Theater werden nicht minder frequentiert". 193 Mierendorff fand es unsinnig, die beiden Medien gegeneinander auszuspielen: „Man kann beides schätzen, beides zum Leben brauchen, für beides sich einsetzen". ${ }^{194}$ Immer mehr Intellektuelle rangen sich zu der Einsicht durch, dass es sich um zwei unterschiedliche Formen handelte, die beide nebeneinander Bestand haben konnten. Das Publikum hatte diesen Schritt längst vollzogen. Wie bereits ausgeführt, gaben die Angestellten in der Zwischenkriegszeit im Schnitt sogar mehr Geld für das Theater als für das Kino aus.

Trotz der ,Kampf-Rhetorik‘ gab es zwischen Theater und Film viele „Verbindungen, Übergänge und Interdependenzen“.195 Obwohl die meisten Theaterschaffenden in der Bühne nach wie vor die edlere Kunstform sahen, schreckten Schauspieler wie Herbert Beerbohm Tree oder Eduard von Winterstein, Theaterregisseure wie Max Reinhardt oder Autoren wie Hugo von Hofmannsthal nicht davor zurück, an Filmen mitzuwirken. ${ }^{196}$ Kooperationen zwischen Theater- und Filmindustrie waren nicht unüblich, so beispielsweise zwischen Oskar Messter

189 Vgl. Smith, The New Survey of London, 1. Bd., S. 290-293; 4. Bd., S. 43 f.

190 Will the Film Outdo the Footlights, The ERA, 29.9. 1920, S. 13.

191 Dussel, Theater in der Krise; siehe auch Hermand und Trommler, Die Kultur der Weimarer Republik, S.247f.; Kolb, Die Weimarer Republik, S.101f.; RüHLE, Theater in Deutschland, S. 481 .

192 MaINTZ, Theater und Film, S. 16.

193 MierendorfF, Über die Grenzen von Film und Bühne, S. 177.

194 Ebd.

195 MainTZ, Theater und Film, S. 5; siehe auch GIESEKAM, Staging the Screen.

196 Vgl. Hickethier, Schauspieler zwischen Theater und Kino; ders., Vom Theaterstar zum Filmstar; ders., Theatervirtuosinnen und Leinwandmimen; BurRows, Legitimate Cinema; sowie das Kapitel über die Schauspieler. 
und dem Metropol-Theater, was Richard Schultz eine Rüge des Bühnenvereins eintrug. ${ }^{197}$ Gerade in der Frühzeit des Kinos war das Theater eine der Hauptquellen für Filmstoffe. 1919 setzte ein wahrer Sturm von Operettenverfilmungen ein. 1925 wurden zwei Operetten verfilmt, 1926 sieben, 1927 neun, 1928 sechs, 1929 drei, 1930 und 1931 jeweils fünf, 1932 vier und 1933 abermals fünf. Der Trend setzte sich also über die Einführung des Tonfilms 1929 hinaus fort. ${ }^{198}$ Der Tenor Richard Tauber, der die Hauptrolle in allen neuen Lehár-Operetten sang, gründete 1930 sogar eine eigene Filmgesellschaft, die Tauber-Film, die seine größten Theatererfolge verfilmte mit ihm in den Rollen, die er zuvor auf der Bühne kreiert hatte. ${ }^{199}$ Ähnliche Entwicklungen gab es in Großbritannien, wo viele Musical Comedies Filmen als Vorlage dienten. ${ }^{200}$

Nach dem Ersten Weltkrieg sah sich das Theater dann einem weiteren Konkurrenten gegenüber: dem Radio. In Großbritannien gab es bereits 1923 zwei Millionen angemeldete Geräte, Ende der dreißiger Jahre waren es mehr als neun Millionen. ${ }^{201}$ In Deutschland waren Ende der dreißiger Jahre über vier Millionen Radiogeräte gemeldet, die ein Publikum von geschätzten zehn bis elf Millionen Menschen erreichten. ${ }^{202}$ Wie das Kino, so löste auch das Radio anfangs Furcht und Ablehnung auf Seiten der Theaterschaffenden aus, wobei dieses Mal die Ängste in Großbritannien ausgeprägter waren als in Deutschland. Die Direktoren, Verleger, Komponisten und Autoren gründeten 1923 eine Lobby, um die Übertragung von Theaterstücken und Konzerten durch die BBC zu verhindern. ${ }^{203}$ Diesmal waren die deutschen Theaterdirektoren weniger kritisch, manche von ihnen ergriffen sogar „sofort die Gelegenheit, ihre Produktionen zu übertragen, weil sie darin eine hochwillkommene Publizität und letztendlich eine Werbung für ihr Unternehmen sahen“. ${ }^{204}$ Ein frühes Beispiel ist die Übertragung von Franz Lehárs Frasquita aus dem Berliner Thalia-Theater von 1924. ${ }^{205}$ Seit Mitte der zwanziger Jahre übertrug der deutsche Rundfunk Aufführungen der großen Revuen aus Berlin, allein 1925 die Charell-Revuen Für Dich und Von Mund zu Mund, die Haller-Revue An und Aus und die Revue Wieder Metropol des Metropol-Theaters. ${ }^{206}$

197 Messter, Mein Weg mit dem Film, S. 108; Hanisch, Auf den Spuren der Filmgeschichte, S. 86; siehe auch den Abschnitt über Filmprojektion in Kapitel 2.1.

198 Vgl. Freisburger, Theater im Film, S. 51; Traubner, Operette als Stoff und Anregung, S. 10; BONO, Glücklich ist, wer vergisst...; WEDEL, Der deutsche Musikfilm.

199 Vgl. ebd., S. 248-251; TraubNer, Operette als Stoff und Anregung, S. 15f.

200 Vgl. International Movie Database: Chu-Chin.Chow (1923), http://www.imdb.com/title/ tt0013925 [21.2.2012]; The Arcadians (1927), http://www.imdb.com/title/tt0017636 [21.2. 2012]; Madame Pompadour (1927), http://www.imdb.com/title/tt0018127 [21.2.2012]; siehe auch GuY, Calling All Stars, S. 99; SHAFER, British Popular Films, S. 21, 23.

201 Vgl. MAcKenZIE, ,In Touch with the Infinite', S. 184.

202 Vgl. Fưhrer, Auf dem Weg zur ,Massenkultur'?, S. 767; siehe auch Ross, Media and the Making of Modern Germany.

203 BRIGGS, The Birth of Broadcasting, S. $251 \mathrm{f}$.

204 Grossmann-Vendrey, Rundfunk und etabliertes Musikleben, S. 789.

205 Vgl. ebd.

206 Vgl. Stoffels, Rundfunk und die Kultur der Gegenwart, S. 977-979; siehe auch Hoffmann, Aspekte zur Jazz-Rezeption, S. 82. 
Noch wichtiger als das Senden vollständiger Aufführungen war die Verwertung von Operettenschlagern, die einen „unverzichtbaren Standard im U-MusikRepertoire“ des Rundfunks stellten. ${ }^{207}$ Eine Umfrage der Zeitschrift Der deutsche Rundfunk unter ihren Lesern, welchen Programmen sie den Vorzug gaben, erbrachte 192476000 Zuschriften, davon nannten 83,3 Prozent als Lieblingsprogramm die Operette. ${ }^{208}$ Für Stefan Frey ist es „kein Zufall, daß Lehár und Tauber gerade mit Beginn der Rundfunkära ihren gemeinsamen Durchbruch erlebten, waren doch die meistgehörten Rundfunkprogramme Operettenübertragungen “209 Lehár selbst meinte, dass sich die Operette dank Schallplatte und Radio nun „an die gesamte Bevölkerung “ wende. ${ }^{210}$

In Großbritannien rangierte das Varieté in der Hörergunst an erster Stelle, dicht gefolgt von ,Theatre and Cinema Organs', ,Military Bands‘ und Musical Comedy, wobei die folgenden Kategorien wie Tanz- und Orchestermusik sowie leichte Musik wahrscheinlich ebenfalls viele Schlager des populären Musiktheaters enthielten. ${ }^{211}$ Dass das Theater vom Radio durchaus profitierte, belegte eindrücklich die Musical Comedy Me and My Girl, die 1937 eher schleppend angelaufen war, nach einer Übertragung durch die BBC im folgenden Jahr aber mit 1646 Vorstellungen zum erfolgreichsten britischen Musical der dreißiger Jahre avancierte. $^{212}$

Wie diese Beispiele zeigen, wurden Kino und Radio zwar zunächst vielfach als Bedrohung des Theaters wahrgenommen, konnten ihm aber auch durchaus nützen, indem sie ihm neue Publikumskreise erschlossen. Durch die neuen Medien erreichten die Operetten-Schlager ein neues Publikum, das zuvor vielleicht niemals ein Theater betreten hatte. Überdies waren die Medien keineswegs gegeneinander abgeschlossen. Vielmehr findet sich auf allen Ebenen - Personal, Stoffe, Themen, Inszenierungsweisen - ein intensiver intermedialer Austausch. Und schließlich verbürgen die vielen Verfilmungen von Theaterstoffen, die bis in die 1930er Jahre hinein ungebrochene Beliebtheit des populären Musiktheaters. Die Gründe für seinen Untergang sind deshalb anderswo zu suchen.

\section{Zwischenfazit}

Zusammenfassend sollen aus den Ergebnissen dieses Kapitels einige Generalisierungen für die wirtschaftliche Entwicklung des Theaters in der Zeit der langen Jahrhundertwende abgeleitet werden. Als zwar grober, aber doch recht verlässlicher Indikator für dessen wirtschaftliche Situation des Theaters wird dabei die Eröffnung neuer beziehungsweise die Schließung bestehender Bühnen herange-

207 Ebd. S. 986.

208 Vgl. Jelavich, Berlin Alexanderplatz, S. 65; SCHrÖDER, Tanz- und Unterhaltungsmusik, S. $318 \mathrm{f}$.

209 FreY, ,Was sagt ihr zu diesem Erfolg', S. 242.

210 Zit. nach ebd., S. 246.

211 Vgl. PeGG, Broadcasting and Society, S. 139.

212 Vgl. Shafe, British Popular Films, S. 69f.; GuY, Calling All Stars, S. 115. 
zogen. Er wird in Bezug gesetzt zur gesamtwirtschaftlichen Entwicklung. Dabei können vier Phasen unterschieden werden: die 1860er bis 80er Jahre, die Jahrzehnte bis zum Ersten Weltkrieg, der Erste Weltkrieg und die Zwischenkriegszeit, die selbst wiederum in drei Phasen zerfällt: die turbulente Nachkriegszeit, die stabilen zwanziger Jahre und die Weltwirtschaftskrise. Abschließend wird dann noch einmal auf die Frage eingegangen, woran das Berliner Geschäftstheater zugrunde ging.

Dass die Liberalisierung der britischen Theatergesetzgebung 1843 nicht zum Bau neuer Theater in London führte, hatte seine Gründe in der allgemeinen wirtschaftlichen Situation, in der sich das Land befand. Auf eine Wachstumsphase nach dem Ende der Napoleonischen Kriege folgte eine lange Phase der Stagnation, die durch fallende Preise und Zinsen charakterisiert war. ${ }^{213}$ Dagegen wurden in Berlin vor allem deshalb kaum neue Bühnen eröffnet, weil es nach wie vor schwierig war, eine Konzession zu erhalten. Das zeigt sich auch daran, dass nach der Unterstellung des Theaters unter die Gewerbeordnung 1869 die Zahl der Konzessionsgesuche und -bewilligungen explosionsartig in die Höhe schoss. So erteilte das Berliner Polizeipräsidium allerin zwischen 1870 und 1880146 Schauspiel-Konzessionen. ${ }^{214}$ Die Reform der Gewerbeordnung machte den Theaterboom möglich, der aber zugleich ganz wesentlich vom allgemeinen wirtschaftlichen Aufschwung im Zeichen des Gründerbooms profitierte. ${ }^{215}$ Auch in London kam es seit Mitte der sechziger Jahre wieder verstärkt zur Eröffnung neuer Theater. Hintergrund war eine allgemeine Hochkonjunktur, die bis zur Krise von 1873 anhielt. ${ }^{216}$ Das legt den Schluss nahe, dass das Wachstum der städtischen Bevölkerung und die Liberalisierung der Theatergesetzgebung zwar notwendige, aber keine hinreichenden Faktoren für das Florieren der Theaterindustrie waren. Das wirtschaftliche Großklima war mindestens ebenso entscheidend.

In den folgenden Jahrzehnten hielt das Wachstum nahezu ungebrochen an. In London eröffneten in dieser Zeit mehr neue Theater als jemals zuvor, insgesamt über vierzig, die meisten von ihnen im West End. ${ }^{217}$ In Berlin waren dies die Jahre der besonders großen und prächtigen Theaterbauten, wie dem Lessing-Theater am Friedrich-Karl-Ufer, dem Metropol-Theater in der Behrenstraße und dem Theater des Westens am Bahnhof Zoo, von denen jedes über weit mehr als 1000 Sitzplätze verfügte. Die wirtschaftliche Krise zwischen 1873 und 1896 wirkte sich demnach kaum auf die Theaterindustrie aus. Diese profitierte vielmehr von den fallenden Preisen, die bei relativ gleichbleibenden oder nur leicht sinkenden Nominallöhnen eine Stabilisierung der Reallöhne zur Folge hatte. Trotz des Abschwungs hatten die Konsumenten nach wie vor denselben, womöglich sogar

\footnotetext{
213 Vgl. Crouzet, Victorian Economy, S. 45, 53.

214 Verwaltungs-Bericht, S. 62.

215 Vgl. NipPERDEY, Deutsche Geschichte 1866-1918, 2. Bd., S. 238-240; WeHLER, Deutsche Gesellschaftsgeschichte, 3. Bd., S. 97-99; BERGHAHN, Das Kaiserreich, S. 54-61; ERBE, Berlin im Kaiserreich, S. 725-730.

216 Vgl. Crouzet, Victorian Economy, S. 46f., 54-58.

217 Siehe Tabelle 1.
} 
einen höheren Etat für Konsumausgaben zur Verfügung. ${ }^{218}$ Noch wichtiger als die wirtschaftliche Gesamtlage war daher die Entwicklung der Reallöhne und der finanzielle Spielraum der Konsumenten.

Der Erste Weltkrieg bescherte dem Unterhaltungstheater nach einer vorübergehenden Krise „eine letzte glänzende Konjunktur“ ${ }^{2} 19$ Zwar wurden keine neuen Theater eröffnet, doch die bestehenden waren voll ausgelastet. ${ }^{220}$ Dann setzte jedoch im letzten Kriegsjahr in Berlin ein deutlicher Rückgang des Publikums ein. ${ }^{221}$ Zugleich begannen in beiden Städten, die Kosten für Theaterinszenierungen im Vergleich zur Vorkriegszeit zu explodieren. Das Berliner Theater litt überdies an der Nachkriegsinflation, die in Deutschland ausgeprägter war als in Großbritannien. ${ }^{222}$ In den sogenannten, goldenen' zwanziger Jahren beschleunigte sich das wirtschaftliche Wachstum wieder und die Reallöhne stabilisierten sich. ${ }^{223}$ Die Konjunktur brachte eine letzte „Hoch-Zeit des Geschäftstheaters“.224 In London und Berlin öffneten in dieser Zeit eine Reihe neuer Bühnen. ${ }^{225}$ Wie in der Gesamtwirtschaft ging nun auch in der Theaterindustrie der Trend zu einer stärkeren Konzentration, Rationalisierung und Kartellierung. ${ }^{226}$ Immer weniger Konzerne teilten immer mehr Theater unter sich auf.

Die Hochkonjunktur der zwanziger Jahre wurde abgeschnitten durch die Weltwirtschaftskrise. Die große Depression traf die deutsche Wirtschaft noch härter als die britische, die sich auch früher wieder erholte. ${ }^{227}$ Das schlug sich auch in der Zahl der Theater nieder: Während in London allein zwischen 1930 und 1932 acht neue Bühnen eröffneten, standen zur selben Zeit in Berlin zahlreiche Theater leer. ${ }^{228} 1932$ meldete dann der Theaterkonzern von Rudolf Bernauer und Carl Meinhard Konkurs an. Im selben Jahr zog sich Max Reinhardt, dessen Konzern

218 Vgl. Hobsbawm, Age of Capital, S. 46; CrouZet, Victorian Economy, S. 58-63; WeHLer, Deutsche Gesellschaftsgeschichte, 3. Bd., S. 100-105; UlLmanN, Kaiserreich, S. 60-68.

219 BAB, Das Theater der Gegenwart, S. 159.

${ }^{220}$ Huntly, The New Spirit, S. 27; Vernon, The Twentieth-Century Theatre, S. 118.

221 Vgl. Theaterkurssturz, Die WeltвÜhne 14 (1918), Bd. 2, S. 392; Levy, Gedanken über Theater und Wirtschaft, Das Junge Deutschland 3 (1920), Nr. 5/6, S. 177-185, hier S. 178; SChultze, Untersuchungen, Bd. 1, S. 350; Felix Pinner, Die Krise der Theaterwirtschaft, DiE DeUTSCHE BÜHNE 17 (1925), Nr. 1/2, S. 2-6.

222 Vgl. Kolb, Die Weimarer Repulik, S.203-206; WeHLER, Deutsche Gesellschaftsgeschichte, 4. Bd., S. 244 f.

223 Vgl. Peukert, Die Weimarer Republik, S. 191; siehe auch WeHLer, Deutsche Gesellschaftsgeschichte, 4. Bd., S. 252-257; THOMAS, The Macro-Economics of the Inter-War Years, S. 338-342.

224 RÜHLE, Theater in Deutschland, S. 472.

225 In London das Fortune Theatre, Gate Theatre, Carlton Theatre, Embassy Theatre, Piccadilly Theatre, Dominion Theatre und Duchess Theatre, in Berlin das Renaissance-Theater, das Theater am Kurfürstendamm, die Komödie am Kurfürstendamm, das Theater in der Klosterstraße, das Theater in der Behrenstraße, das Theater im Palmenhaus und das Theater in der Lützowstraße.

226 Vgl. Booth und Glynn, Modern Britain, S. 71-73; PeukerT, Die Weimarer Republik, S. 116122.

227 Vgl. Wehler, Deutsche Gesellschaftsgeschichte, 4. Bd., S. 257-262; ThOMAs, The Macro-Economics of the Inter-War Years, S. 342-347; Bоотн und GlynN, Modern Britain, S. 118-120.

228 So etwa das Theater im Admiralspalast, das Theater in der Lützowstraße, das RenaissanceTheater, das Residenz-Theater, das Theater in der Stadt, das Thalia-Theater, das Trianon- 
2,5 Millionen Mark Schulden angehäuft hatte, von der Leitung seiner Bühnen zurück, womit sich auch die Reibaro auflöste. ${ }^{229}$ Im Januar 1933 brach dann der Rotter-Konzern zusammen. ${ }^{230}$ Damit war das Berliner Geschäftstheater am Ende. Erich Kästner resümierte am 31. Januar 1933, einen Tag nachdem Adolf Hitler zum Reichskanzler gewählt worden war, in einem Artikel in der Neuen Leipziger Zeitung: „Die Rotter-Bühnen, zirka ein Dutzend Berliner Theater, sind bankrott. [...] Erhalten haben sich, von den ehemals drei Dutzend Bühnen, nur die subventionierten Staatstheater [...]. Mit anderen Worten: Das [...] für die vergangenen Jahre typische Theatersystem ist verschwunden." 231

Zwischen den Zeilen gab Kästner dem Geschäftstheater selbst die Schuld für seinen Niedergang. Andere Kommentatoren verwiesen auf die gestiegenen Ausgaben und die neuen Medien. ${ }^{232}$ Diese Deutung übernimmt der Historiker Konrad Dussel, wenn er die „intermediale[n] Konkurrenzen“ für den „Zuschauerschwund" und diesen wiederum für den Untergang des Geschäftstheaters verantwortlich macht. ${ }^{233}$ Auch Günter Rühle folgt dieser Argumentation. ${ }^{234}$ Bei genauerer Prüfung überzeugt sie nur bedingt, denn sowohl die Steigerung der Ausgaben als auch die mediale Konkurrenz waren in London ebenso ausgeprägt, ohne dass es hier zu ähnlichen Zusammenbrüchen kam. Zwar erlebte das Theater in den späten zwanziger Jahren tatsächlich einen Publikumsschwund, dieser war jedoch nicht primär auf Kino und Radio zurückzuführen, sondern auf die Arbeitslosigkeit und die einbrechenden Reallöhne in Folge der Weltwirtschaftskrise - und davon war auch das Kino betroffen, dessen Einnahmen 1930 auf das Niveau von 1926 zurückging. ${ }^{235} \mathrm{Da}$ Kinos in der Regel niedrigere Eintrittspreise verlangten als die Theater und geringere Ausgaben hatten, traf sie die wirtschaftliche Krise allerdings nicht im selben Maß. Mit der wirtschaftlichen Erholung kehrte das $\mathrm{Pu}-$ blikum dann wieder zurück. In London sank die Zahl der Theater am Höhepunkt der Wirtschaftskrise - wenn auch weniger drastisch - von 92 auf 82, schon 1931 aber war das alte Niveau wieder erreicht. ${ }^{236}$ Nachdem in den Jahren zuvor einige Theater in Kinos umfunktioniert worden waren, eröffneten nun sogar neue Theater. Auch in Deutschland sank die Zahl der Theater nur marginal von 268 Theatern vor der Krise auf 262 am Ende der dreißiger Jahre. ${ }^{237}$ Deshalb war die

Theater, das Walhalla-Theater und das Wallner-Theater; vgl. das Verzeichnis der Theater im DeutsChen BÜHNENJAhrbuCH 1930-1932; siehe auch Huesmann, Welttheater, S. 68.

229 Vgl. Huesmann, Welttheater, S. 68; RüHLE, Theater in Deutschland, S. 650.

230 Vgl. Kamber, Der Zusammenbruch; ders., Zum Zusammenbruch; Rưhle, Theater in Deutschland, S. 668.

231 Kästner, Gemischte Gefühle, 2. Bd., S. 295.

232 Heinrich K. Strohm, Binsenwahrheiten zur heutigen Theaterlage, Die Deutsche BüHne 22 (1930), Nr. 5, S. 110-114; ähnlich: August Zoepffel, Bericht über die wirtschaftliche Lage der Theater, ebd. 22 (1930), Nr.3, S. 53-62; Wolfgang Lenk, Die Theaterkrisis, ebd. 23 (1931), Nr. 10, S. 198-202 und Nr. 11, S. 221-226.

233 Dussel, Theater in der Krise, S. $222 \mathrm{f}$.

234 RüHLE, Theater in Deutschland, S. 631.

235 Vgl. Torp, Konsum und Politik, S. 82f.

236 Vgl. SMith, The New Survey of London Life \& Labour, 5. Bd., S. 47.

237 Vgl. STURY, Deutsche Theaterstatistik, S. 5. 
Theaterkrise der Zwischenkriegszeit am Ende keine „Publikumskrise“, sondern eine wirtschaftliche Krise. ${ }^{238}$

Nicht zu vernachlässigen ist auch der Beitrag des Staates zum Untergang des Berliner Geschäftstheaters, denn dieser bestand noch am Höhepunkt der Krise auf die Abführung der Lustbarkeitssteuer, von der die gemeinnützigen Bühnen befreit waren. Diese hatten damit nicht nur einen klaren Wettbewerbsvorteil gegenüber dem kommerziellen Theater, sondern sie wurden von ihm geradezu gegenfinanziert. ${ }^{239}$ Zwar gab es auch in Großbritannien eine entertainment tax, jedoch hatten gerade die großen Theaterkonzerne Wege gefunden, sich dieser Abgabe zu entziehen. ${ }^{240}$ Was dem Geschäftstheater schließlich den Todesstoß versetzte, war die Verstaatlichung der Bühnen in der Zeit des Nationalsozialismus. Hatten sich in der letzten Spielzeit vor der Weltwirtschaftskrise in Deutschland von 268 Theatern 91 in privater Hand befunden, so waren es in der Spielzeit 1936/37 nur noch 42 - anderen Quellen zufolge sogar nur noch 28. ${ }^{241}$ Während sich die Gesamtzahl der Theater also kaum verringert hatte, hatte gerade einmal die Hälfte der Geschäftstheater überlebt und selbst jene von ihnen, die offiziell noch privat betrieben wurden, kontrollierte nun das Propagandaministerium. ${ }^{242}$ Kontrafaktisch ließe sich deshalb danach fragen, ob sich das Berliner Geschäftstheater nicht - wie das Londons - nach dem Ende der Krise wieder erholt hätte. Diese Frage stellte sich nur deshalb nicht, da zu diesem Zeitpunkt bereits eine nationalsozialistische Regierung herrschte, die stärker als jede Regierung zuvor in die Wirtschaft und Kultur eingriff und die Theater ökonomisch sowie politisch gleichschaltete. Mediale Konkurrenz, Kommerzialisierung und Wirtschaftskrise betrafen sowohl das Londoner als auch das Berliner Theater. Worin sich die Berliner Situation von der Londoner unterschied, war der Staatsinterventionismus, der sich bereits in der Weimarer Republik vorbereitet hatte, aber erst im Nationalsozialismus seine volle Wirkung entfaltete. Obwohl die Geschichtswissenschaft in den letzten Jahren die traditionelle Sichtweise auf Großbritannien und Deutschland in vielen Aspekten korrigiert und auf Ähnlichkeiten und Gemeinsamkeiten hingewiesen hat, bleibt der Umfang, in dem der Staat in das Leben seiner Bürger und vor allem in den Bereich der Kultur eingriff, daher nach wie vor ein wesentlicher Unterschied.

238 Dussel, Theater in der Krise, S. 220.

239 Dussel entgeht diese Problematik, da er sich in erster Linie auf Quellen zu den subventionierten Theatern, wie die Zeitschrift Die Deutsche Bühne, stützt, siehe ebd.

240 Vgl. WeIngärtner, The Arts as a Weapon of War, S. 114f.; GALE, The London Stage, S. 165; dies., West End Women, S. 145-147.

241 Stury, Deutsche Theaterstatistik, S. 5; HoffMAnN, Theaterrecht, S. 9; siehe auch Kapitel 3.1.

242 Zum Theater im Nationalsozialismus siehe DrewniaK, Das Theater im NS-Staat; Dussel, Ein neues, ein heroisches Theater?; DAIBER, Schaufenster der Diktatur; EICHER et al. (Hrsg.), Theater im ,Dritten Reich'; STROBL, The Swastika and the Stage. 
Ein Theaterstück ist eine Ware.

Alexander Lernet Holenia 243

The theatre is a shop, and, if you do not offer suitable wares, nobody calls after the second time to buy.

George Edwardes 244

\subsection{Produkte}

Betrachtet man das Theater als Geschäft, dann stellt sich zwangsläufig die Frage nach seinen Produkten. Tracy Davis unterscheidet in ihrer Wirtschaftsgeschichte des britischen Theaters zwischen dem Textbuch, das als Blaupause für eine unbegrenzte Anzahl von Inszenierungen dienen kann, und der Aufführung, die nur für die Dauer eines Abends in der Gegenwart eines Publikums existiert und die vergänglicher ist als jede andere Ware. ${ }^{245} \mathrm{Da}$ der Besuch von Theatervorstellungen nicht gerade unentbehrlich ist, zählt er in die Kategorie der Luxusgüter. Als immaterielles Gut lässt er sich überdies den Dienstleistungen zurechnen, denn ökonomisch gesehen ist Unterhaltung ein Service. Zwar waren das Kaiserreich und das edwardianische Großbritannien noch keine Dienstleistungsgesellschaften, wie sie sich im 20. Jahrhundert herausbildeten, doch expandierte der Dienstleistungssektor kontinuierlich in der Zeit der langen Jahrhundertwende - vor allem in Großstädten wie London und Berlin. ${ }^{246}$ Ökonomisch betrachtet kann die Ausdehnung der Theaterunterhaltung deshalb als Teil der Expansion des Dienstleistungssektors gesehen werden.

Während das vorangegangene Kapitel die Strukturen und Funktionsweisen der Theaterindustrie zum Gegenstand hatte, geht es im Folgenden um die Produkte des Theaters: und zwar, der Definition von Tracy Davis folgend, um seine Texte und Aufführungen. Im Mittelpunkt stehen dabei vor allem zwei Prozesse. Zum einen die ,Industrialisierung' des Theaters, eine Vorstellung, auf die Autoren um 1900 immer wieder rekurrierten, wenn sie von „Operetten-Industrie“, „entertainment industry“, „Operettenfabrikation" und "musical-comedy factory“ schrieben. ${ }^{247}$ Wenn es sich dabei auch um übertriebene Metaphern handelte, gilt es doch, den Prozessen nachzugehen, die sie bezeichneten. Zum anderen wird der Internationalisierung des Theaters nachgegangen, die seit dem letzten Drittel des 19. Jahrhunderts rasant voranschritt. Die Inszenierung von Theaterstücken im

243 Holenia, Dramaturgisches, S. 587.

244 A Chat with George Edwardes, The ErA, 18.4.1903, S. 15.

245 Vgl. DAvIs, The Economics, S. 6.

246 Vgl. NipPERDEY, Deutsche Geschichte 1866-1918, 1. Bd., S.260-267; WeHLER, Deutsche Gesellschaftsgeschichte, 3. Bd., S. 582, BERGHAHN, Das Kaiserreich, S. 41-53; KlugE, Die Weimarer Republik, S. 159; Stevenson, British Society, S. 114, 183; Mowat, Britain between the Wars, S. 270, 452f.

247 Bernauer, Das Theater, S.210; Godfrey, Back-Stage, S. 186; Hinsmann, Theaterelend und kein Ende?, S. 11; Plays and Players, The Theatre 3 (1903), S. 158-163, hier S. 161. 
eigenen Haus blieb zwar nach wie vor das Schlüsselprodukt eines Theaters, doch zunehmend kam es zu einer Ausdehnung des Geschäfts über die Grenzen der Nationalstaaten hinweg, etwa in Form von internationalen Gastspielen und Tourneen oder durch den Im- und Export von Stücken. Dabei nahmen die Theaterund Musikverlage als Vermittler und Agenten eine Schlüsselstellung ein. Ein Ergebnis der Kontakte war die Kodifizierung eines internationalen Urheber- und Aufführungsrechts, das den Austausch kanalisierte, ihm aber auch neue Wege eröffnete.

\section{Industrialisierung}

Kurz vor dem Ersten Weltkrieg konstatierte Max Epstein, auf keinem Gebiet der Kunst sei die „Industrialisierung widerwärtiger und trostloser, als auf dem der dramatischen Produktion“, deren Urheber er als „Stückefabrikanten“ bezeichnete. ${ }^{248}$ Wie Epstein ereiferten sich viele Theaterkritiker aufgrund einer von ihnen beobachteten Zunahme der „industriellen Dramatik“. 249 Ihre Kritik galt dabei in erster Linie Schriftstellern, die für die populäre Bühne schrieben. So zeigt eine englische Karikatur unter dem Titel „A Busy Plawright“ den Autor Walter Melville am Schreibtisch seiner bis zur Decke mit Büchern, Papier und Karteikästen vollgestopften „Drama Factory“ sitzend (Abbildung 23). Neben seiner Tätigkeit als Theaterdirektor und Regisseur schrieb Melville zwischen 1898 und 1910 pro Jahr ein bis zwei neue Melodramen. ${ }^{250}$ Eine ganz ähnliche Karikatur zeigt den Komponisten Franz Lehár in seiner „Operettenfabrik“, vor sich auf dem Schreibtisch das „Cassa-Hauptbuch“, darunter die Bildunterschrift: „Jetzt kann ich ausruhen. Denn zu dem Buch fliegen mir die ,Noten“ von selber zu“ (Abbildung 24). Als Fabrikanten der Theaterindustrie galten demnach zunächst weniger die Direktoren als vielmehr die Autoren aufgrund eines als ,immens' wahrgenommenen Ausstoßes neuer Stücke und als ,horrend' betrachteter Einnahmen. Ein Berliner Beispiel ist der Komponist Jean Gilbert: Nach dem Erfolg von Polnische Wirtschaft 1910 am Thalia-Theater brachte er im Schnitt drei neue Stücke pro Jahr heraus - als er Deutschland 1933 verlassen musste, konnte er fast 60 Operetten vorweisen. ${ }^{251}$ Angeblich beschäftigte der „König der modernen Operette“ dazu einen „Stab von Kopisten, die seinen Einfall sofort ins Reine bringen, schreiben, vervielfältigen, fertig machen“, weshalb er vielen als der verkörperte „musikalische Großbetrieb" galt. ${ }^{252}$

Damit ist bereits ein weiterer Aspekt angedeutet, der häufig unter Industrialisierung gefasst wurde: die zunehmende Arbeitsteilung. In seiner Geschichte des Daly's Theatre meint etwa Forbes-Winslow:

\footnotetext{
248 EPSTEIN, Theater und Volkswirtschaft, S. $17 \mathrm{f}$.

249 Martersteig, Das deutsche Theater, S. 585.

$250 \mathrm{Zu}$ Melville siehe NiColl, English Drama, S. 25; Aston und Clarke, The Dangerous Woman of Melvillean Melodrama; MAYER, Encountering Melodrama; DAVIS, The East End.

251 GÄNZL, The Encyclopedia, S. 1530.

252 Erich Urban zit. nach SCHNEIDEREIT, Berlin, wie es weint und lacht, S. $159 \mathrm{f}$.
} 


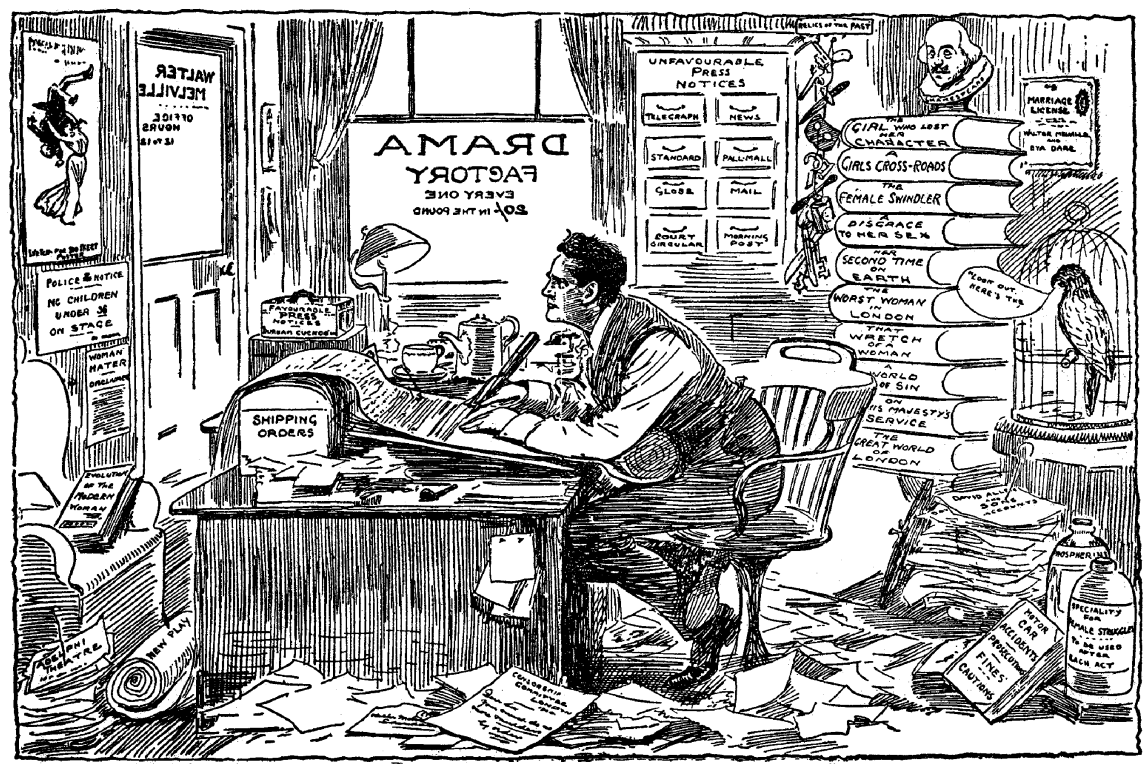

Abbildung 23: Walter Melville, Theaterdirektor und Melodramen-Autor, in seiner ,Drama Factory:

Abbildung 24: ,Jetzt kann ich ausruhen. Denn $z u$ dem Buch fliegen mir die ,Noten' von selber zu. '- Franz Lehár am Schreibtisch seiner, Operetten-fabrik؛.

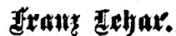

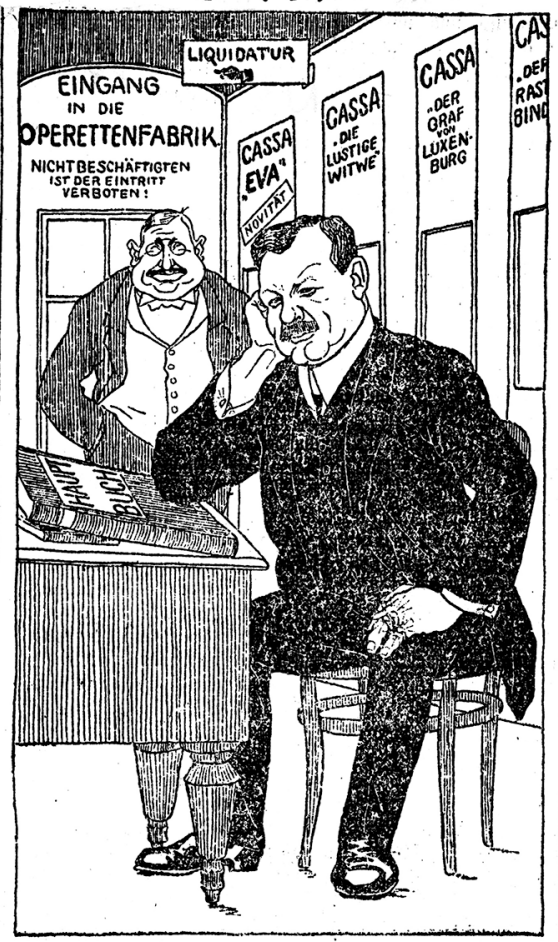

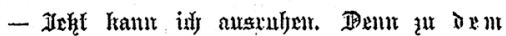

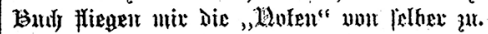


In the old days one man wrote the entire libretto and another man composed the music. This simplified matters. Nowadays, a play is brought to a manager, who says he does not like this, and would rather cut out that. The production is discussed from all aspects for months, and then, after the ground has been cleared, so to speak, the author sits down to write it. Even after that it is re-arranged and re-modelled till the original is hardly recognisable. ${ }^{253}$

Wenn er von der ,alten Zeit' sprach, dachte Forbes-Winslow vermutlich an die jahrelange Partnerschaft von Gilbert und Sullivan. An den Musical Comedies hingegen war eine Vielzahl von Komponisten, Librettisten und Liedtexter beteiligt unter der Leitung von George Edwardes, der die Aufträge vergab, die einzelnen Arbeitsschritte überwachte und die Einzelteile auf der Bühne zu einem Ganzen zusammenfügte. ${ }^{254}$ Denn Edwardes' Inszenierungen „were written on the stage“, wie sein Verleger William Boosey meinte. ${ }^{255}$ Es war diese neue Qualität der Arbeitsteilung, auf die der Kritiker Huntly Carter Bezug nahm, wenn er das Theater mit einer Fabrik verglich: „conventional theatre is like a modern factory in which everyone has his special job“. ${ }^{256}$ Hatte noch 1871 der Autor eines Artikel über „Dramatic Collaboration“ darauf hingewiesen, dass zwar viele Stücke und Methoden aus Frankreich importiert worden seien, nicht jedoch die Methode Kollaboration mehrerer Autoren (eine Praxis, die er zur Nachahmung empfahl), hatte sich diese drei Jahrzehnte später längst fest etabliert. ${ }^{257}$

Am Metropol-Theater war die Arbeitsteilung weniger ausgeprägt, da Richard Schultz auf feste Hausautoren und -komponisten zurückgriff. Beinahe jedes Stück, das er zwischen 1898 und 1913 inszenierte, stammte entweder direkt aus der Feder von Julius Freund oder war zumindest von ihm bearbeitet worden. Die Komponisten hingegen wechselten häufiger. So arbeiteten nacheinander Julius Einödshofer, Victor Hollaender und Paul Lincke für das Theater. Oft waren aber auch mehr Personen an einem Stück beteiligt. Bei Die verkehrte Welt etwa wiesen die Zeitungen ironisch darauf hin, dass sie „nicht weniger als acht Väter“ gehabt hatte. ${ }^{258}$ Mit der Zeit wuchs auch in Berlin die Zahl der beteiligten Personen. Die Operette Das Weiße Rössl, die 1930 am Großen Schauspielhaus uraufgeführt wurde, basierte auf einem Lustspiel von Oscar Blumenthal und Gustav Kadelburg von 1898. ${ }^{259}$ Ralph Benatzky komponierte den Großteil der Musik und schrieb zusammen mit Hans Müller-Einigen und Erik Charell, dem Produzenten des Stücks, das Libretto. Die Liedtexte wiederum stammten von Robert Gilbert, der, ebenso wie Bruno Granichstaedten und Robert Stolz, auch musikalische Einlagen beisteuerte. So waren am Weißen Rössl (das Original nicht mit eingerechnet) insgesamt neun Autoren beteiligt. 260

253 The Cingalee, BL, MSS LCP 1904/6; ForBEs-WinsLow, Daly's, S. $46 \mathrm{f}$.

254 Vgl. Forbes-WinsLow, Daly's, S. 71-73; GänZl, The Encyclopedia, S. 381 f.

255 Vgl. Boosey, Fifty Years of Music, S. 122.

256 CARTER, New Theatre, S. 89.

257 Dramatic Collaboration, ORCHESTRA 17 (1871), S. 155.

258 Das Metropol-Theater, BerLiner Neueste NaChrichten, 27. 12. 1899.

259 Blumenthal und Kadelburg, Im weissen Rössl.

260 Vgl. die Beiträge in Tadday (Hrsg.), Im Weißen Rössl; Clarke und Peter (Hrsg.), Im weißen Rössl; sowie Clarke, Im Rausch der Genüsse. 
Da nur wenige Künstler das Talent des Autors, Komponisten und Regisseurs in sich vereinigen, hatte das Theater zwar immer schon ein höheres Maß an Arbeitsteiligkeit aufgewiesen als andere Künste. Nirgends jedoch war diese soweit fortgeschritten wie im Bereich des populären Musiktheaters, denn hier waren Kommerzialisierung, Konkurrenz und Erfolgsdruck am ausgeprägtesten. Selbst wenn ein Stück ein ganzes Jahr lang lief, stand bereits nach der Premiere die Frage im Raum, wie es danach weitergehen sollte. Wie das Thalia-Theater mit Jean Gilbert, so arbeiteten viele Bühnen eng mit einem bestimmten Komponisten zusammen, von dem sie im Gegenzug erwarteten, stets fristgerecht ein neues Werk zu liefern. Hatte ein Komponist oder Autor einen Erfolg gelandet, rissen sich überdies viele Bühnen um ihn. Kritiker meinten, dass deshalb „nicht die Qualität der Produkte, sondern die Nachfrage die Masse des Angebots“ bestimmte. ${ }^{261}$ Arbeitsteilung war ein Mittel, um den Produktionsprozess zu beschleunigen, denn wenn der Komponist sich auf das Ersinnen neuer Melodien beschränkte, deren Arrangement anderen überließ und wenn auf bestimmte Aspekte spezialisierte Autoren im Team arbeiteten, ließen sich in kürzerer Zeit mehr Stücke produzieren. Diese Arbeitsteiligkeit aber widersprach der verbreiteten Vorstellung von dem autonomen Kunstwerk, das dem Genie eines Individuums entspringt. Zugleich erinnerte sie an die Spezialisierung der Arbeitskräfte in einer Fabrik, weshalb diese Metapher in der Kritik am Unterhaltungstheater so häufig vorkam.

Doch Industrialisierung konnte noch einen weiteren, eng mit der Arbeitsteiligkeit verbundenen Aspekt bezeichnen. In einem nach dem Zweiten Weltkrieg geführten Interview meinte der Impresario Hermann Haller, die Operette sei in der Zwischenkriegszeit „längst völlig industrialisiert gewesen“ und man habe sie in Auftrag gegeben wie einen „Anzug vom Maßschneider“: „Man sagte dem Librettisten, für welchen Komiker man saftige Rollen brauchte, und bekam ein auf Taille genähtes Textbuch geliefert. Die Komponisten griffen einfach in ihre Schubladen, holten ein paar Schlager, die sie immer auf Lager hielten, heraus und komponierten die fehlende Verbindungsmusik mit dem jeweiligen Zeittempo entsprechend hinzu“.262 Auch Haller verstand unter ,Industrialisierung' also zunächst die Arbeitsteiligkeit des Produktionsprozesses, darüber hinaus aber auch den gestiegenen Grad der Standardisierung. Industrialisiert war die Operette seiner Ansicht nach, weil sie nach einem festen Muster aus bestimmten, gleichbleibenden Bestandteilen zusammengesetzt wurde. Und Haller musste es wissen: Nicht nur gab er als Theaterdirektor des Admiralspalastes und anderer Berliner Theater zahlreiche Stücke in Auftrag, als Librettist schrieb er selbst an vielen Revuen und Operetten mit. ${ }^{263}$

Tatsächlich zeichneten sich die meisten Revuen, Operetten und Musical Comedies durch denselben Aufbau aus. Die Jahresrevuen des Metropol-Theaters vor

261 Klaus Pringsheim, Operette, Süddeutsche Monatshefte 9 (1912), 2. Bd., S. 178-187, hier S. 183.

262 So Haller gegenüber dem Journalisten Paul Marcus, zit. nach Pem, Operette, S. 127.

263 Vgl. Biographisches Handbuch Der Deutschsprachigen EMigration, 2. Bd., S. 565. 
dem Ersten Weltkrieg verarbeiteten zwar immer neue Ereignisse, wiesen aber alle dasselbe Schema auf. Möglicherweise wirkten sie deshalb nach einiger Zeit eintönig. Aber auch im Fall der von wechselnden Teams produzierten Musical Comedies waren Wiederholungen an der Tagesordnung. Jede Musical Comedy begann mit einem Chor, auf den die Vorstellung der Hauptfigur folgte, dann kam es zu zahlreichen Verwechslungen und Verwirrungen, die alle am Ende wieder aufgelöst wurden - oft im Rahmen einer (oder mehrerer) Hochzeiten. Nicht anders verhielt es sich bei der Operette, der Kritiker immer wieder ihre Tendenz zu „Produktionsnormung, Schablonenverfahren, Massen- und Schnellproduktion“ vorwarfen. ${ }^{264}$

Dennoch lässt sich fragen, inwieweit Begriffe wie Industrialisierung, Industrie und Fabrik berechtigt waren. Sogar Theodor W. Adorno warnte davor, sich die „Produktionsweise der leichten Musik [...] allzu buchstäblich wie die industrielle Massenproduktion“ vorzustellen: „So sehr auch Züge wie die Zerlegung in kleinste Bestandstücke, die bruchlos dem Schema sich einpassen, oder die Teilung der Produzenten in Leute, die den angeblichen Einfall, solche, die den Schlager formulieren, in Texter, Arrangeure die industrielle Arbeitsteilung beschwören, der Vorgang bleibt sozusagen handwerklich“. ${ }^{265}$ Auch bei Adorno meinte Industrialisierung Arbeitsteilung, Spezialisierung und Standardisierung, er wies aber zugleich darauf hin, dass mehr von einem Handwerk im traditionellen Sinne als von einer modernen Industrie zu sprechen wäre. Hermann Haller gab ihm indirekt recht, wenn er die Operette mit einem ,Anzug' verglich, den man bei einem ,Maßschneider' bestellt - und nicht mit einem Anzug von der Stange. Während solche Vergleiche in Deutschland meist abwertend gemeint waren, bestand darin für einen britischen Schriftsteller wie William Somerset Maugham, der allein im Jahr 1912 fünf neue Stücke herausbrachte, nichts Anrüchiges: „A play is very like a suit of clothes. The tailor must make it fit or the client will not wear it", meinte er lakonisch. ${ }^{266}$

Dass das populäre Musiktheater seit der Jahrhundertwende eine Neigung zu „schablonenhaften Handlungen“ und zur „Zurückdrängung komplexerer musikalischer Formen zugunsten verkaufsfördernder Schlager" erkennen ließ, ist kaum zu bestreiten. ${ }^{267}$ Die Frage ist jedoch, wie man diese Entwicklung bewertet. Zeitgenössische Kritiker sahen in ihr einen eindeutigen Beleg für den industriellen Charakter des populären Musiktheaters und damit für seine kulturelle Wertlosigkeit. Diese Wertung muss man aber nicht übernehmen, denn erstens weist jede kulturelle Form ein gewisses $\mathrm{Maß}$ an Schablonenhaftigkeit auf, vom mittelalterlichen Minnesang bis zum modernen Popsong. Zweitens erlaubte die Reduzierung von Komplexität und der Verzicht auf intellektuelle Volten es dem Massenpublikum, diese Stücke zu genießen. Und drittens ist Standardisierung eines der

264 Westermeyer, Die Operette, S. 156.

265 Adorno, Leichte Musik, S. 40.

266 Zit. nach Hastings, The Secret Lives of Somerset Maugham, S. 266.

267 LinHARDT, ,Warum es der Operette so schlecht geht', S. 213. 
Elemente, das Populärkultur bis heute kennzeichnet. Was im populären Musiktheater der langen Jahrhundertwende erprobt wurde, sollte Vorbildcharakter haben für andere Sparten. So übernahm der Film, wie Walter Freisburger schon in den dreißiger Jahren feststellte, gerade „das ,Genormte“ der Operette“.268

\section{Spezialisierung}

Wenn das Theater mit einer Industrie oder Fabrik verglichen wurde, bezog sich das meist auf einen Produktionsprozess, der zunehmend durch Arbeitsteilung, Standardisierung und Spezialisierung geprägt war - mitunter aber auch auf die Theater selbst. Das Gaiety Theatre etwa war „more like a factory than a theatre“.269 Ein naheliegendes Bild, da die Theater die Stücke in Auftrag gaben, die Arbeit aller Beteiligten koordinierten und der Ort waren, an dem das Endprodukt zusammengesetzt wurde. Und auch die Theater selbst erlebten einen Prozess der Spezialisierung.

Noch zu Beginn des 19. Jahrhunderts war es üblich gewesen, dass ein Theater die unterschiedlichsten Gattungen spielte, von Melodramen bis zu Tragödien, von Operetten bis zu Opern. Um 1900 hingegen wiesen fast nur noch Theater in mittleren und kleineren Städten eine derartige Vielfalt auf, während sich jene in den Großstädten meist ganz auf ein Genre spezialisierten, um sich voneinander abzusetzen. So unterschied der Kritiker Theodor Lessing zwischen den „Provinzialbühnen“, die „wirr und wahllos Tragödien, Possen, Opern und Lustspiele durcheinander spielen“ und den "großstädtische[n] Theater[n], deren Spezialisierung und Differenzierung [...] soweit vorgeschritten ist, daß ein bestimmtes Theater jahraus, jahrein immer denselben Dichter spielt und oft viele hundert Male dasselbe Stück zur Aufführung bringt“. ${ }^{270}$ Da das Theaterpublikum in Mittelstädten begrenzt war, spielten die Theater hier möglichst jeden Abend ein anderes Stück, um dieselben Besucher immer wieder aufs Neue zu mobilisieren. „Nur in Weltstädten, wie Berlin und Paris“, meinte der Theaterkritiker Paul Schlenther, „deren Theater nicht bloß mit der einheimischen Bevölkerung, sondern auch mit einem ungeheuren Fremdenzudrang rechnen dürfen, können sich einzelne Bühnen auf ein bestimmtes Gebiet der dramatischen Kunst einschränken “. ${ }^{271}$ Tatsächlich aber gingen viele Berliner Theater nach 1900 dazu über sich zu spezialisieren und erfolgreiche Stücke en suite zu spielen.

In London war zu dieser Zeit das long run-System längst etabliert: „We have become so accustomed to the long run in recent years that we are likely to forget that this factor in the conduct of the theatre was utterly unknown until the last half century“, meinte ein Autor $1917 .{ }^{272}$ Hatte das Gaiety Theatre noch unter

268 Freisburger, Theater im Film, S. 49.

269 Hollingshead, ,Good Old Gaiety', S. 15.

270 Theodor Lessing, Neue künstlerische Tendenzen, DoKUmente DES ForTsCHritTs 1 (1907), Nr. 1, S. 102-105, hier S. 103.

271 SCHLEnTHer, Das Theater, S. 477.

272 Hamilton, Problems of the Playwright, S. 248. 
John Hollingshead ganz verschiedene Genres gespielt, zeigte es nach dem Erfolg der Musical Comedy bis zu seiner Liquidierung in den dreißiger Jahren ausschließlich diese Gattung. Und während noch in der ersten Hälfte des 19. Jahrhunderts kaum ein Stück mehr als 100 Aufführungen erlebt hatte, erreichten in den 1880er Jahren 46 Stücke über 200 Aufführungen, in den 1930er Jahren 143 über 200 und 66 über 300 Aufführungen. ${ }^{273}$ Viele dieser Stücke waren Musical Comedies. Die größten Hits brachten es sogar auf mehr als 1000 Aufführungen, wie The Maid of the Mountains (1352 Aufführungen) oder A Chinese Honeymoon (1075 Aufführungen). Chu Chin Chow, das bis zum Zweiten Weltkrieg erfolgreichste West End-Stück, lief zwischen 1916 und 1921 ununterbrochen im His Majesty's Theatre und erlebte 2238 Aufführungen.

Auch das Metropol-Theater brachte anfangs ein abwechslungsreiches Programm aus Varieté, Komödien, Operetten und zeigte mitunter sogar Ringkämpfe. Nach dem Erfolg von Neuestes! Allerneuestes! spielte es dann fast das ganze Jahr hindurch dieselbe Jahresrevue. ${ }^{274}$ Zog diese kein Publikum mehr an, setzte Richard Schultz bisweilen eine Operette auf den Spielplan, um die Zeit bis zur Premiere der nächsten Revue zu überbrücken. ${ }^{275}$ Die Tendenz zum long run ließ sich also auch in Deutschland beobachten. Wie viele Intellektuelle sah der Kritiker Kurt Weiss darin einen Beleg für die Degeneration des Theaters und die Herrschaft des Pöbels: „Und die en suite-Aufführungen der Operetten und Schwänke, Jubiläen von 200,300, ja sogar 500maligem Spiel, - sind sie für den Geschmack und für das Kunstverständnis der Masse nicht niederschmetternde Anklagen?!“276 Noch mehr empörte ihn, dass die Aufführungszahlen von Franz Lehárs Operette Der Graf von Luxemburg 1913 im deutschen Sprachraum von 1365 auf 1794 gestiegen, die sämtlicher Dramen Schillers aber von 2044 auf 1584 gesunken waren. ${ }^{277}$

Sowohl die Spezialisierung auf ein Genre als auch der Übergang zum en suiteSystem waren in erster Linie ökonomisch begründet. Schon die Ausstattung für die Jahresrevuen des Metropol-Theaters hatte enorme Summen verschlungen. Richard Schultz wendete pro Revue 200000 Mark auf, während sich das Königliche Schauspielhaus für eine Neuinszenierung von Aida mit 30000 Mark begnügen musste. ${ }^{278}$ Max Epstein zufolge operierte er sogar mit einem Tagesetat von 5000 Mark. ${ }^{279}$ Die Glanzrevuen der Zwischenkriegszeit verschlangen noch wesentlich höhere Summen. Während ein Berliner Durchschnittstheater über einen Tagesetat von 3500 Mark verfügte, wendete Erik Charell für seine erste Revue 6000 Mark täglich auf, bei Im weißen Rössl 1931 waren es dann 60000 Mark am Tag. ${ }^{280}$ Damit sich solche Investitionen amortisierten, war eine lange Laufzeit unabding-

273 Vgl. Pick, West End, S. 31.

274 Vgl. LAB, A Pr. Br. Rep. 030-05 Nr. 706.

275 Freund, Aus der Frühzeit.

276 WeIss, Deutsche Theaterverhältnisse, S. 43.

277 Ebd.

278 Vgl. Born, Berliner Luft, S. 135.

279 EPSTEIN, Theater als Geschäft, S. 19.

280 Vgl. PaCher, Sehen Sie, das war Berlin, S. 264. 
bar. Wurde sie nicht erreicht, entstand ein kaum noch auszugleichendes Loch in der Bilanz - der Untergang des Rotter-Konzerns ist dafür das beste Beispiel. ${ }^{281}$

Die Spezialisierung der Theater aber betraf außer dem Repertoire noch viele weitere Aspekte. Bis zum Ende des 19. Jahrhunderts war es üblich, dass jedes Theater seine eigenen Bühnenbilder, Requisiten, Kostüme und Perücken herstellte, wozu es eigene Handwerker beschäftigte. An deren Stelle traten nun zunehmend spezialisierte Theaterateliers. ${ }^{282}$ Das älteste Londoner Theateratelier war L. \& H. Nathan, das in den 1830er Jahren aus einem Herrenausstatter hervorgegangen war. ${ }^{283}$ Größer und internationaler war das Theateratelier Hugo Baruch \& Co. mit Sitz in Berlin. Auch Hugo Baruch hatte seine Karriere als Herrenschneider begonnen, doch trat die Herstellung von Kleidung mit der Zeit immer mehr zurück. Da Köln, wo das Unternehmen ursprünglich ansässig war, wenig Entwicklungsmöglichkeiten bot, siedelte die Firma 1890 nach Berlin über. Neben Kostümen produzierte Hugo Baruch \& Co. Dekorationen, Möbel und Requisiten. ${ }^{284}$ Fast alle Berliner Theater gehörten zu den Kunden dieses Ateliers, darunter auch das Metropol-Theater, das hier die Ausstattung der Revuen bestellte. ${ }^{285}$ Gleichzeitig gehörte Hugo Baruch zu den 17 Personen, die sich 1897 an Richard Schultz' GmbH zur Übernahme und zum Betrieb des Metropol-Theaters beteiligt hatten. Von den 400000 Mark Stammkapital hatte er 30000 Mark eingebracht. ${ }^{286}$ Wie Max Epstein schreibt, hielt Hugo Baruch Anteile an vielen Berliner Theatern, wobei er aber kaum je bares Geld gab, sondern einen festen Auftrag in Höhe von etwa 100000 Mark verlangte, auf die das in die Gesellschaft eingebrachte Geld angerechnet wurde. ${ }^{287}$ Im Fall des Metropol-Theaters schuldete Richard Schultz dem Atelier 70000 Mark, ohne dass er selbst einen Pfennig Bargeld sah. Mit dieser Geschäftspraxis fuhr Hugo Baruch nicht schlecht; 1897 betrug der Umsatz der Firma zwei Millionen Mark. ${ }^{288}$ Schon vor der Jahrhundertwende begann sie dann ihre Fühler nach Übersee auszustrecken, so kamen Aufträge aus London, New York, Chicago, Liverpool, Edinburgh, Glasgow, Dublin und Brüssel. Vor allem Großbritannien war so wichtig, dass Hugo Baruch \& Co. hier eine eigene Filiale eröffnete. ${ }^{289}$ Nach dem Tode Hugo Baruchs führten seine drei Söhne das Geschäft weiter. Von der Wirtschaftskrise ebenso betroffen wie seine Kundschaft, meldete es 1927 Konkurs an. ${ }^{290}$

$281 \mathrm{Zu}$ Kostensteigerung und Rotter-Konzern siehe das vorangegangene Unterkapitel.

282 Vgl. Davis, The Economics, S. 313-324.

283 Vgl. IBscher, Theaterateliers, S. 91; NATHAN, Costumes by Nathan; WaTZKA, Baruch, Sliwinski und Co.

284 Vgl. ebd,, S. 92-95; STANGE, Berliner Ausstattungsfirmen, insbes. S. 72-76.

285 Vorwärts, 15.3. 1904; Das Kleine Journal, 12.3. 1904; Berliner Morgenpost, 13.3. 1904.

286 Vgl. Notarielle Verhandlung vom 19.10.1897 über die Errichtung einer Gesellschaft und Statut für Metropol-Theater Gesellschaft mit beschränkter Haftung vom 19. 10. 1897, LAB, A. Pr. Br. 030-05-3061.

287 Vgl. EPsteIN, Theater als Geschäft, S. 50.

288 Vgl. STANGE, Berliner Ausstattungsfirmen, S. 72.

289 Vgl. IBSCHER, Theaterateliers, S. 95; DAVIS, The Economics, S. 321.

290 Vgl. ebd., S. $93 \mathrm{f}$. 


\section{Internationalisierung I: Tourneen}

Das Theater industrialisierte und spezialisierte sich nicht nur seit dem späten 19. Jahrhundert, es wurde auch zunehmend internationaler. Quantitativ wie qualitativ noch bedeutender als der personelle Austausch waren Tourneen. Die Praxis, ein Ensemble zusammenzustellen, um mit ihm auf Reisen zu gehen, war zunächst nichts radikal Neues. Bereits in der frühen Neuzeit hatten ,englische Komödianten' auf diese Weise die Dramen Shakespeares im deutschen Sprachraum bekannt gemacht. ${ }^{291}$ Dennoch waren internationale Tourneen bis zur Mitte des 19. Jahrhunderts eine Seltenheit. Als dann die Mobilitätsrevolution im Zeichen von Eisenbahn und Dampfschiff das Reisen wesentlich vereinfachte und verbilligte, nahmen sie an Umfang und Frequenz bedeutend zu. ${ }^{292}$

Das Unterhaltungstheater erkannte sofort das ökonomische Potential der Tournee. Kaum hatte sich Jacques Offenbach mit seinen Bouffes-Parisiens in Paris etabliert, da überfiel er auch schon an „der Spitze eines Trupps von fünfzig Personen [...] London mit den Glanzstücken seines Repertoires“.293 Insgesamt zog es ihn vier Mal nach London, wo seine Operetten Gilbert und Sullivan beeinflussten, deren frühe Werke am Gaiety Theatre herauskamen, Offenbachs Stammhaus in London. ${ }^{294}$ Noch wichtiger als die britische Metropole waren für Offenbach aber der Kurort Bad Ems, seine „Sommerfiliale“ und Wien, das sich zu seiner „zweiten Hauptstadt“ entwickelte, in der er fast jedes Jahr gastierte. ${ }^{295}$ Auch diese Aufenthalte blieben nicht ohne Wirkung, manche Autoren meinen sogar, die „Wiege der Wiener Operette“ habe in Paris gestanden. ${ }^{296}$ Berlin wurde schließlich aufgrund der emphatischen Aufnahme seiner Operetten „nach Wien zu einer der wichtigsten Metropolen für Offenbach“. ${ }^{297}$ Den Höhepunkt erreichte seine Reisetätigkeit schließlich mit einer Tournee durch die USA im Jahr $1876 .{ }^{298}$

Obwohl Offenbach durch seine Präsenz in den europäischen Metropolen neue Maßstäbe setzte, erreichten seine Gastspielreisen nicht annähernd die Reichweite, die ein knappes Jahrzehnt später den von Richard D’Oyly Carte organisierten Tourneen mit den Operetten von Gilbert und Sullivan beschieden war. D'Oyly Carte schickte mitunter drei bis vier, 1884 sogar sechs Ensembles gleichzeitig auf Reisen durch die Welt. Obschon die Tournee-Ensembles in der Regel aus zweiten und dritten Besetzungen bestanden, legte er größten Wert darauf, dass möglichst

291 Vgl. FisCHER-Lichte, Kurze Geschichte des deutschen Theaters, S. $62 \mathrm{f}$.

292 Vgl. Geyer und Paulmann, Introduction; Conrad, Globalisierung und Nation; OsterhamMEL, Die Verwandlung der Welt.

293 Kracauer, Jacques Offenbach, S. 167.

294 Vgl. Hollingshead, Gaiety Chronicles; ders., ,Good Old Gaiety'; Lamb, How Offenbach Conquered London; ders., Offenbach in London.

295 KraCAUER, Jacques Offenbach, S. 232; HaWIG, Jacques Offenbach in Bad Ems.

296 SpOHR, Inwieweit haben Offenbachs Operetten die Wiener Operette aus der Taufe gehoben?, S. 33; siehe auch OBERMAIER, Offenbach in Wien.

297 Vgl. Rosenthal, Offenbachs Operetten in Berlin.

298 Vgl. Kracauer, Jacques Offenbach, S. 325. 
exakte Reproduktionen der Londoner Inszenierung gezeigt wurden. ${ }^{299}$ Für Regionen wie Australien und Neuseeland, in die er keine eigenen Ensembles schickte, vermietete er die Rechte an andere Theaterunternehmer für 300 Pfund pro Stück und Jahr. ${ }^{300}$ Nachdem 1896 die Kooperation zwischen D’Oyly Carte, Gilbert und Sullivan geendet hatte, versandete auch zunehmend der Strom der Tourneen: 1900 schickte das Savoy Theatre nur noch zwei Ensembles auf Reisen, nach 1903 nur noch eines. ${ }^{301}$

Eine dieser Tourneen kam 1886 nach Berlin, wo D'Oyly Carte das Wallner Theater für 30 Nächte angemietet hatte. ${ }^{302}$ Hier erlebte der Mikado einen großen Erfolg, obwohl „neun Zehntel der im Theater Anwesenden von dem Text der vorgeführten Operetten kein Wort" verstand, wie ein Kritiker notierte. ${ }^{303}$ Erstaunt fuhr er fort: „Wie erklärt sich diese seltsame Erscheinung, die so sehr der landläufigen Tradition widerspricht, wonach wohl Paris und Wien, aber doch niemals London als eine berufene Pflanzstätte der Operettenkomik anzusehen war?"304 Das Staunen über den Erfolg einer britischen Operette wurzelte in der verbreiteten Ansicht, Großbritannien sei ein „Land ohne Musik“. ${ }^{305}$ Während Paris und Wien dank der Operetten von Jacques Offenbach und Johann Strauß längst etablierte Orte auf der Landkarte des populären Musiktheaters waren, war Großbritannien dahingehend eine Terra incognita. Ein anderer Kritiker empfand den Mikado als „eine erfrischende Brise vom stammverwandten Inselreiche [...], von dem den Deutschen künstlerisches Heil schon manches mal gekommen“ und fragte besorgt: „Woran liegt es also, daß sich bei uns nichts Ähnliches bilden will?"306 Ähnlich wie die enthusiastische Wagner-Rezeption in Großbritannien löste in Berlin der Erfolg von Gilbert und Sullivan sofort die bange Frage nach der Situation des heimischen Musiktheaters aus. ${ }^{307}$ Tatsächlich hatte Berlin noch in den 1880er Jahren nichts aufzuweisen, das den Operetten Gilbert und Sullivans, geschweige denn dem Pariser und Wiener Musiktheater vergleichbar gewesen wäre. Die Konkurrenz weckte jedoch den Ruf nach einer genuinen Berliner Musikkultur. Von Berlin aus brach die britische Operettentruppe zu einer Tournee durch ganz Deutschland auf, sodass der Mikado bis 1886 spektakuläre 8954 Vorstellungen weltweit erlebte. ${ }^{308}$ Trotz dieses anfänglichen Erfolgs konnten sich die Operetten Gilbert und Sullivans außerhalb des angelsächsischen Kulturkreises nicht dauerhaft etablieren. Kein anderes ihrer Werke erreichte auch nur annä-

\footnotetext{
299 JosePh, The D’Oyly Carte Opera Company, S. 86-92.

300 Vgl. DAVIS, The Economics, S. 349.

301 Vgl. Joseph, The D’Oyly Carte Opera Company, S. 138.

302 Vgl. The ,Mikado' at Berlin, The Times, 3.6. 1886, S. 6; siehe auch Young, Sullivan, S. 143145; Müller, Friction, Fiction and Fashion, S. $235 \mathrm{f}$.

303 H. Trab, Englische Operetten in Berlin, Die Nation 3 (1885/86), Nr. 38, S. 561.

304 Ebd.

305 Siehe SCHMITZ, Land ohne Musik.

306 Karl Borinski, Englische Oper in Berlin, Die Grenzboten 45 (1886), 2. Bd., Nr. 26, S.619626, hier S. $625 \mathrm{f}$.

307 Vgl. MÜller, Friction, Fiction and Fashion; ders., A Musical Clash of Civilisations.

308 Vgl. HansLICK, Der Mikado von Sullivan, S. 288-295.
} 
hernd die Popularität des Mikado und D’Oyly Carte scheint auch keine weitere Tournee auf den Kontinent geschickt zu haben. ${ }^{309}$

Mit dem Aufstieg der Musical Comedy nahmen dann die Tourneen in Reichweite und Dauer noch einmal bedeutend zu. Gleich eine der ersten Musical Comedies, A Gaiety Girl von 1894, ging von London aus auf eine Tournee, die jene von D'Oyly Carte organisierten in den Schatten stellte: Sie dauerte 431 Tage und führte über New York und die amerikanische Ostküste nach San Francisco und von dort durch den pazifischen Raum bis nach Australien. ${ }^{310}$ Noch erfolgreicher war Our Miss Gibbs von 1909, deren geradezu globale Popularität sich dank genauer Auflistung der Tantiemen im Gaiety Royalties Book im Victoria and Albert Museum genau rekonstruieren lässt. Es listet allein für die Jahre zwischen 1910 und 1911 Aufführungen des Stücks in mehr als 150 Städten auf den britischen Inseln auf, von Bornemouth bis Glasgow und von Llandudno bis Scarborough. Parallel dazu spielten Tournee-Ensembles es in allen Teilen des britischen Empires: 1910 beispielsweise in Johannesburg, Bulawayo, Kimberly, Kapstadt, Pretoria, Bloemfontein, Lucknow und Allahabad; 1911 in Kalkutta, Kairo, Alexandria, Singapur, Hongkong, Sydney, Shanghai, Yokohama und Tientsin; 1912 in Melbourne, Brisbane, Toowoomba und in vielen Städten Neuseelands sowie in Manila, Rangoon und Bombay. ${ }^{311}$ Und Our Miss Gibbs war keineswegs eine Ausnahme, denn die meisten Musical Comedies legten ähnliche Wege zurück. Wenn ein Stück im West End erfolgreich war, wurde es bis in die entlegensten Gebiete des britischen Empires verschifft. Wie diese Beispiele belegen, müssen die Anfänge der kulturellen Globalisierung deshalb bereits in der Zeit der langen Jahrhundertwende gesucht werden.

Neben der Tournee gab es noch eine weitere, nicht ganz so aufwändige Form der Internationalisierung, nämlich den Transfer einer Inszenierung an ein Theater in einer anderen Stadt. Insbesondere zwischen dem West End und dem Broadway war dies gängige Praxis. So war beispielsweise die Inszenierung von The Girl on the Film, die im Dezember 1913 in New York zu sehen war, weitgehend identisch mit jener, die im April desselben Jahres im Gaiety Theatre uraufgeführt worden war. Auch in New York spielten George Grossmith Jr. und Emmy Wehlen die Hauptrollen, ein Drittel der Nebenrollen wurde nun allerdings mit amerikanischen Schauspielerinnen und Schauspielern besetzt. ${ }^{312}$ Obwohl Sprache kein Hinderungsgrund war, wurden die meisten Musical Comedies mit amerikanischen Darstellern neu einstudiert. Die New Yorker Aufführungen von The Arcadians beispielsweise glichen in Text und Musik weitgehend dem Londoner Vorbild, in allen anderen Dingen jedoch handelte es sich um eine vollständige Neuinszenierung. ${ }^{313}$ Ein ähnlicher Austausch wäre zwischen Berlin und Wien zu vermuten,

\footnotetext{
309 Zumindest verzeichnet JOSEPH, D’Oyly Carte keine solche Tournee.

310 BANTOCK und Aflalo, Round the World.

311 Gaiety Royalties Book, No. 2 in der Theatersammlung des Victoria \& Albert Museums (unkatalogisiert).

312 Vgl. ,The Girl on the Film' Pretty and Lively, The New York Times, 31. 12. 1913.

313 Vgl. ,The Arcadians‘ Charm at Liberty, The New York Times, 18. 1. 1910.
} 
doch tatsächlich gab es derartige Transfers kaum, und das, obwohl zahlreiche Schauspieler und Regisseure in beiden Städten aktiv waren. ${ }^{314}$

Komplizierter waren Gastspiele und Tourneen, wenn sie über Sprachgrenzen hinweg führten. Stars wie Sarah Bernhardt, Eleonora Duse oder Enrico Caruso spielten im Ausland ganz selbstverständlich in ihrer Muttersprache, aber selbst der führende Londoner actor-manager konnte in Berlin Schiffbruch erleiden, wenn er den Hamlet auf Englisch gab. ${ }^{315}$ Die Mikado-Tournee von 1886 ist eines der ganz wenigen Beispiele für ein Stück, das in englischer Sprache in Deutschland Erfolg hatte. Dass das Londoner Publikum dem deutschen Theater gegenüber aufgeschlossener war, zeigt die Karriere von Max Reinhardt, der wiederholt von britischen Managern wie Oswald Stoll und Charles Cochran eingeladen wurde. Im Jahr 1911 waren mit Sumurun und Das Mirakel gleich zwei seiner Inszenierungen in London zu sehen. ${ }^{316}$ Der Erste Weltkrieg setzte dem Austausch dann vorläufig ein Ende. Erst $1931 \mathrm{kam}$ in London mit The White Horse Inn wieder eine Inszenierung eines deutschen Regisseurs heraus. Nachdem Erik Charelles Version von Im weißen Rössl 1931 fünf Monate lang die 3000 Plätze des Großen Schauspielhauses gefüllt hatte, holte ihn Stoll nach London, um dort das Stück zu inszenieren. Das war ein Novum, denn Operetten waren bis dato nie als vollständige Produktionen eingekauft worden. Stets hatte ein Theaterdirektor sich nur die Aufführungsrechte gesichert, um das Stück dann übersetzen und adaptieren zu lassen, um es anschließend selbst zu inszenieren. Im Fall des Weißen Rössl hingegen kaufte Stoll die komplette Inszenierung. Das war naheliegend, hatte diese doch einen wesentlichen Anteil am Erfolg des Stücks in Berlin gehabt. Umgekehrt lag es aber auch in Charells Interesse, die Londoner Aufführung persönlich zu betreuen, denn auf diese Weise behielt er die Kontrolle über sein Werk. Außerdem zahlte Stoll in stabilem Pfund, auf dem Höhepunkt der Wirtschaftskrise zweifellos ein zusätzlicher Anreiz. Neben der Londoner Inszenierung betreute Charell auch die Pariser am Théâtre Mogador 1936 und die New Yorker am Center Theatre im selben Jahr. ${ }^{317}$ Obwohl er schon aus Sprachgründen neue Darsteller vor Ort engagierte, blieben die folgenden Inszenierungen bis in ihre Details dem Original treu. Da das Weiße Rössl nur als Paket, bestehend aus Text, Musik, der Inszenierung Charells, dem Bühnenbild bis hin zu den Tiroler Jodlern, zu bekommen war, markiert dieser Transfer eine neue Stufe der Internationalisierung wie der Standardisierung des populären Musiktheaters.

314 Zum Austausch zwischen Wien und Berlin siehe BAB und HandL, Wien und Berlin; WarreN und ZitZlSPERger (Hrsg.), Vienna Meets Berlin.

315 Vgl. FoulKes, Performing Shakespeare, S. 139-145; BECKER, Londoner Theater in Berlin.

316 Vgl. Carter, The Theatre of Max Reinhardt, S. 223-229; StefaneK, Max Reinhardt; BeCKer, Das doppelte Mirakel; zu Reinhardts mehrere Länder überspannende Karriere siehe auch Leisler und Prossnitz (Hrsg.), Max Reinhardt in Europa; dies. (Hrsg.), Max Reinhardt in Amerika; HuEsManN, Welttheater Reinhardt; MARX, Max Reinhardt.

317 Vgl. BruYas, Histoire de L'Opérette, S. 519f.; GänZL, The Encyclopedia, S. 697-699; NorTON, ,So this is Broadway', S. 167. 
Der Transfer des Weißen Rössls nach London, Paris und New York belegt nicht zuletzt, dass das deutsche Theater im ersten Drittel des 20. Jahrhunderts Produkte hervorbrachte, die international konkurrenzfähig waren und die sich in die ganze Welt verkauften. Als Umschlagplatz in diesem Austausch fungierte oft die britische Hauptstadt. Von London aus trat Die Lustige Witwe ihren Siegeszug durch die Welt an, London diente Max Reinhardt, Erik Charell und vielen anderen Theatermachern und Schauspielern als Sprungbrett in andere Länder, insbesondere in die USA. Doch nicht zwangsläufig wurden Operetten immer erst in London gespielt, bevor sie in anderen Metropolen herauskamen. Der tapfere Soldat von Oscar Straus beispielsweise wurde in New York uraufgeführt und von dort nach London transferiert. Dasselbe gilt für Die Kino-Königin von Jean Gilbert und Der letzte Walzer von Lehár. Andere Operetten wurden in New York gespielt, fanden aber nie den Weg nach London, wie Die Tango-Prinzessin und Fräulein Tra-la-la von Jean Gilbert. ${ }^{318}$ So rege der Austausch zwischen London und Berlin also war, so finden sich doch ähnliche intensive Kontakte zu New York, Paris, Wien und anderen Metropolen.

\section{Internationalisierung II: Stücke}

Eine weitere Form des internationalen Austausches bestand im Im- und Export von Stücken (im Gegensatz zur vollständigen Inszenierung). Die erste in Berlin aufgeführte Musical Comedy war A Gaiety Girl, die unter dem Titel Ein fideles Corps 1894 am Adolf-Ernst-Theater in Berlin zu sehen war, aber kaum noch etwas mit dem Original gemein hatte. ${ }^{319} 1897$ folgte mit The Geisha die auf dem Kontinent erfolgreichste Musical Comedy. ${ }^{320}$ Viele Zuschauer und Kritiker fühlten sich schon wegen des japanischen Schauplatzes stark an den Mikado erinnert und nannten die beiden Stücke und ihre Komponisten in einem Atemzug. ${ }^{321} \mathrm{Al}-$ lein in Berlin erreichte die Geisha, die erst im Lessing Theater, später im CentralTheater $\mathrm{zu}$ sehen war, über 1000 Vorstellungen. ${ }^{322}$ Das Central-Theater entwickelte sich daraufhin zu einer Heimstatt der Musical Comedy: 1899 brachte es A Greek Slave (als Der griechische Sklave), 1901 San Toy (als San Toy), 1902 A Silver Slipper (als Der silberne Pantoffel) und 1903 A Chinese Honeymoon (als Chinesische Flitterwochen) heraus. ${ }^{323}$ „Die Erfolge der ,Geisha' locken die Direktion schon zum zweiten Male, es wieder mit einer im fernen Ostasien spielenden Operette zu versuchen“, meinte die Volkszeitung. ${ }^{324}$ Diese Hoffnung erfüllte sich

318 Vgl. GänZL, The Encyclopedia, S. 1427-1429, 774f., 850-85, 1424 f.

319 Vgl. LAB, A Pr. Br. Rep. 030-05-01 Nr. F441; siehe auch GänZL, The Encyclopedia, S. 509 f.

320 Die Geisha, LAB, A Pr. Br. Rep. 30-05-02 Nr. 372.

321 Vgl. Leopold Schmidt, Die Operette, Der Kunstwart und Kulturwart 27 (1914), S. 259263.

322 Vgl. SCHNeIDEREIT, Berlin, wie es weint und lacht, S. 141.

323 Vgl. LAB, A. Pr. Br. Rep. 030-05-473 und -477; Der griechische Sklave, LAB, A. Pr. Br. Rep. 030-05-02-1259; Der silberne Pantoffel, LAB, A. Pr. Br. Rep. 030-05-02-2078; San Toy, LAB, A Pr. Br. Rep. 030-05-02 Nr. 1669.

324 Volkszeitung, 26.4. 1903. 
jedoch nicht, denn keinem dieser Stücke gelang es, an den Erfolg von The Geisha anzuknüpfen. Ihre laue Aufnahme durch das Berliner Publikum führte dazu, dass erst 1908 wieder eine Musical Comedy den Weg nach Berlin fand, als das Metropol-Theater eine Adaptation von The Arcadians unter dem Titel Schwindelmeier \& Co. herausbrachte (Tabelle 7). ${ }^{325}$

Was The Geisha für den Import von Musical Comedies auf dem Kontinent war, war der Erfolg von Die Lustige Witwe im umgekehrten Fall. 1905 am Theater an der Wien uraufgeführt, erlebte sie noch im selben Jahr im gesamten deutschsprachigen Raum 441 Aufführungen, 1906 2738, 19071778 und selbst 1908 noch 671 Aufführungen. ${ }^{326}$ Kein anderes deutschsprachiges Stück war bis dahin in so kurzer Zeit so oft gespielt worden. Das entging auch George Edwardes in London nicht. Dennoch dauerte es eine Weile, bis er sich dazu durchringen konnte, für 1000 Pfund die Rechte für das Daly's Theatre zu erwerben. ${ }^{327}$ Mit 778 Aufführungen war die Merry Widow in London so erfolgreich wie auf dem Kontinent. Und London war erst der Beginn „eines Welterfolgs von bisher unbekanntem Ausmaß“.328 Manchen Berechnung zufolge soll die Operette bis zum Mai 1909 18000 Aufführungen in 442 deutschen, 135 englischen und 154 amerikanischen Städten erlebt haben. ${ }^{329}$ Mühelos überwand sie Grenzen und Ozeane, um bis in weit von Europa entfernte Regionen vorzudringen, wie ein italienischer Forschungsreisender in Afrika feststellen musste: „Bei einer Expedition nach den Victoria Falls wunderte der Afrikareisende sich nicht wenig, als im Urwaldhotel nach aufgehobener Tafel eine Bühne improvisiert ward, auf der eine Afrika durchziehende europäische Operettengesellschaft die Lustige Witwe aufführte!“330

Der weltumspannende Erfolg der Lustigen Witwe bewies, dass österreichische und deutsche Operetten auch im Ausland populär sein konnten und löste eine regelrechte Adaptationswelle aus. Theaterunternehmer und Verlage aus aller Welt sicherten sich die Rechte an erfolgreichen Operetten, um diese übersetzen zu lassen und sie vor Ort herauszubringen. Da das Wiener Angebot bald erschöpft war, profitierte davon zunehmend auch die Berliner Theaterindustrie. Denn obwohl mit Eine tolle Nacht (The Circus Girl) schon 1896 ein Berliner Stück den Weg nach London gefunden hatte, dauerte es noch bis 1912, bis der Export an Umfang zunahm (Tabelle 8). ${ }^{331}$ In diesem Jahr kam in London Die keusche Susanne (The Girl in the Taxi) von Jean Gilbert heraus, die derart erfolgreich war, dass ihr viele

325 Schwindelmeier \& Co., TSFU, NL Freund 97/02/W163; siehe auch FrEUND, Aus der Frühzeit, S. 56.

326 Diese Zahlen beruhen auf einer Auswertung des Deutschen BüHnENSPIELPLANs für die entsprechenden Jahre.

327 Vgl. Boosey, Fifty Years of Music, S. 166-168; siehe auch MacQueEN-Pope, Fortune's Favourite, S. 47-49; PEM, Und der Himmel hängt voller Geigen, S. 50 f.

328 FreY, ,Was sagt ihr zu diesem Erfolg', S. 78.

329 Ebd., S. 91.

330 Die Lustige Witwe am Zambesi, Berliner TAgBlatT, 22.2. 1910; zit. nach ebd., S. 87 [Hervorhebung im Original].

331 Ausgenommen die Operette Madame Sherry, die 1903 im Apollo Theatre in London zu sehen war. 
weitere folgten; 1914 zeigten gleich vier West End-Theater parallel Operetten von Gilbert. ${ }^{332}$ Im Jahr 1913 hatte am Gaiety Theatre bereits Filmzauber (The Girl on the Film) von Gilberts Konkurrent Walter Kollo Premiere gehabt, sodass in diesen Jahren im West End mehr Berliner Operetten als einheimische Musical Comedies zu sehen waren. ${ }^{333}$ Noch zu Beginn des Jahres 1914 schien es, als würde sich dieser Austausch weiter steigern. Auf dem Weg zur Kur in Bad Nauheim hatte George Edwardes in Berlin einen Zwischenstopp eingelegt, wo er die Rechte an Jean Gilberts Puppchen für 1000 Pfund erworben hatte. ${ }^{334}$ Mit dem Ausbruch des Weltkriegs wurde diese Investition jedoch wertlos, denn deutsche Operetten konnten nun nicht mehr aufgeführt werden. Das bekam auch der Direktor des Shaftesbury Theatre, Robert Courtneidge, zu spüren, der Edwardes die Rechte an Gilberts Die Kino-Königin abgekauft hatte: „The play promised to be one of the most successful I had produced, and I looked forward with confidence to the future when the outbreak of the Great War ruined all my hopes. The German origin of The Cinema Star was fatal“. 335 Als die Londoner und Berliner Theater nach einer vorübergehenden Zwangspause nach Kriegsbeginn ihre Pforten wieder öffneten, waren fast alle Stücke deutscher Herkunft aus dem Programm verschwunden. ${ }^{336}$

Der Erste Weltkrieg brachte den Austausch zwischen Großbritannien und Deutschland völlig zum Erliegen, jedoch nicht auf eine Weise, die eine Wiederbelebung unmöglich gemacht hätte. Sobald der Krieg vorbei war, hielten britische Theaterunternehmer wieder auf dem Kontinent nach frischer Ware Ausschau. Allerdings dauerte es eine Weile, bis sich die Öffentlichkeit an den Gedanken gewöhnte, wieder deutsche Operetten anzusehen. Als der Impresario Albert de Courville die alten Beziehungen wiederbeleben wollte, erntete er lautstarke Kritik, die ihn fragen ließ:

are we still at war with Germany or not? America evidently thinks not. I am told that Lehár is going over and Reinhardt has been invited. Are we in the theatrical world free to buy plays from the late enemy in the same way as we buy razors? Are we at liberty to reawaken public interest in a class of show highly delectable before the war? And in what manner should the movement be begun? Will it be a gradual process, starting with a production of a Lithuanian show, followed by one from Czecho-Slovakia, and proceeding to a Hungarian and thence to a purely Teutonic production? Perhaps this will be the solution of the difficulty. ${ }^{337}$

Courville sollte recht behalten. Die öffentliche Erregung ebbte ab und schon bald liefen im West End wieder zahlreiche deutsche Operetten. Den Anfang machte im

332 The Girl in the Taxi, BL, MSS MSS LCP 1912/37; Autobliebchen als Joy Ride Lady, BL, MSS MSS LCP 1914/7; Die Kino-Königin als The Cinema Star BL, MSS MSS LCP 1914/12 und Fräulein Tra-la-la als Mam'selle Tra-La-La BL, MSS LCP 1914/14; siehe dazu auch die entsprechenden Artikel in GÄNZL, The Encyclopedia.

333 Vgl. The Girl on the Film, BL, MSS LCP 1913/11; Kollo, ,Als ich jung war in Berlin....

334 Vgl. GÄnZL, The Encyclopedia, S. 1663.

335 Courtneidge, I Was an Actor Once, S. $218 \mathrm{f}$.

336 Siehe BAUMEISTER, Kriegstheater; HeBESTREIT, Die deutsche bürgerliche Musikkultur; KRIVANEC, Unterhaltungstheater als Medium; dies., Kriegsbühnen; WilliaMs, British Theatre; Collins, Theatre at War; KosoK, The Theatre of War.

337 Vgl. Leserbrief, The Times, 8. 4. 1920, S. 8. 
Jahr 1921 Wenn Liebe erwacht (Love's Awakening) von Eduard Künneke. ${ }^{338} \mathrm{Im}$ nächsten Jahr folgten Die Frau im Hermelin (The Lady of the Rose) von Jean Gilbert und Der letzte Walzer (The Last Waltz) von Oscar Straus; 1923 kamen Der Vetter aus Dingsda (The Cousin from Nowhere) von Eduard Künneke und $\mathrm{Ma}$ dame Pompadour (Madame Pompadour) von Leo Fall heraus, 1924 Der Fürst von Pappenheim (Toni) von Hugo Hirsch und 1927 Mädi (The Blue Train) von Robert Stolz. ${ }^{339}$ Nach dieser kurzen Blüte versiegte der Strom der Operetten aus Berlin zunächst. Ein Grund war zweifellos, dass diesen Operetten nicht derselbe Erfolg beschieden war wie ihren Vorläufern vor 1914. ${ }^{340}$ Hinzu kam, dass Operette und Musical Comedy in den zwanziger Jahren ganz im Schatten der Revuen standen. ${ }^{341}$

Als Ende der zwanziger Jahre die Operette in Berlin wieder populär wurde, kehrte sie auch auf den Spielplan der Londoner Theater zurück. Inzwischen war Franz Lehár, mit dem der internationale Erfolg der österreichisch-deutschen Operette begonnen hatte, zum Berliner geworden - zwar nicht dem Wohnsitz nach, aber doch insoweit seine neuen Stücke nun alle an der Spree uraufgeführt wurden. Verantwortlich dafür war zunächst vor allem ein Zerwürfnis zwischen Lehár und dem Wiener Schauspieler und Regisseur Hubert Marischka. Überdies konnte sich kein Wiener Theater die Gagen leisten, die Lehárs Startenor Richard Tauber verlangte. ${ }^{342}$ Nachdem seine Karriere längere Zeit stagniert hatte, bescherte Berlin Lehár einen Erfolg nach dem anderen. Der Komponist zeigte sich entsprechend dankbar: „Nirgends in der Welt habe ich auf dem Theater diese aufopferungsvolle Liebe gefunden, die mit eiserner Energie nur ein Ziel kennt: das Allerbeste zu geben. Herrliche Direktoren, herrliche Künstler, herrliche Stadt!“, schwärmte Lehár ausgerechnet in einer Wiener Zeitschrift. ${ }^{343}$ Die Berliner Erfolge führten dazu, dass seine Werke mit nur geringer Zeitverzögerung auch in London aufgeführt wurden. 1928 brachte das Metropol-Theater die Goethe-Operette Friederike heraus, die als Frederica 1930 in London lief; es folgte, ebenfalls am Metropol-Theater, Das Land des Lächelns, das 1931 als The Land of Smiles am Drury Lane zu sehen war. ${ }^{344}$ Im selben Jahr erwarb Oswald Stoll Im Weißen Rößl für sein Coliseum Theatre. ${ }^{345} 1933$ folgten dann Eine Frau, die weiß, was sie will

338 Vgl. Love's Awakening, BL, MSS MSS LCP 1923/31; siehe auch GÄNZL, The Encyclopedia, S. 1587.

339 Vgl. The Lady of the Rose, BL, MSS LCP 1921/30; The Last Waltz, BL, MSS LCP 1931/15; The Cousin from Nowhere, BL, MSS LCP 1922/35; Madame Pompadour, BL, LCP 1923/31; siehe auch GÄNZL, The Encyclopedia, S. 491 f., 850 f., 1508f., $923 \mathrm{f} ., 800$.

340 Vgl. Forbes-WinsLow, Daly's, S. 164-192.

341 Vgl. Kothes, Die theatralische Revue; Jansen, Glanzrevuen; LeHne, Admiralspalast; Clarke, Im Rausch der Genüsse; BERG, ,Det Jeschäft ist richtig!‘.

342 Vgl. FreY, ,Was sagt ihr zu diesem Erfolg?', S. 243.

343 Franz Lehár, Der neue Weg der Operette, NeUES WIENER JOURNAL, 19.10.1929; zit. nach FrEY, ,Was sagt ihr zu diesem Erfolg?', S. 245.

344 Vgl. The Land of Smiles, BL, MSS LCP 1932/31; siehe dazu GänZL, The Encyclopedia, S. 496f., 814f..

345 Vgl. The White Horse Inn, BL, MSS LCP 1931/12; siehe auch NorTON, ,So this is Broadway', eine ausführlichere Besprechung folgt im Abschnitt über die Tourneen. 
(Mother of Pearl) von Oscar Straus und Ball im Savoy (Ball at the Savoy) von Paul Abraham. ${ }^{346}$

Im Überblick betrachtet zeigt sich, dass der Austausch zwischen London und Berlin in Schüben verlief. Nach dem Erfolg von The Geisha in London erwarben die Berliner Theaterunternehmer die Rechte an einer Reihe weiterer Musical Comedies. Als diese die in sie gesetzten Erwartungen nicht erfüllten, stagnierte der Austausch. Umgekehrt schafften zwischen 1912 und 1914 sieben in Berlin uraufgeführte Operetten den Sprung nach London. Nach der Unterbrechung durch den Ersten Weltkrieg folgten sieben weitere zwischen 1921 und 1927 und nach einer erneuten Pause weitere sieben Transfers zwischen 1930 und 1933. Erstaunlich ist, dass in der Zwischenkriegszeit mit Mr Cinders (Jim und Jill) nur eine einzige Musical Comedy in Berlin gespielt wurde. „Berlin continued its aversion from foreign operettas, and not a single musical piece by a non-German author was produced during the whole year", hieß es 1928 im Stage Year Book. ${ }^{347}$ Doch von einer generellen Abneigung gegen ausländische Stücke konnte keine Rede sein, denn gleichzeitig klagten deutsche Kritiker immer wieder über die vielen Importe aus dem Ausland, so ebenfals 1928 Erich Kästner: „Ein Rückblick auf die Berliner Premieren im September zeigt, daß man sich, zum mindesten vorläufig, und im Gegensatz zu dem gemachten Versprechen, fast ausschließlich mit der Aufführung leichter ausländischer Stücke begnügt“.348 Tatsächlich standen im Sprechtheater viele britische Stücke auf den Spielplänen der Berliner Bühnen: Dramen von George Bernard Shaw und John Galsworthy, Thriller von Edgar Wallace und Komödien von Noël Coward. ${ }^{349}$ Dagegen schaffte Cowards Operette Bitter Sweet nicht den Sprung über den Kanal. ${ }^{350}$ Abgesehen von Bitter Sweet, das fast 700 Mal über die Bühne ging, war aber auch kaum eine einheimische Musical Comedy in London erfolgreich. Die populärsten Stücke der Zwischenkriegszeit waren fast allesamt Importe aus dem Ausland: Lilac Time (626 Vorstellungen) war eine Adaption der Wiener Operette Das Dreimäderlhaus; und mit No, No Nanette (665 Vorstellungen) und Rose Marie (851 Vorstellungen) kündigte sich bereits der internationale Aufstieg des amerikanischen Musicals an. ${ }^{351}$

Wie Kästner begrüßten viele Kritiker die Möglichkeit, vermehrt mit Stücken aus anderen Ländern in Berührung zu kommen, keineswegs. Als um 1900 häufiger Pariser Lustspiele in Berlin gespielt wurden, bemäkelten sie sogleich die „friedliche französische Invasion“ und die „Franzosenherrschaft auf der Bühne“. 352 Als dann die Wiener und Berliner Operette international in Mode ka-

346 Vgl. GäNZL, The Encyclopedia, S. 489f., $72 \mathrm{f}$.

347 C. Hooper Trask, The Berlin Stage, The Stage Year Book 1928, S. 160.

348 KäsTNER, Gemischte Gefühle, S. 133.

349 Vgl. ebd. S.32, 68f., 77, 188; W. F., Berliner Theater, Deutsche Rundschau 212 (1927), S. 80f.; Arthur Eloesser, Theater an sich, Die WeltbüHne 23 (1927), 1. Bd., S.950-952; C. Hooper Trask, The Berlin Stage, The Stage Year Book, 1928, S. 152.

350 Bitter Sweet, BL, MSS LCP 1929/32; siehe auch AGATE, Immoment Toys, S. 69-72.

351 Vgl. Nicoll, English Drama, S. 159 f.

352 Heinrich Stümcke, Von den Berliner Theatern 1899/1900, Bưhne und Welt 2 (1899/1900), 1. Bd., S.124-126, hier S.124; ders., Von den Berliner Theatern, BüHNE UND WeLt 5 
men, war in London und Paris von einer „Austro-German invasion“ beziehungsweise einer „invasion austro-hongroise“ die Rede. ${ }^{353}$ Manche lehnten die Musical Comedy generell ab, weil sie ihnen als Fremdkörper galt: „the music that is gaining fame and fortune in London seems to have been made in Germany, while the librettos are Anglicised versions of stories that are either stridently Teutonic or characteristically Gallic“, kritisierte ein Anhänger von Gilbert und Sullivan 1911. ${ }^{354}$ Nur in einer Hinsicht waren sich die Kritiker über die Grenzen hinweg einig: dass die größte Gefahr für die Kultur des eigenen Landes von Amerika ausging. Noch ehe die ersten amerikanischen Stücke auf der europäischen Szene erschienen, sahen sie in der „Abwehr des Amerikanismus eines der ernsthaftesten Probleme für unser Theaterwesen“ oder führten die „Übelstände des großstädtischen Theaterbetriebes [...] auf den Amerikanismus der deutschen Reichsmetropole“ zurück, wobei Amerikanismus Materialismus meinte. ${ }^{355}$ Nach dem Ersten Weltkrieg mehrten sich solche Stimmen. Vor allem in Großbritannien ging nun das Schlagwort von der „American invasion“ um, die das britische Theater angeblich in seinen Grundfesten bedrohe. ${ }^{356}$ Auch in Berlin und Paris wurden nun immer häufiger die „Amerikanisierung des Theaters“ und die „amerikanische Invasion" beklagt. ${ }^{357}$

Dieser Antiamerikanismus speiste sich aus der Ablehnung gegen die verstärkte Kommerzialisierung des Theaters, die sich zwar international beobachten ließ, die aber, da sie in den USA am ausgeprägtesten und am weitesten fortgeschritten war, als amerikanisch wahrgenommen wurde. Ein weiterer Grund war die zunehmende Präsenz amerikanischer Stars wie Josephine Baker, amerikanischer Ensembles wie den Chocolate Kiddies und amerikanischer Stücke wie No, No, Nanette in Europa. Nicht nur französische Theaterautoren empfanden die neue Situation als „a strange reversal of the day when Paris not only wrote its own plays, but largely supplied those of Europe and America“. 358 Tatsächlich konnte von einer Umkehrung aber keine Rede sein, denn am Broadway liefen nach wie vor viele Stücke aus Europa. Der transatlantische Austausch war nun lediglich keine Einbahnstraße mehr.

\section{Übersetzung}

Der Transfer eines Stücks ließ dieses selbst nicht unberührt, zumal wenn es von einer Sprache in eine andere übersetzt wurde. Der Dramatiker J. B. Priestley

(1903/04), 1. Bd., S. 122-124, hier S. 124.

353 ReEs, Hold Fast to Dreams, S. 86; BRUYAS, Histoire de l'opérette, S. 383.

354 Music Made in Germany, The ERA, 11.11.1911, S. 19.

355 Wolzogen, Theatralische Probleme, S. 314; Kienzl, Die Bühne ein Echo der Zeit, S. 84.

356 ArCher und Barker, National Theatre, S. VIII; Asche, His Life, S. 231; Graves, Gaieties and Gravities, S. 217; Du MAURIER, Gerald, S. 206.

357 Friedrich Wallisch, Amerikanisierung des Theaters, Neue Schaubühne 3 (1921), Heft 6, S. 135f.; Rudolf Pechel, Berliner Theater, Deutsche Rundschau 221 (1929), 4. Bd., S. 268270.

358 French Playwrights Resent American Invasion, Literary Digest 104 (1930), Nr. 5, S. 27. 
parodierte die gängige Praxis in seinem Theaterroman The Good Companions anhand der fiktiven Musical Comedy The Mascot Girl:

He had in hand, it seemed, a splendid new musical comedy, that bore the provisional title The Mascot Girl. It had begun as a French farce, but had been taken to Vienna, where it was transformed into an operetta, which was entirely rewritten in New York as a song-and-dance show; and now, the last vestiges of the original plot having been removed, new words and music were being introduced so that it could blossom out again as an English comedy. 359

The Mascot Girl war das vorläufige Produkt eines fortwährenden, transnationalen Austauschprozesses, der von Paris über Wien und New York nach London führte, bei dem Text, Musik und selbst Genrebezeichnung immer wieder angepasst wurden. Priestley mag damit eine satirische Absicht verfolgt haben, aber tatsächlich gibt es zahlreiche Beispiele für Stücke, die kaum weniger verschlungene Wege zurücklegten. George Bernard Shaws Komödie Arms and the Man beispielsweise, die 1894 in London und zehn Jahre später in Wien und Berlin Premiere feierte, diente 1908 den Bühnenschriftstellern Rudolf Bernauer und Leopold Jacobson als Vorlage für ihre Operette Der tapfere Soldat - ohne allerdings Autor oder Verleger davon in Kenntnis gesetzt zu haben. Als Shaw davon erfuhr, verbat er sich die von ihm nicht autorisierte Adaptation. Nur nachdem die Autoren ihm versichert hatten, weder die Namen der Originalfiguren noch Teile des Originaldialogs verwendet zu haben, nahm er Abstand davon, sie zu verklagen. Zu ihrer Erleichterung konnte die Operette wie geplant im November 1908 in Wien und im darauffolgenden Monat in Berlin aufgeführt werden. Da sie in beiden Städten volle Häuser bescherte, interessierte sich alsbald das Ausland für das Stück. Ein amerikanischer Theaterdirektor kaufte es, ließ es ins Englische übersetzen und brachte es 1909 unter dem Titel The Chocolate Soldier am Broadway heraus, wo es einer der größten Erfolge des Jahres war. Der Kreis schloss sich, als ein britischer Unternehmer die Rechte erwarb und das Stück im West End aufführte, wo es 500 Aufführungen erlebte. 1911 folgten Produktionen in Sydney und Paris sowie 1912 in Budapest. ${ }^{360}$ Wie das fiktive The Mascot Girl, so ist Der tapfere Soldat ein Beispiel für grenzüberschreitenden Austausch im Theater und die damit einhergehende kulturelle Anpassung. Stücke wurden nicht lediglich übersetzt, sondern vielmehr in jeder Beziehung - Gattungsbezeichnung, Struktur, Plot, Charaktere, Dialoge und Musik - an den veränderten kulturellen Kontext angepasst, sodass am Ende die ursprüngliche Herkunft oft nicht mehr zu erahnen war. Das gilt insbesondere für die Frühzeit des Austausches. Ein fideles Corps beispielsweise war eine denkbar freie Bearbeitung von A Gaiety Girl gewesen und The Circus Girl hatte von Julius Freunds Sensationserfolg Eine tolle Nacht lediglich die grundsätzliche Idee und den Schauplatz übernommen. ${ }^{361}$ Bei späteren Adaptationen waren die Eingriffe

359 Priestley, The Good Companions, S. 591.

360 Vgl. Bernauer und JacobSOn, Der tapfere Soldat; Shaw, Advice to a Young Critic, S. 204f.; Bernauer, Das Theater, S. 296-270; siehe auch Henderson, George Bernard Shaw, S. 540543; GÄNZL, The Encyclopedia, S. $2014 \mathrm{f}$.

361 Vgl. A Gaiety Girl, BL, MSS LCP 53535; Ein fideles Corps, LAB, A. Pr. Br. Rep. 030-05-01F441; Freund und MannstÄDT, Eine tolle Nacht; The Circus Girl, BL, MSS LCP 53601. 
der Bearbeiter nicht ganz so radikal, doch selbst die großen Werke Lehárs erfuhren weitgehende Änderungen. Basil Hood, der Übersetzer von Die lustige Witwe, Der Graf von Luxemburg und vielen anderen deutschsprachigen Operetten, meinte 1911 über seine Arbeit:

It has become quite clear to me, during the last few years, that most people do not know, and possibly do not care, what the process of adaptation means. Probably the few who have given the matter a thought presume that the English version of a Continental libretto is a translation of the original work. For more than one reason a translation would not suit or satisfy the taste of our English audiences; [...] because our audiences desire different methods of construction and treatment from those which our Continental cousins consider sufficient in the ,book ' of light opera. [...] To come from general statements to particular, in the case of ,The Count of Luxembourg' there are not, I think, thirty lines of dialogue in the English adaptation which are actually translated from the German $\left[\ldots . .{ }^{362}\right.$

Hood, einer der wenigen Übersetzer, der sich über seine Arbeit äußerte, war überzeugt, dass eine bloße Übersetzung aufgrund tief greifender kultureller Unterschiede zwischen Deutschland und Großbritannien beim Publikum keinen Zuspruch finden würde und dass jedes Stück dessen spezifischem Geschmack angepasst werden müsse. Bei The Count of Luxembourg gab es kaum „thirty lines of dialogue in the English adaptation which are actually translated from the German“ und Gypsy Love war „practically a new play“.363

Nicht nur der Dialog fiel der Überarbeitung zum Opfer, sondern mitunter auch ganze Akte, denn im Unterschied zu den meisten kontinentalen Operetten besaßen die Musical Comedies in der Regel nur zwei Akte. Hood strich deshalb oft den dritten Akt und setzte das Finale an das Ende des zweiten. Es liegt auf der Hand, dass dies auch Folgen für die Musik hatte, die oft ebenfalls völlig überarbeitet wurde. In seiner Überzeugung, dass eine rigorose Anpassung an den britischen Geschmack notwendig war, wusste sich Hood einig mit George Edwardes, für den er hauptsächlich arbeitete. Als dessen Inszenierung von Ein Walzertraum beim Publikum scheiterte, machte er dafür vor allem die seiner Ansicht nach ungenügende Bearbeitung verantwortlich, das Stück sei „not adapted sufficiently for the English taste. I think, of course, this is the reason why it failed in London and why it succeeded in the provinces when it was further adapted under my supervision“. ${ }^{364}$ Auf die Übersetzung und Bearbeitung von Text und Musik folgte dann die Neuinszenierung des Stücks, die gerade anfangs meist ebenfalls wenig mit der Originalinszenierung gemein hatte. Im Fall der Lustigen Witwe etwa war diese Edwardes in jeder Hinsicht als „hopelessly Teutonic“ erschienen und damit als alles andere als vorbildhaft. ${ }^{365}$

Die Kommentare von Hood und Edwardes, die nicht zufällig in Zeitungen erschienen, waren nicht zuletzt der Werbung verpflichtet. Vor dem Hintergrund einer weitverbreiteten Germanophobie vor dem Ersten Weltkrieg war die Insze-

362 Basil Hood, My Dear Mr. Findon, The Play Pictorial 18 (1911), Nr. 108 (The Count of Luxembourg), S. 50f.

363 Ebd.; Hood zit. nach Forbes-WINSLOw, Daly's, S. 108.

364 Report (1909), S. 242.

365 Ebd. 
nierung von deutschen Operetten in London nicht unproblematisch. ${ }^{366}$ Wenn Hood und Edwardes die Bearbeitung hervorhoben, ging es ihnen nicht zuletzt darum, den britischen Charakter der Stücke zu betonen. Es ist durchaus fraglich, ob der Geschmack des britischen Publikums sich tatsächlich so fundamental von dem des deutschen unterschied, wie beide behaupteten.

Mit keineswegs allen Adaptationen gingen so substantielle Veränderungen einher, wie sie aufgrund der Kommentare von Hood und Edwardes zu erwarten wären. In vielen Fällen beschränkten sich die Eingriffe des Übersetzers und Bearbeiters auf äußerliche Details. Fast immer geändert wurden die Namen der Charaktere und Schauplätze sowie lokale Anspielungen. The Arcadians beispielsweise, 1912 im Metropol-Theater als Schwindelmeier \& Co. aufgeführt, spielte teilweise auf einer Pferderennbahn, die nur unschwer als Ascot zu erkennen war. Mehrfach war darüber hinaus von Londoner Orten wie Piccadilly, Regent Street, Oxford Street und Bond Street die Rede. In der von Julius Freund besorgten Berliner Version wurden diese Ortsangaben einfach gegen Berliner Entsprechungen wie Unter den Linden, Friedrichstraße und Tauentzienstraße ausgetauscht. ${ }^{367}$ Die wenigen Fotografien, die von den beiden Inszenierungen erhalten geblieben sind, zeigen, wie eng sich die Adaptation am Original orientierte (Abbildungen 25 und 26). Dennoch behaupteten die Berliner Besprechungen - derselben Logik wie Hood und Edwardes folgend -, Freund habe sich lediglich „ein paar Anregungen aus dem Englischen“ geholt und ,aus dem britischen Original für sein Publikum ein neues Stück gemacht“. 368 Umbenennung von Personen blieben auch nach dem Ersten Weltkrieg gang und gäbe. White Horse Inn spielte wie das Original im Salzkammergut, aber aus dem Berliner Unternehmer Wilhelm Giesecke wurde im Zuge der Übersetzung John Ebenezer Ginkle, ein Fabrikant aus der britischen Provinz. ${ }^{369}$

Eine grundsätzliche Bewertung des Adaptationsprozesses fällt schwer, da dieser sich von Bearbeiter zu Bearbeiter und von Stück zu Stück unterschied. Letztlich lag es im Ermessen des jeweiligen Übersetzers, wie gravierend seine Eingriffe ausfielen. Bei dem von einer grundlegenden kulturellen Adaptation überzeugten Basil Hood konnten diese sehr weitgehend sein. Harry Graham hingegen hielt sich bei der Übersetzung des Weißen Rössl eng an das Original. Diese unterschiedlichen Herangehensweisen beruhten allerdings nicht nur auf individuellem Temperament. Im Laufe des ersten Drittels des 20. Jahrhunderts wich die Bereitschaft zu substantiellen Eingriffen zugunsten einer größeren Treue zum Original. Ein Grund dafür war sicherlich, dass nun vermehrt deutsche Stars wie Richard Tauber oder Produzenten wie Erik Charell selbst nach Großbritannien reisten, sodass eine größere Werktreue gewahrt blieb. Ein zweiter Grund mag gewesen sein, dass das britische Deutschlandbild nach dem gewonnenen Weltkrieg positivere Züge

366 Vgl. StiBbe, German Anglophobia.

367 Vgl. Ambient und Thompson, The Arcadians; Schwindelmeier \& Co., TSFU, NL Freund 97/02/w163.

368 Vossische Zeitung, 28. 4. 1912; ähnlich: Berliner Börsen COURIER, 28. 4. 1912.

369 Vgl. BenatzKY et al., Im weißen Rössl; The White Horse Inn, BL, MSS LCP 1931/12; siehe auch NorTON, ,So this is Broadway'. 
Abbildungen 25 und 26: Jim Smith (Dan Rolyat) belauscht auf dem Baum sitzend seine Frau in The Arcadians, Louis Meier (Guido Thielscher) tut dasselbe in der Adaptation Schwindelmeier \& Co.
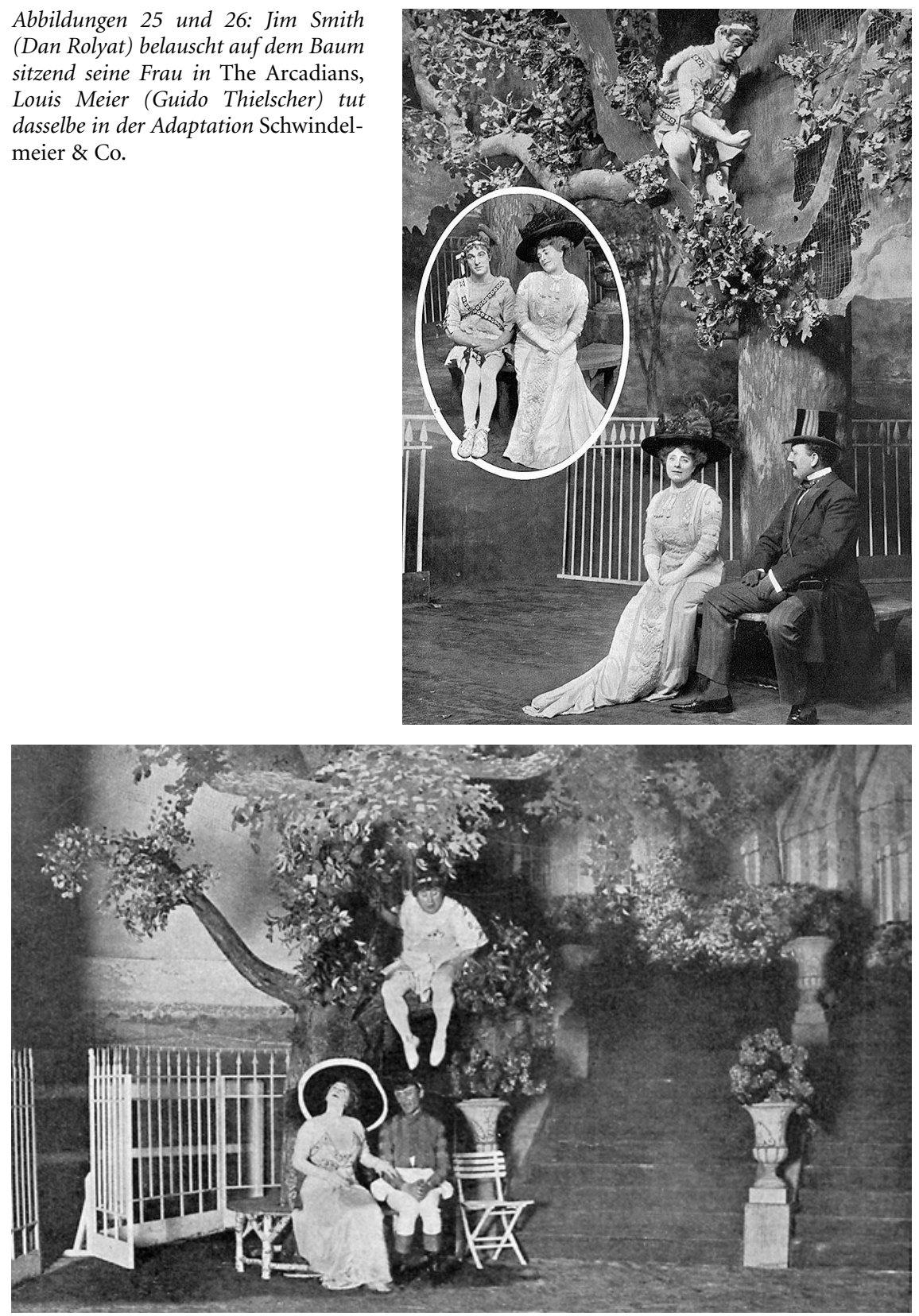

annahm und es deshalb nicht mehr nötig war, die Herkunft eines Stückes zu kaschieren. ${ }^{370}$ Im Gegenteil galten Charell und Tauber nun als Garanten für gute

370 Vgl. WitteK, Auf ewig Feind?. 
Unterhaltung, die mit Abbildungen in den britischen Programmheften gewürdigt wurden - eine Ehre, die vor dem Krieg allenfalls Max Reinhardt zuteilgeworden war. ${ }^{371}$ Und schließlich könnte man den Rückgang der Eingriffe auch als Beleg dafür lesen, dass sich der Publikumsgeschmack in London und Berlin einander angeglichen hatte und somit eine tief greifende Adaptation nicht mehr notwendig war.

\section{Verlage}

Die große Anzahl von Stücken und Inszenierungen, die zwischen London, Berlin und anderen Städten ausgetauscht wurden, wirft die Frage nach der Praxis des Austauschs auf: Wie wurden Theaterdirektoren auf Stücke aufmerksam, die im Ausland erfolgreich waren? Welche Wege beschritten sie, um diese an ihrem eigenen Theater herauszubringen? Eine Möglichkeit, über Premieren und Erfolge im Ausland auf dem Laufenden zu bleiben, war die Presse, insbesondere Branchenzeitungen und -jahrbücher. Die wöchentlich erscheinende Era beispielsweise enthielt in fast jeder Ausgabe eine Sparte über „The Drama in Berlin“, in der aktuelle Uraufführungen besprochen wurden. Deutsche Journale wie Bühne und Welt berichteten seltener, aber doch mit einer gewissen Regelmäßigkeit über das britische Theater. ${ }^{372}$ Frank Washburn Freund, ein Theaterjournalist mit deutschbritischem Hintergrund, schrieb für die Schaubühne und Die Deutsche Bühne über das Londoner und für The Stage Year Book über das Berliner Theater. ${ }^{373}$

Zeitungsberichte mögen die Neugier manches Direktors geweckt haben, sie ersetzten aber nicht die persönlichen Kontakte. Fast alle Theaterdirektoren reisten regelmäßig in andere Metropolen, um sich über neue Stücke zu informieren. Ein Stück oder eine Inszenierung, die bereits einmal den Zuspruch des Publikums gefunden hatte, erweckte immer die Hoffnung, den Erfolg anderenorts zu wiederholen. Es war diese Hoffnung, die Oswald Stoll nach Wien, Charles Cochran nach Berlin zog. George Edwardes, der mehr kontinentale Operetten nach London brachte als irgendeiner seiner Konkurrenten, überquerte den Kanal so oft, dass er eine Dauerkarte für die Fähre besaß. ${ }^{374}$ Mitunter schickte er aber auch Mitarbeiter wie George Grossmith, der für ihn die Rechte an Filmzauber in Berlin er-

371 Vgl. die Programmhefte zu The Land of Smiles und The White Horse Inn im Victoria and Albert Museum.

372 Siehe etwa The Drama in Berlin, The ErA, 2.4.1903, S. 14, 14.4.1906, S. 13, 4.4. 1908, S.21, 6.2.1909, S.24, 20.8.1910, S. 19; Ernst Meyer, Die Londoner Theatersaison, BüHNE UND WeLt 5 (1903/04), 1. Bd., S. 119-121; Ernst Schultze, Theater und Volksbildung in England, ebd. 14 (1912), Nr. 15, S. 95-108.

373 Vgl. Frank Freund, Das Londoner Theaterjahr, Die SchaubÜHne 5 (1909), 2. Bd., S. 271-274; Frank E. Washburn Freund, Londoner Theater, Die DeuTsche BüHNe 2 (1910), Nr. 8, S. 142 f., Nr. 13, S. 228 f.; ders., Londoner Theater, ebd. 3 (1911), Nr.3, S. 46f. und Nr. 13, S. 234-237; ders., The Theatrical Year in Germay, The Stage Year Book 1909, S. 102-119; ders., The Theatrical Year in Germany, The Stage Yearbook 1914, S. 81-96.

374 Vgl. Jupp, Gaiety, S. 84. 
warb. ${ }^{375}$ Auch Richard Schultz ging oft auf „Entdeckungsreisen nach London und Paris, um Neues ausfindig zu machen “ ${ }^{376}$ Aus Paris brachte Schultz nicht nur das Genre der Jahresrevue mit, hier engagierte er auch viele neue Talente für das Metropol-Theater. ${ }^{377}$

Die reisenden Theaterdirektoren waren vielleicht der wichtigste Motor des internationalen Austauschs, aber sie waren keineswegs der einzige. Der Übersetzer Siegfried Trebitsch beantwortete die Frage: „Wie ist denn damals und wohl bis zum heutigen Tag ein fremdsprachiges Stück auf die deutsche Bühne gekommen?", folgendermaßen:

Das ging so: ein rühriger Theateragent hatte etwa in Paris ein neues Stück angesehen, dessen Ruf ihn hingelockt hatte und von dem er sich in deutscher Sprache einen großen Erfolg versprach. Er wandte sich nun an den Autorenverband, erwarb das Stück gegen klingende Münze, brachte es wieder nach Hause und sah die Liste seiner Berufsübersetzer durch, welcher von ihnen für dieses Stück wohl am geeignetsten sein könnte. Diesen ließ er dann zu sich kommen und übergab ihm das neuerworbene, fremdländische Werk zur Übersetzung. [...] Dies war der normale Geschäftsgang. ${ }^{378}$

Trotz der ihnen von Trebitsch zugebilligten Bedeutung ist über die Theateragenten bislang nur sehr wenig bekannt. ${ }^{379}$ Trebitsch selbst übernahm diese Funktion für George Bernard Shaw. Nachdem er bei einem Aufenthalt in London mit diesem in Kontakt gekommen war, begann er seine Stücke zu übersetzen, um sie dann an deutsche Theater und Verleger zu vermitteln. Im Deutschen Reich wuchs die Zahl der Theateragenturen im Laufe des 19. Jahrhunderts kontinuierlich, allein zwischen 1880 und 1890 von 30 auf 50.380 Ein wesentlicher Grund für ihren Aufstieg war die rasche Expansion der Theaterunterhaltung. „Früher war die Zahl der Bühnen nicht so groß“, meinte Max Epstein, „dass nicht der einzelne Autor mit dem betreffenden Theaterdirektor direkt in Beziehung treten konnte“; erst aufgrund der gestiegenen Anzahl der Theater hätten die Autoren auf „gewerbsmäßige Agenten“ zurückgegriffen, weshalb sich der "Stand der Bühnenverleger“ gegründet habe. ${ }^{381}$ Dass Epstein die Begriffe Agent und Verleger synonym verwendete, war kein Zufall, denn tatsächlich dürfen die Theaterverlage nicht mit Buchverlagen verwechselt werden. Im Unterschied $\mathrm{zu}$ diesen verdienten sie ihr Geld nicht mit dem Druck, sondern mit der nationalen und internationalen Vermittlung, weshalb sie sich mitunter auch „Bühnenvertriebe“ nannten. ${ }^{382}$

Ein prominentes Beispiel für ein Stück, das auf Vermittlung eines Agenten nach London kam, ist die Lustige Witwe. Als sich der britische Musikverleger William Boosey 1906 in Berlin aufhielt, um die Aufführungsrechte an einer deutschen

375 Vgl. Grossmith, G.G., S. 90.

376 ThielsCHer, Erinnerungen, S. 183.

377 Vgl. The Drama in Berlin, The Era, 10.4. 1909, S. 21; Vossische Zeitung, 25. 4. 1909; BerLINER Morgenpost, 18.9. 1910; DAs Kleine Journal, 1.5. 1911.

378 Trebitsch, Chronik eines Lebens, S. 124.

379 Vgl. WATZKA, Verborgene Vermittler, S. 10.

380 Vgl. JÄHrig-OstertaG, Das dramatische Werk, S. 64.

381 EPSTEIN, Theater als Geschäft, S. $80 \mathrm{f}$.

382 Vgl. ReICHE, Der Bühnenvertrieb, S. 34. 
Komödie zu erwerben, wies ihn sein Berliner Kollege Adolf Sliwinski auf Lehárs Operette hin, die zu dieser Zeit sehr erfolgreich in Wien lief und an der er die Aufführungsrechte hielt. Sliwinski überzeugte Boosey, zusammen mit George Edwardes nach Wien zu fahren, um sich die Operette anzusehen, Boosey wiederum überzeugte Edwardes, die Rechte an dem Stück zu kaufen. ${ }^{383}$ Dieses Beispiel illustriert, wie eng die Agenten mit den Theaterdirektoren zusammenarbeiteten und dass sie sich aktiv darum bemühten, die Stücke, deren Aufführungsrechte sie verwalteten, im Ausland zu vermarkten. Ein Grund dafür war, dass sie bei der Vermittlung ins Ausland in der Regel eine Provision von 20 Prozent bezogen, doppelt so viel wie bei der Vermittlung im Inland. ${ }^{384}$

Mit Adolf Sliwinski und William Boosey waren an dem Deal zwei der wichtigsten Theateragenten ihrer Zeit beteiligt. Sliwinksi, der „bekannteste aller Verleger“, wurde 1858 in Posen geboren und arbeitete zunächst als Einkäufer in der Konfektionsbranche. ${ }^{385}$ Durch die Heirat mit der Witwe des Verlegers Felix Bloch wurde er Chef des Verlags Felix Bloch Erben, den er innerhalb kürzester Zeit zur einflussreichsten deutschen Theateragentur ausbaute. Während der Verlag zuvor vor allem Autoren des Sprechtheaters betreut hatte, erkannte Sliwinski früh die Profitabilität der Operette. Unter seiner Leitung kaufte Felix Bloch Erben die Rechte an vielen Werken der größten Operettenkomponisten der Zeit, darunter Franz Lehár (der allerdings nach Streitigkeiten zu einem Wiener Verlag wechselte), Oscar Straus und, nach dem Weltkrieg, Ralph Benatzky. ${ }^{386}$ Max Epstein zufolge machte Sliwinski nie einen Hehl daraus, dass er „den Verlag lediglich als Geschäft betrachtete“: „Wenn er nach Paris fährt, so liebt er es, davon zu sprechen, dass er für die Theater einkaufen gehe. Er nennt die literarische Produktion seiner Autoren stets Ware“. 387 Obwohl (oder gerade weil) Sliwinski offen aussprach, was viele andere nur dachten, machte er sich viele Feinde.

Sein Geschäftsgebaren tat ein Übriges. So erfand Sliwinski den Koppelvertrag, bei dem er einen Kassenschlager nur im Paket mit weniger erfolgreichen Stücken anbot. Wollte ein Theater beispielsweise die populäre Operette Ein Walzertraum von Oscar Straus aufführen, musste es gleichzeitig die Rechte an der weniger erfolgreichen Operette Die lustigen Nibelungen kaufen. Somit verdiente Sliwinski an einem Vertrag gleich doppelt und ging sicher, dass er auch seine Ladenhüter loswurde. ${ }^{388}$ Damit erfand er eine Praxis, wie sie heute wieder bei der Vermarktung von Megamusical angewandt wird. ${ }^{389}$ In der Folge gelang es ihm, konkurrierende

383 Vgl. Boosey, Fifty Years of Music, S. 166-168; siehe auch MacQueEn-Pope und MurraY, Fortune's Favourite, S. 47-49; PEM, Und der Himmel hängt voller Geigen, S. 50 f.

384 Vgl. ReIche, Der Bühnenvertrieb, S. 40.

385 EPSTEIN, Theater als Geschäft, S. 86.

386 Zum Verlagsprogramm siehe auch http://www.felix-bloch-erben.de/ [1.2.2012].

387 EPstein, Theater als Geschäft, S. 91.

388 Vgl. ebd. S. 80-92; Bernauer, Das Theater, S. 60; Jährig-Ostertag, Das dramatische Werk, S. 67f., 84f.; dies., Zur Geschichte der Theaterverlage, insbes. S. 12; FreY, ,Was sagt ihr zu diesem Erfolg?', S. 220 f.; WaTZKA, Verborgene Vermittler, S. 65-67; KuHBandner, Unternehmer zwischen Markt und Moderne, S. $186 f$.

389 Vgl. Burston, Spectacle, Synergy and Megamusicals, S. 74. 
Verlage auszuschalten und kleineren Theatern den Spielplan zu diktieren. „Der Blochsche Verlag [...] beherrschte so mit der Zeit den ganzen deutschen Operettenmarkt; er war und ist ein gar gestrenger Herrscher, der den von ihm abhängigen Direktoren [...] Bedingungen vorschreiben konnte", kommentierte Alfred Holzbock. ${ }^{390}$ Doch damit nicht genug: Da das Berliner Publikum über den Erfolg oder Misserfolg eines Stücks entschied, musste ein „Operettenverlag, der heute konkurrenzfähig sein, für seine Autoren eintreten will, [...] über ein Theater in Berlin verfügen". 391 Zusammen mit dem Theaterdirektor Max Monti übernahm Sliwinski deshalb das Theater des Westens und das Theater am Schiffbauerdamm, in denen er fast ausschließlich Werke seines eigenen Verlags aufführen ließ. ${ }^{392} \mathrm{Da}-$ rüber hinaus betrieb er das Carl Schultze-Theater in Hamburg. Sogar im Ausland pachtete er Theater, wie das New Amsterdam Theatre in New York und das Théâtre Apollo in Paris. ${ }^{393}$ Und in London besaß Felix Bloch Erben ein Büro nahe des Theaterviertels am Strand. 394

William Boosey, „the greatest music publisher of his time“, wurde 1864 in London als Ururenkel von John Boosey geboren, der dort bereits im 18. Jahrhundert einen Musikalienleihhandel betrieben hatte. ${ }^{395}$ Boosey stieg zunächst in den Familienbetrieb ein, wechselte aber 1892 als Geschäftsführer zu dem größeren Musikverlag Chappell \& Co. ${ }^{396}$ Wie viele andere Musikverlage hatte der 1810 gegründete Chappell \& Co. mit dem Verkauf von Instrumenten und der Organisation von Konzerten begonnen, mit denen er für sein Verlagsprogramm warb. ${ }^{397}$ Seine eigentliche Hochzeit begann jedoch mit den Operetten von Gilbert und Sullivan. ${ }^{398}$ Später vertrieb der Verlag die Noten von zahllosen Musical Comedies, wie The Orchid, Our Miss Gibbs, The Arcadians oder The Cinema Star. ${ }^{399}$ Wie der gemeinsame Ankauf der Rechte an der Lustigen Witwe zeigt, verband den Verleger William Boosey mit dem Theaterdirektor George Edwardes ein enges Arbeitsverhältnis. Das war auch notwendig, denn anders als in Deutschland, wo die Verlage alle Rechte verwalteten, besaß Boosey die Urheber-, Edwardes die Aufführungsrechte. So soll Chappell \& Co. allein am Verkauf von Noten der Merry Widow 140000 Pfund verdient haben, während Edwardes die Tantiemen für Aufführun-

390 Alfred Holzbock, Aus dem Reich der modernen Operette, BERLINER LOKALANZEIGER, 29. 9. 1912, zit. nach LiNHARDT (Hrsg.), Stimmen zur Unterhaltung, S. 74-77, hier S. 75.

391 Ebd.

392 Vgl. Epstein, Theater als Geschäft, S. 86-92; ders., Theatervertrustung, Die SCHAUBÜHNE 11 (1915), 1. Bd., S. 100-102; JÄHrig-OsterTAG, Das dramatische Werk, S. 84-86; TheATER DES Westens (Hrsg.), 100 Jahre Theater des Westens, S. 58-68; Funke und JANSEN, Theater am Schiffbauerdamm; MaRX, Max Reinhardt, S. 175; WaTZKA, Verborgene Vermittler, S. 65-67.

393 Vgl. FreY, ,Was sagt ihr zu diesem Erfolg', S. 220.

394 Vgl. BÜHNENJAHRBUCH 1909, S. III.

395 MacQueEn-Pope und MurraY, Fortune's Favourite, S. 47.

396 Mr. William Boosey, The Times, 29.4. 1933, S. 14; MAIR, The Chappell Story, S. 25 f.

397 Vgl. Boosey, Fifty Years of Music, S. $77 \mathrm{f}$.

398 Vgl. ebd. S. 77-82; MaIr, The Chappell Story, S. 21-23.

399 Tanner, The Orchid; Tanner und Cryptos, Our Miss Gibbs; Ambient et al., The Arcadians; GILbERT, The Cinema Star. 
gen kassierte. ${ }^{400}$ Das bereits erwähnte Gaiety Theatre Royalties Book verzeichnet den Eingang von Tantiemen (royalties) aus allen Ländern der Welt sowie ihre Aufteilung unter die beteiligten Komponisten und Autoren. ${ }^{401}$ Ähnlich wie Sliwinski in Berlin arbeitete Boosey eng mit verschiedenen Theatern zusammen. Chappell \& Co. besaß Aktienanteile am Gaiety Theatre, Adelphi Theatre und Savoy Theatre. Boosey selbst war Vorstandsvorsitzender der Adelphi Company. Nach dem Tod von George Edwardes griff er persönlich in die Leitung der Theater ein, indem er sich intensiv an der Gestaltung des Spielplans beteiligte und gezielt neue Stücke für die von ihm mitverwalteten Bühnen erwarb. ${ }^{402}$

Die Verlage beschränkten sich allerdings nicht auf die Vermarktung der Stücke, sondern druckten die Schlager aus den Operetten und Musical Comedies auch separat. Chappell \& Co. bot Drucke einzelner Musikstücke und Songs an, beispielsweise den Picture Postcard Song von Ivan Caryll aus dem Stück The Earl and the Girl oder Some Sort of a Boy aus The Cinema Star von Jean Gilbert sowie Sammlungen von Hits aus einer oder mehreren Musical Comedies, so 1930 ein Album of Ten Popular Musical Comedy Songs. ${ }^{403}$ Die Musical Comedy hatte regen Anteil an der Expansion des Musikmarktes, dessen Produktion in Großbritannien zwischen 1800 und 1914 um geschätzte 50 bis 100 Prozent wuchs. ${ }^{404}$ Am Ende des 19. Jahrhunderts verkauften die Musikverlage 20 Millionen Drucke pro Jahr, wobei populäre Schlager nicht selten eine Auflage von 200000 Stück erreichten. ${ }^{405}$ Gleichzeitig sanken die Preise für einzelne Titel kontinuierlich: von vier Schillingen in den 1860er Jahren auf drei Schillinge in den siebziger und zwei Schillinge in den achtziger Jahren, sodass sich immer größere Teile der Bevölkerung den Erwerb gedruckter Musik leisten konnten. ${ }^{406}$

Ähnlich verhielt es sich in Deutschland, ablesbar beispielsweise an der Titelproduktion, die zwischen der Reichsgründung und der Jahrhundertwende um 250 Prozent zunahm oder an der Zahl der Berliner Musikverlage, die von $28 \mathrm{im} \mathrm{Jahr}$ 1880 auf 78 im Jahr 1900 und auf 108 im Jahr 1920 anstieg. ${ }^{407}$ Als Verlagsort nie so bedeutend wie Frankfurt am Main oder Leipzig, behauptete Berlin in der Unterhaltungsmusik neben Wien den ersten Platz im deutschsprachigen Raum. 408 Bote \& Bock, einer der bedeutendsten Berliner Musikverlage, besorgte zwischen 1905 und 1912 die Musikausgaben der Jahresrevuen des Metropol-Theaters. Der

400 Vgl. SHORT, Fifty Years of Vaudeville, S. 79; BoOsEY, Fifty Years of Music, S. 122-135; Mr. William Boosey, The Times, 29.4. 1933, S. 14.

401 Vgl. Gaiety Royalties Book, No. 2 in der Theatersammlung des Victoria \& Albert Museums.

402 Boosey, Fifty Years of Music, S. 130-132, 147-151.

403 Picture Postcards Song. Sung in I. Caryll's Musical Comedy ,The Earl and the Girl'. Words by S. Damerell, London 1911; Some Sort of a Boy Song. Sung in J. Gilbert's Musical Comedy ,The Cinema Star'. Words by P. Greenbank, London 1914; Album of ten popular Musical Comedy Songs, London 1930.

404 Vgl. Russell, Popular Music in England, S. 172.

405 Vgl. Ehrlich, Harmonious Alliance, S. 5.

406 Vgl. Richards, Imperialism and Music, S. 343.

407 Vgl. JÄGER, Der Musikalienverlag, S. 7; DölL, Das Berliner Musikverlagswesen, S. 63, 125.

408 Vgl. JÄGER, Der Musikalienverlag, S. 47. 
größte Erfolg dieser Kooperation war die Revue Auf in's Metropol!, „von deren Musiknummern 68 verschiedene Ausgaben in Arrangements für alle möglichen Besetzungen von der Zither bis zur Infanterie-Musik mit Flügelhorn-Solo gedruckt wurden ". 409 Wie Chappell \& Co. brachte Bote \& Bock überdies Sammlungen wie Metropoliana. Grosses Potpourri zum Mitsingen heraus, eine Vorform des Best-of-Albums. ${ }^{410}$ Der Verkauf der Notendrucke war so einträglich, dass manche Komponisten sich als Verleger selbstständig machten. Paul Lincke beispielsweise gründete den Apollo-Verlag, der zunächst vor allem seine eigenen Werke vertrieb, dann aber durch den Aufkauf kleinerer Verlage sein Angebot systematisch erweiterte. ${ }^{411}$ Seinem Beispiel folgte Walter Kollo, der 1916 den Kollo-Verlag ins Leben rief. ${ }^{412}$ Viele Werke von Jean Gilbert, dem dritten im Bunde der Berliner Operettenkomponisten, erschienen im Thalia-Theater-Verlag, der dem Thalia-Theater angegliedert war, an dem viele seiner Operetten uraufgeführt wurden. ${ }^{413}$

Über die Notendrucke war das Theater eng mit der Musikindustrie verschränkt, die umgekehrt ganz wesentlich vom populären Musiktheater profitierte, denn die Theaterbesucher waren immer auch potentielle Käufer von Noten. Die „operetten- und revuefreudigen Eltern“ von Willy Haas etwa besuchten nicht nur regelmäßig das Metropol- und andere Berliner Unterhaltungstheater, sondern kauften auch stets die „Noten der Schlager“. 414 Noch wichtigere Kunden als die privaten Abnehmer waren die Unterhaltungs- und Tanzorchester, die oft Stücke aus den Operetten in ihr Repertoire übernahmen. Dem Komponisten Oscar Straus zufolge spielten „die Tanzkapellen die Schlager, bis unsere Melodien zu Gassenhauern und so allmählich zu Tode gehetzt wurden".415 Dabei verschwieg Straus allerdings, dass er selbst daran verdiente, zum einen über die Tantiemen, zum anderen durch die Popularisierung der Operetten. Auch die Theater profitierten von der Verbreitung der Noten, denn diese fungierten als kostenlose Werbung. ${ }^{416}$ Selbst Teile der Bevölkerung, die nie ein Theater besuchten, partizipierten durch den Notendruck und die öffentliche Aufführung der Musik am populären Musiktheater. Wenn das Metropol-Theater auch nicht allen Schichten zugänglich war, kreierte es mit seinen Schlagern doch „eine Art neues Berliner Volkslied“. ${ }^{17}$ Auch die Melodien aus den Operetten wurden oft „unverändert als Gassenhauer übernommen “. ${ }^{418}$ Bis zum Aufstieg des Radios war das populäre Musiktheater deshalb

409 KunZ, 125 Jahre Bote \& Bock, S. 60.

410 Metropoliana. Grosses Potpourri zum Mitsingen nach Melodien von Victor Hollaender und anderen, Berlin 1911; siehe dazu auch BECKER, Die Anfänge der Schlagerindustrie.

411 Vgl. BorN, Paul Lincke, S. 128, 136; Döll, Das Berliner Musikverlagswesen, S. 77 f.

412 Vgl. Schneidereit, Berlin, wie es weint und lacht, S. 184; DölL, Das Berliner Musikverlagswesen, S. 95.

413 Vgl. HAHN, Das Thalia-Theater.

414 HAAs, Die literarische Welt, S. 117.

415 Zit. nach PEM, Und der Himmel hängt voller Geigen, S. 25.

416 Vgl. Oost, Gilbert and Sullivan, S. 58, siehe auch S. 37 f., $74 \mathrm{f}$.

417 Modrow, Berlin 1900, S. 188; siehe auch MugaY, Berliner Musike, S. 316-320.

418 RiCHTER, Der Berliner Gassenhauer, S. $184 \mathrm{f}$. 
einer der wichtigsten, wenn nicht der wichtigste Schöpfer und Verbreiter populärer Musik.

Die nächste Stufe der Popularisierung und Kommerzialisierung war die Vermarktung der Musik auf Schallplatte. Auch an dieser Neuerung war das Metropol-Theater von Beginn an beteiligt. Die Veröffentlichung der „hauptsächlichsten Melodien“ der Revue Der Teufel lacht dazu von 1906 gilt in der Musikgeschichte als „Markstein“, da die Schallplatte bereits am Tag nach der Uraufführung (und noch vor den gedruckten Noten) in den Handel kam. ${ }^{419}$ Das Metropol-Theater warb selbst für den Absatz der Aufnahmen. Auf dem Theaterprogramm von Die Reise um die Erde in 40 Tagen, dem letzten Stück, das vor dem Ersten Weltkrieg am Metropol-Theater herauskam und eines seiner größten Erfolge war, hieß es: „Soeben erschienen ,Grammophon'-Aufnahmen. Alle Schlager aus: Die Reise um die Erde in 40 Tagen ". 420 Auch die Operettenkomponisten erkannten früh die Schallplattenindustrie als zusätzliche Einnahmequelle, Jean Gilbert etwa galt vor dem Ersten Weltkrieg als der „Napoleon der Grammophonplatte“421 Dagegen nahmen George Edwardes und William Boosey das neue Medium eher als Konkurrenz, denn als Bereicherung wahr, denn Edwardes verbot seinen Künstlern, bei Aufnahmen mitzuwirken, und Boosey hetzte gegen die „terrible invasion of mechanical music“, weil die Plattenindustrie zunächst keine Tantiemen an die Verleger abführen musste. ${ }^{422}$

Die vielfältigen Beziehungen zwischen Unterhaltungstheatern und Verlagswesen belegen die enge Verflechtung des Theaters mit anderen Industrien und Medien. Die Theater mussten zwar mitunter beträchtliche Tantiemen an die Verlage abführen und gerade die kleineren unter ihnen hatten unter der Dominanz von Marktführern wie Felix Bloch Erben zu leiden. Dennoch profitierten sie davon, dass die Verlage im In- und Ausland neue Stücke akquirierten und ihnen anboten. Der Vertrieb der Notendrucke durch die Verlage und der Grammophon-Platten durch die aufkommende Plattenindustrie nützte vor allem den Komponisten und Autoren, indirekt dürfte dies jedoch auch für die Theater rentabel gewesen sein. Weder Noten noch Aufnahmen ersetzten den Reiz der Aufführungen, doch sie sorgten für eine Popularisierung der Stücke und kurbelten somit den Verkauf von Theaterbilletts an. Das mit Abstand beste Geschäft machten zweifellos die Verlage selbst, die ihre Position eifersüchtig verteidigten und sich kontinuierlich neue Strategien zur Gewinnmaximierung ausdachten. Ihr Einfluss auf das Unterhaltungstheater in London und Berlin, insbesondere auf die Spielplangestaltung, war immens, wenn sie, wie Chappell \& Co., über Aktien an den Theatern beteiligt waren oder, wie Sliwinski, die Theater gleich in Eigenregie führten. Umgekehrt

419 Gauss, Nadel, Rille, Trichter, S. 192; zum Aufstieg der Plattenindustrie siehe auch Ross, Entertainment, Technology and Tradition.

420 Programmheft zu: Die Reise um die Erde in 40 Tagen, Theatersammlung, Stiftung Stadtmuseum Berlin, unkatalogisiert.

421 Erich Urban zit. nach SCHNEIDEREIT, Berlin, wie es weint und lacht, S. $159 \mathrm{f}$.

422 Boosey, Fifty Years of Music, S. 109, siehe auch S. 145-157; Mander und Mitchenson, Musical Comedy, S. 32; sowie PeArsall, Victorian Popular Music. 
wurden einige Komponisten und Bühnen wie das Thalia-Theater als Verlage aktiv, um die Zwischenhändler auszuschalten. Und schließlich zeigt das Verlagswesen den hohen Grad an internationaler Verflechtung in der Theaterindustrie vor dem Ersten Weltkrieg. Während Felix Bloch Erben über eine Außenstelle in London verfügte und Theater in New York und Paris pachtete, reiste William Boosey regelmäßig auf den Kontinent, um hier neue Stücke zu erwerben. Neben den Theaterdirektoren waren deshalb die Verlage der wichtigste Motor des wachsenden Kulturaustauschs und der zunehmenden Internationalisierung der Theaterindustrie.

\section{Urheberrecht}

Die Expansion des Theaters war nicht der einzige Faktor, den Max Epstein für den Aufstieg der Agenten verantwortlich machte. Hinzu kamen seiner Ansicht nach der „moderne Verkehr und die Urhebergesetze“, die „gerade das Ausland für die Autoren zu einer wichtigen Einnahmequelle gemacht" hätten. ${ }^{423}$ Fiel es den Autoren schon im Inland schwer zu kontrollieren, welche Bühnen ihre Werke aufführten, war das im Ausland geradezu unmöglich, weshalb sie zunehmend ihre Rechte an international operierende Verlage abtraten. Zunächst stellte sich dieses Problem jedoch auf nationaler Ebene. Vor allem in London kam es zu Beginn des 19. Jahrhunderts häufig vor, dass Autoren rücksichtslos die Stücke von Kollegen kopierten oder Theater Stücke aufführten, ohne dafür Tantiemen zu zahlen: „Piracy was so widespread that it became almost an accepted hazard of theatrical life“.424 Deshalb ließen nur die allerwenigsten Autoren ihre Werke gedruckt erscheinen, womit sie freilich nicht verhindern konnten, dass findige Unternehmer Stenografen anheuerten, die während der Aufführung mitschrieben. ${ }^{425}$

Obwohl in England, dem „Pionierland eines werkzentrierten Vervielfältigungsrechts", bereits 1710 mit dem Statute of Anne ein Urheberrechtsgesetz verabschiedet worden war, nutzte das Theaterautoren nur wenig, da dieses sich primär auf den Buchdruck bezog. ${ }^{426}$ Verboten war lediglich der Nachdruck eines Theaterstücks (sofern es als Buch vorlag), nicht jedoch dessen Aufführung auf der Bühne. ${ }^{427}$ Erst im Lauf des 19. Jahrhunderts kristallisierte sich die Trennung zwischen Urheber- und Aufführungsrecht heraus, setzte sich die Gewinnbeteiligung der Autoren in Form einer Tantieme durch. Pionier war wiederum England, wo der Dramatiker und Parlamentsabgeordnete Edward Bulwer-Lytton 1833 einen Gesetzesentwurf ins Parlament einbrachte, der diesem Missbrauch ein Ende setzen sollte: Der Dramatic Copyright Act (auch Bulwer Lytton's Act) von 1842 schützte nun auch musikalische Werke. Obschon nicht perfekt, schuf das Gesetz

423 Epstein, Theater als Geschäft, S. $80 \mathrm{f}$.

424 STEPHENS, The Profession of the Playwright, S. 88, siehe auch dort S. 84-115.

425 Ebd., S. 84-88, $113 \mathrm{f}$.

426 LÖHR, Die Globalisierung geistiger Eigentumsrechte, S. 42; siehe auch ALEXANDER, Copyright Law, S. 17-28.

427 Vgl. Stephens, The Profession of the Playwright, S. 84-88, $113 \mathrm{f}$. 
zum ersten Mal eine rechtliche Anerkennung der Theaterautoren und ihrer Werke. ${ }^{428}$

Im deutschsprachigen Raum begann die Novellierung des Urheberrechts wesentlich später. Preußen verabschiedete 1837 das Gesetz zum Schutz des Eigentums an Werken der Wissenschaft und Kunst gegen Nachdruck und Nachbildung. Es verbot allerdings nur die Vervielfältigung eines Bühnenwerks, nicht jedoch seine unerlaubte Aufführung, die wiederum nur bei ungedruckten Werken untersagt war. Erst 1854 wurde diese Gesetzeslücke durch ein preußisches Gesetz, 1857 durch einen Beschluss des Deutschen Bundes beseitigt. ${ }^{429}$ Zum vorläufigen Abschluss kam die Entwicklung des Urheberrechts in Deutschland, als der Norddeutsche Bund 1870 das Gesetz betreffend das Urheberrecht, Schriftwerken, Abbildungen, musikalischen Kompositionen und dramatischen Werken verabschiedete, das dramatische und dramatisch-musikalische Werke gegen unbefugte öffentliche Aufführung bis 30 Jahre nach dem Tod des Urhebers schützte und das im folgenden Jahr als Reichsgesetz übernommen wurde. ${ }^{430}$

Bei musikalischen Werken war der Schutz der Rechte noch wesentlich schwieriger. Obwohl die Preise für Notendrucke stetig sanken, gab es einen regen Schwarzhandel. Technische Innovationen im Bereich des Buchdrucks, zum Beispiel die Lithographie, erlaubten das massenhafte Kopieren und Nachdrucken von Noten: „Popular songs only required two or three pages of paper, and they could be photographed or litho'ed in any old shed or barn which happened to be handy. They could then be retailed to an army of street hawkers for distribution. This in fact was what was done, and in 1902 popular songs were sold by thousands, both openly on the London streets and everywhere throughout the provinces“. ${ }^{331}$ Wie die Online-Tauschbörsen unserer Tage untergrub der Schwarzmarkt die Position der Musikindustrie. Zusammen mit der weiteren Kodifizierung des Urheber- und Aufführungsrechtes sorgte die Piraterie dafür, dass die Musikindustrie ein neues Geschäftsmodell ausbildete. Noch bis ins 20. Jahrhundert hinein hatte sie ihr Geld primär mit dem Verkauf von Noten gemacht. Um den Absatz anzukurbeln, organisierten die Musikverlage Konzerte und bezahlten bekannte Darsteller, damit diese ihre Lieder sangen und ihnen so zu Popularität verhalfen, in der Hoffnung, daraufhin mehr Noten abzusetzen. ${ }^{432}$ Dieses Geschäftsmodell war immer weniger rentabel. Die Verlage erkannten, dass große Einnahmen sich nicht länger durch den Verkauf der Noten erwirtschaften ließen, sondern durch die Vermarktung der Aufführungsrechte. Anstatt den Darstellern

428 Vgl. James, The Story, S. 13; StePhens, The Profession of the Playwright, S. 90 f.; AleXander, Copyright Law, S. 130.

429 Vgl. JÄHrig-OstertaG, Das dramatische Werk, S. 10-16; WATZKA, Verborgene Vermittler, S. 36-42.

430 Vgl. BORCHARD, Das Aufführungsrecht, S.2f.; VOGEL, Die Entwicklung des Urheberrechts, S. 122-131.

431 Boosey, Fifty Years of Music, S. 113; siehe auch EHrLICH, Harmonious Alliance, S. 8.

432 Vgl. Boosey, Fifty Years of Music, S. 77 f.; Russell, Popular Music in England, S. 77. 
Prämien zu zahlen, kassierten sie nun im Gegenteil Tantiemen für die Aufführung von Musikstücken. ${ }^{433}$

Kaum hatten die Staaten das Urheberrecht auf nationaler Ebene kodifiziert, entstanden Probleme auf internationaler Ebene. Die internationale Freizügigkeit führte dazu, dass Theater im Ausland immer häufiger Stücke plagiierten, aufführten oder adaptierten, ohne die Autoren dafür zu vergüten. Noch ehe beispielsweise Offenbach das erste Mal in Wien gastierte, hatte sich ein dortiger Theaterdirektor einen Klavierauszug einer seiner Operetten aus Paris kommen lassen und diese dort aufgeführt. ${ }^{434}$ Englische Autoren wie Gilbert und Sullivan hatten vor allem unter der Piraterie ihrer Stücke in den USA zu leiden. Um dies zu unterbinden, brachte D'Oyly Carte sie deshalb so früh wie möglich selbst in New York heraus, um sich so die amerikanischen Rechte zu sichern. ${ }^{435}$ Die Zunahme der Gastspiele und Tourneen kann daher auch als eine Konsequenz aus der Piraterie gesehen werden, diesen ersetzten allerdings nicht eine international verbindliche Regelung des Urheberrechts. Zwar begannen die europäischen Staaten um die Mitte des 19. Jahrhunderts bilaterale Verträge zum Schutz des Urheberrechts abzuschließen, diese blieben jedoch lückenhaft. Vor allem bei den Schriftstellern und Verlegern wurde die Forderung nach einem internationalen Abkommen immer lauter. So rief etwa die Neue Zeit, das publizistische Organ der Deutschen Genossenschaft Dramatischer Autoren und Componisten, 1871 mit Verweis auf die „stets wachsenden Verkehrsbeziehungen zwischen den verschiedenen Nationen" nach einer internationalen Regelung. ${ }^{436}$

Nach langwierigen Verhandlungen schlossen zehn Staaten, unter ihnen auch Deutschland und Großbritannien, 1886 eine Übereinkunft zur Bildung eines völkerrechtlichen Vertrags zum Schutz von Werken der Literatur und Kunst, die nach dem Verhandlungsort kurz Berner Übereinkunft hieß. Sie galt sowohl für gedruckte als auch für aufgeführte Werke und setzte die Gleichbehandlung der In- und Ausländer fest, das heißt die Staaten verpflichteten sich, ausländische Autoren nach denselben Gesetzen wie die einheimischen zu behandeln. Wer gegen die Verletzung seiner Rechte vorgehen wollte, musste daher in dem Land Klage erheben, in dem diese begangen wurde. ${ }^{437}$ Mit der Berner Übereinkunft bestand nun erstmals ein internationales rechtliches Abkommen zum Urheberrecht, das in den folgenden Jahren noch weiter ausgebaut wurde. So kam es $1908 \mathrm{zu}$ einer Nachfolgekonferenz in Berlin, auf der die Bestimmungen der Berner Überein-

433 Vgl. NotT, Music for the People, S. $115 \mathrm{f}$.

434 Vgl. Kracauer, Offenbach, S. 233; Obermaier, Offenbach in Wien, S. 15.

435 Vgl. Stephens, The Profession of the Playwright, S. 107-110.

436 Adolar Gerhard, Internationaler Schutz des Urheberrechts, NeUE ZeIT 1 (1872), Nr. 13, S. $97-$ 100 und Nr. 15, S. 113-117, hier S. 97.

437 Vgl. Bernard Weller, How to Protect a Play, The Stage Yearbook 1908, S. 35-44, hier S. 39; Strong, Dramatic \& Musical Law, S. 116-119; JÄHRIG-OsterTaG, Das dramatische Werk, S. 33; James, The Story, S. 13; StePhens, The Profession of the Playwright, S. 114; Vogel, Die Entwicklung des Urheberrechts, S. 132-134; LÖHR, Die Globalisierung geistiger Eigentumsrechte, S. 46-73. 
kunft noch einmal überarbeitet wurden. ${ }^{438}$ Das war aufgrund neuer technischer Herausforderungen notwendig geworden. So konnten Stücke verfilmt und Musik aufgenommen werden, ohne dass die Autoren oder Komponisten gefragt wurden oder Tantiemen erhielten. Deshalb wurde vor dem Ersten Weltkrieg das Urheberrecht noch einmal novelliert. Das deutsche Urheberrechtsgesetz von 1910 und der britische Copyright Act von 1911 umfassten nun erstmals auch die „mechanische Reproduktion" auf Film oder Schallplatte. ${ }^{439}$ Dass das Urheberrecht zum Gegenstand zwischenstaatlicher Abkommen geworden war, zeigt eindrücklich, wie weit die Internationalisierung der Kultur vor dem Ersten Weltkrieg fortgeschritten war.

Dass seit der Berner Übereinkunft ein einheitliches internationales Urheberrecht bestand, heißt allerdings nicht, dass es nun nicht mehr zu Urheberrechtsverletzungen und zu Streitigkeiten über das Urheberrecht kam. So fanden Richard Schultz und Julius Freund sich 1903 auf der Anklagebank wieder, nachdem der Verlag Ahn \& Simrock Anzeige gegen sie erstattet hatte. ${ }^{440}$ Nebenkläger war der französische Schriftsteller Georges Feydeau, den der Verlag in Deutschland vertrat. Seiner Ansicht nach handelte es sich bei dem Stück Durchlaucht Radieschen, das 1903 im Metropol-Theater aufgeführt worden war, um ein Plagiat von Feydeaus Komödie La duchesse des Folies Bergère aus dem Vorjahr. Julius Freund gab zwar zu, dass er das Stück in Paris gesehen hatte, behauptete aber, die fraglichen Motive bereits früher entwickelt und schon einmal in seiner Posse Berlin bleibt Berlin verwendet zu haben, womit er nun seinerseits Feydeau des Plagiats bezichtigte. ${ }^{41}$ Nachdem bereits zwei Instanzen die Klage abgewiesen hatten, zog Ahn \& Simrock schließlich vor das Reichsgericht, dem obersten Straf- und Zivilgericht des Deutschen Reiches, das 1906 die Entscheidung der vorangegangenen Instanzen bestätigte. Es kam zwar zu dem Schluss, dass Freund das „Hauptmotiv“ aus Feydeaus Stück übernommen habe, dass dieses sich aber im Dialog, in der Handlung und in den Nebenfiguren von diesem unterschied, weshalb es als ,eigentümliche Schöpfung" angesehen werden müsse. ${ }^{442}$ In der Begründung hieß es, das Urheberrechtsgesetz erstrecke sich nur auf „die ,Bearbeitung' eines Werkes, wogegen $[\ldots]$ die ,freie Benutzung eines Werkes" "zulässig sei. Damit stand allerdings die Frage im Raum, was unter „Bearbeitung“ zu verstehen war. Das Gericht stellte dazu fest, „daß einem Werke dessen Motive entlehnt werden dürfen, sofern sie in so eigenartiger Weise verarbeitet werden, daß das Erzeugnis sich als eine

438 Vgl. James, The Story, S. 14f.; LöHR, Die Globalisierung geistiger Eigentumsrechte, S. 117.

439 Vgl. Gauss, Nadel, Rille, Trichter, S.114; James, The Story, S. 15; BorChard, Das Aufführungsrecht, S.3.

$440 \mathrm{Zu}$ Ahn \& Simrock siehe EpsteIn, Theater als Geschäft, S. 81; JÄHrig-OsterTaG, Das dramatische Werk, S. 71; DöLL, Das Berliner Musikverlagswesen, S. 113-116.

441 Vgl. Brief Rechtsanwälte Rosenstock und Münzer an Polizei-Direktion Berlin, 14.11.1903, LAB, A. Pr. Br. Rep. 030-50 Nr. 714; siehe auch Berliner Zeitung, 24.11. 1903.

${ }^{442} \mathrm{Zu}$ den Begriffen der ,Bearbeitung' und der ,freien Benutzung' eines Werkes im Sinne der $\$ \$ 12$ und 13 des Urheberrechtsgesetzes vom 19. Juni 1901, ENTSCHEIDUNGEN DES REICHSGERICHTS IN ZIVILSACHEN 63 (1906), S. 158-160, hier S. 159 f. 
eigene geistige Schöpfung darstellt“. ${ }^{443}$ Damit schuf es einen Präzedenzfall, der bis heute in der Literatur zum Urheberrecht zitiert wird. ${ }^{44}$ Obwohl Feydeau am Ende verlor, zeigt der in seinem Namen angestrengte Prozess, dass nun effektive Mittel existierten, um die Verletzung des eigenen Urheberrechts in einem anderen Land zur Anzeige zu bringen und zu ahnden.

Im Fall von Durchlaucht Radieschen war es der deutsche Verlag Feydeaus, der auf die mögliche Verletzung seines Urheberrechts aufmerksam wurde und der den Prozess anstrengte. Mit der fortschreitenden Internationalisierung war es aber selbst großen Verlagen immer weniger möglich, die Rechte ihrer Autoren wahrzunehmen, vor allem im Bereich der Musik. Deshalb kam es zur Gründung von Verwertungsgesellschaften. Pionier auf diesem Gebiet war Frankreich, wo sich 1851 die Société des Auteurs, Compositeurs et Éditeurs de Musique (SACEM) gründete. ${ }^{445}$ In Deutschland entstand nach Verabschiedung des Gesetzes zum Urheberrecht an Werken der Literatur und der Tonkunst 1902 die Genossenschaft deutscher Tonsetzer (GDT) mit der ihr angeschlossenen Anstalt für musikalisches Aufführungsrecht (AFMA). ${ }^{446}$ Die AFMA orientierte sich nicht nur stark am französischen Vorbild, sondern unterhielt auch gute Beziehungen zur SACEM. So hatten sich die beiden Gesellschaften 1904 vertraglich verpflichtet, die Aufführungsrechte der Mitglieder der jeweils anderen Gesellschaft im eigenen Land mitzuvertreten. ${ }^{447}$ Die Verhandlungen wurden unter anderem von Paul Lincke geführt, der nicht nur mit der Pariser Musikszene bestens vertraut war, sondern aufgrund des Erfolgs seiner Kompositionen wohl auch ein großes Interesse daran hatte, diese im Ausland zu schützen. ${ }^{448}$ Mit Großbritannien unterhielt die AFMA zu diesem Zeitpunkt noch keine Beziehungen, was dem Umstand geschuldet war, dass dort zwar schon früh eine Verwertungsgesellschaft für Texte, nicht aber für musikalische Werke existierte. Erst 1914 gründete sich dort die Performing Right Society (PRS), die das Vorbild der SACEM und der AFMA nachahmte. ${ }^{449}$ An ihrer Gründung beteiligt waren mit Paul Rubens, Howard Talbot, Percy Greenbank, Lionel Monckton und Adrian Ross die führenden Komponisten von Musical Comedies, was darauf schließen lässt, dass sie das größte Interesse am Schutz ihrer Werke hatten, weil diese die größte nationale und internationale Verbreitung fanden. ${ }^{450}$ Der erste Vorsitzende aber war niemand anderes als William Boosey, der bereits im Vorfeld ganz wesentlich zur Entstehung der PRS beigetragen hatte. ${ }^{451}$

443 Ebd., S. 159.

444 Vgl. z. B. DreYer et al., Urheberrecht, S. 68.

445 Vgl. James, The Story, S. 16; zur SACEM siehe DưmLING, Musik hat ihren Wert, S. 25-27.

446 Vgl. Dúmling, Musik hat ihren Wert, S. 59-63.

447 Vgl. ebd., S. 74.

448 Vgl. ebd., S. 75.

449 Vgl. EHRLICH, Harmonious Alliance, S. 1.

450 Vgl. ebd., S. 17; JAmes, The Story, S. 21; EhrLICH, Harmonious Alliance, S. 16.

451 Vgl. Boosey, Fifty Years of Music, insbes. S. 174-179; JAMES, The Story, S. 21; EHrLich, Harmonious Alliance, S. 17-21. 
Der Erfolg der Verwertungsgesellschaften lässt sich an ihren steigenden Einnahmen ablesen: im Fall der GDT von 65143 Mark im Jahr 1904 auf 610728 Mark im Jahr 1913 und, nach einer kriegsbedingten Flaute, wiederum auf 565322 Mark im Jahr 1920; die der PRS von 1572 Pfund im Jahr 1915 auf 227945 Pfund im Jahr 1933. ${ }^{452}$ Nachdem aufgrund des Ersten Weltkriegs die Beziehungen zwischen den einzelnen Gesellschaften abgerissen waren, wurden diese in den zwanziger Jahren neu geknüpft. So kam es 1929 zur Gründung eines internationalen Dachverbandes, der Confédération Internationale des Sociétés d'Auteurs et Compositeurs (CISAC). ${ }^{453}$ Nach der Kodifizierung des Urheber- und Aufführungsrechts, erst auf nationaler, dann auf internationaler Ebene, markierte die Gründung der Verwertungsgesellschaften, die die Einhaltung des Rechts überwachten und die Tantiemen für die von ihnen vertretenen Künstler einzogen und verteilten, den letzten Schritt in der Regulierung des internationalen Marktes. Sie war Ausdruck der im Lauf des 19. Jahrhunderts rasant vorangeschrittenen Internationalisierung des Kulturmarktes und trieb diese gleichzeitig weiter voran. Denn wie Epstein erkannt hatte, machte erst die Sicherung der Rechte im Ausland dieses zu einem interessanten Markt.

\section{Zwischenfazit}

Die fortschreitende Kommerzialisierung, die Herausbildung großer Theaterkonzerne und die Steigerung der Ausgaben blieben nicht ohne Folgen für die Produkte des Theaters. Das Schlagwort von der Industrialisierung mag übertrieben gewesen sein, es spiegelte jedoch tatsächliche Veränderungen wider. Die zunehmende Nachfrage nach Erfolgsstücken führte dazu, dass die Arbeitsteilung bei der Abfassung und Inszenierung von Stücken zunahm. Dem entsprach eine stärkere Spezialisierung sowohl der Autoren und Komponisten als auch der Theater. Wenn ein Theater eine Nische gefunden hatte, blieb es ihr häufig treu. Nur wenn der Publikumsgeschmack sich radikal änderte, ging es von den gewohnten Pfaden ab und versuchte sich an anderen Genres. Die Spezialisierung der einzelnen Theater führte zu einer immer stärkeren Ausdifferenzierung der Theaterlandschaft: Neben Opern- und Schauspielhäuser traten nun Klassiker-, Komödien-, Lustspiel-, Operetten-, Revue- und Varietétheater.

Ein zweiter tief greifender Prozess, der die Produktionsseite des Theaters in der langen Jahrhundertwende veränderte, war die Internationalisierung. Seit der zweiten Hälfte des 19. Jahrhunderts nahm der Austausch kontinuierlich zu, um vor dem Ersten Weltkrieg einen vorläufigen Höhepunkt zu erreichen. Obwohl es auch in Deutschland vereinzelte Wandertheater gab, war die ausgedehnte Tournee durch die Provinz und die überseeischen Kolonien eine britische Spezialität, für die es auf dem Kontinent aufgrund einer relativ dichten Verteilung von lokalen, selbstständig betriebenen Theatern keine Entsprechung gab. In Großbritannien 
hingegen entwickelte sich die Tournee zu einem neuen, eigenständigen Produkt. Theaterunternehmen beschränkten sich nicht länger auf Inszenierungen im eigenen Haus, sie schickten sie in alle Teile des britischen Weltreichs oder vermieteten die Aufführungsrechte an Subunternehmer, die auf die Ausrichtung von Tourneen spezialisiert waren: „With headquarters in London, the Gaiety and the Savoy operated as multi-nationals“. ${ }^{454}$ Das gilt auch für Berliner Theaterdirektoren wie Max Reinhardt und Erik Charell. Mit dem Vertrieb der Inszenierung von Im weißen Rössl als komplettes Paket nach London, Paris und New York war ein Grad der Standardisierung erreicht, der erst von den Megamusicals der 1980er Jahre übertroffen wurde. ${ }^{455}$

Manche Historiker sehen in der Herausbildung des geistigen Urheberrechts eine Folge der Vernetzung und erklären sie - und damit die Globalisierung - aus sich selbst heraus und unter Ausblendung ökonomischer Faktoren. ${ }^{456}$ Obwohl die verbesserte Kommunikation und die gestiegene Mobilität wichtige Voraussetzungen der wirtschaftlichen Globalisierung waren, wurde diese, wie sich am Theater ablesen lässt, doch in erster Linie von wirtschaftlichen Interessen vorangetrieben. So lässt sich die Intensivierung des transnationalen Austausches auf die gewachsene Nachfrage nach Stücken zurückführen, die sich wiederum der stark angestiegenen Zahl von Theatern verdankte. Da die Nachfrage nach neuen Stücken nicht mehr durch die einheimische Produktion befriedigt werden konnte, richtete sich der Blick der Theaterdirektoren auf das Ausland. Mit der Adaptation eines Stücks, das zuvor bereits anderenorts erfolgreich gewesen war, verband sich überdies die Hoffnung, dass es diesen Erfolg wiederholte. Desgleichen war die zunehmende Verrechtlichung des Austausches in Form von bilateralen und internationalen Abkommen in erster Linie ökonomisch motiviert. Vor diesen Abkommen war es üblich gewesen, dass Direktoren Stücke von ausländischen Autoren und Komponisten aufführten, ohne Tantiemen an diese abzuführen. Für die Theater machte diese Praxis Sinn, da sie so die Ausgaben sparten. Den Autoren und Komponisten entstand dadurch aber ein wirtschaftlicher Schaden, der sie Interessenorganisationen gründen und nach Gesetzen rufen ließ. Die internationale Absicherung geistiger Eigentumsrechte war also keine Folge der Vernetzung, sondern vielmehr ein Ergebnis wirtschaftlicher Interessen.

Die Kodifizierung des Urheberrechts und die Gründung von Verwertungsgesellschaften resultierten ihrerseits wieder in internationalen Kontakten und eröffneten neue Wege des Austauschs, der sich dadurch verstetigte. Der Erste Weltkrieg führte dann zwar zu einem völligen Abbruch aller Kontakte, die aber bald nach dem Krieg wiederbelebt wurden. Obwohl es sich grundsätzlich um einen reziproken Austausch handelte, war er nie ganz gleichgewichtig. Während 23 Berliner Operetten in London aufgeführt wurden, schafften lediglich 11 Musical

454 Davis, The Economics, S. 353.

455 Vgl. Burston, Theatre Space as Visual Place; ders., Spectacle, Synergy and Megamusicals; ReBellato, Theatre \& Globalization, S. 39-42.

456 Vgl. LöHR, Die Globalisierung geistiger Eigentumsrechte. 
Comedies den Sprung nach Berlin. Über die Gründe für diese Asymmetrie lässt sich nur spekulieren: Möglicherweise waren die britischen Stücke eher für den Binnenmarkt konzipiert oder im Zuge ihrer Adaptation nicht genügend dem $\mathrm{Pu}$ blikumsgeschmack angepasst worden; vielleicht war die Musik im Vergleich zur Operette zu unambitioniert oder das deutsche Publikum stand britischen Erzeugnissen generell skeptisch gegenüber. Auch war die Zahl der Theater und damit die Nachfrage nach neuen Stücken in London größer als in Berlin, so dass hier mehr Stücke aus dem Ausland importiert wurden. Keine dieser Hypothesen überzeugt jedoch restlos. Eine Erklärung fällt auch deshalb schwer, weil die Zeitgenossen den Transfer - und erst recht dessen Ausbleiben - selten kommentierten. Äußerte sich doch einmal ein Kritiker über den Austausch, nahm er diesen meist weniger als kulturelle Bereicherung, sondern als Fremdkörper oder gar bedrohliche Invasion wahr. Die Internationalität des populären Musiktheaters dieser Zeit darf daher nicht als kulturelle Annäherung missverstanden werden - gleichwohl erreichte sie in Umfang, Reichweite und Intensität beeindruckende Dimensionen. 
Lange schon ist die Bühne Mittlerin der neuesten Mode geworden. Elsa Herzog 457

Although only partially recognized, it is an indisputable fact that the stage has a considerable influence in its effect upon the prevailing and future modes.

The Era ${ }^{458}$

\subsection{Inszenierter Konsum}

Die Kommerzialisierung des Theaters beschränkte sich nicht auf den Theaterbetrieb, sondern erfasste auch die Bühne, die den beginnenden Massenkonsum zum Thema machte. Zwar waren Großbritannien und Deutschland zur Zeit der langen Jahrhundertwende noch keine Konsumgesellschaften in dem Sinne, wie sie es in der zweiten Hälfte des 20. Jahrhunderts werden würden. Trotzdem entstanden bereits seit dem Ende des 19. Jahrhunderts aufgrund steigender Löhne, sinkender Ausgaben für die Sicherung der Grundbedürfnisse, der Einführung neuer Konsumgüter und neuer Orte des Konsums erste Voraussetzungen für eine Entwicklung in diese Richtung - die „Basis der Konsumgesellschaft“ war gelegt. ${ }^{459}$ An kaum einem Ort waren diese Veränderungen so augenfällig wie im Warenhaus, das nicht nur den Konsum revolutionierte, indem es eine völlig neue Freizeitbeschäftigung, das Shopping, kreierte, sondern auch, indem es zur Demokratisierung des Konsums beitrug. ${ }^{460}$ Unter anderem erprobten und praktizierten die Warenhäuser neue Formen der Reklame und ermöglichten wachsenden Teilen der Bevölkerung, an der Mode zu partizipieren. Dies führte zu einer Beschleunigung modischer Trends, da die oberen Schichten sich weiterhin durch ihre Kleidung vom Rest der Bevölkerung absetzen wollten. ${ }^{461}$ Mode und Reklame trugen zudem als „Konsumverstärker“ zur Verbreiterung und öffentlichen Präsenz des Konsums bei. ${ }^{462}$ Wie im Folgenden gezeigt wird, arbeitete das Unterhaltungstheater nicht nur eng mit den Warenhäusern und der Modeindustrie zusammen,

457 Elsa Herzog, Mode und Bühne, Jahrbuch der Berliner BÜHnen 1925/26, S. 119-123, hier S. 119.

458 The Influence of the Stage upon Fashion, THE ErA, 24.2. 1912, S. 11.

459 Vgl. SPIEKERMAnN, Basis der Konsumgesellschaft; siehe auch KöNIG, Kurze Geschichte der Konsumgesellschaft, S.37; zu Großbritannien siehe RICHARDS, The Commodity Culture of Victorian England.

460 Die Geschichte des Warenhauses und seiner sozialen und kulturellen Implikationen ist bestens erforscht, siehe etwa Stürzebecher, Das Berliner Warenhaus; StrohmeYer, Kathedralen des Konsums; Chaney, The Department Store as a Cultural Form; LeACH, Transformations in a Culture of Consumption; GerLaCH, Das Warenhaus; LaERMANS, Learning to Consume; LanCaster, The Department Store; Crossick und Jaumain (Hrsg.), Cathedrals of Consumption; RAPPAPORT, Shopping for Pleasure; SPIEKERMANn, Das Warenhaus; BrIESEN, Warenhaus; KÖNIG, Konsumkultur.

461 Vgl. Simmel, Philosophie der Mode.

462 Vgl. KÖNIG, Geschichte der Konsumgesellschaft, S. 387-406. 
sondern betätigte sich sogar selbst als Konsumverstärker, wenn es neue Moden lancierte oder für Produkte warb.

\section{Reklame}

„Die Zeitung, die Zeitschrift, die technische Neuerung, die wissenschaftliche Entdeckung: alles wurde vom Kaufmann seinem Beruf, seinen Zwecken dienstbar gemacht. Nur eine Kunst, eine der wichtigsten, hat die Reklame, hat der moderne Großkaufmann noch nicht erobert: die Theaterkunst." 463 So schrieb der Werbefachmann Alfred Faust 1915. Wahrscheinlich ging er nur selten ins Theater, sonst hätte er anders geurteilt. Denn die Geschäftstheater hatten bereits seit Mitte des 19. Jahrhunderts die Reklame als einen einträglichen Nebenverdienst entdeckt. So beschwerte sich 1855 ein Londoner Theaterbesucher:

Let me not pass from the Covent Garden pantomime without commenting also upon the bad taste of the curtain provided for it, which is not in the least intended for the pleasure of the public eye, but is a mass of advertisements collected from Moses and Son and other well-known advertisers. This, in a place meant for refreshment and amusement, pains the eye with a reproduction of the nuisance of a hoarding, or of a ticket-bedaubed second-class carriage on the railway. ${ }^{464}$

In der Tat muss man sich die Theatervorhänge vieler Bühnen wie eine vergrößerte Version der Reklameseiten in den damaligen Zeitungen vorstellen: über und über bedruckt mit Annoncen für Firmen und Produkte. Diese Praxis war keineswegs eine Londoner Besonderheit, sondern fand sich ebenso in Berlin, wobei deutsche Kritiker ihr allerdings noch ablehnender gegenüberstanden. So hieß es im notorisch kulturkritischen Kunstwart: „Theatervorhänge als Anzeigetafeln hab ich im Ausland schon vor Jahren gesehn, - sie ziehen nun auch bei uns ein, um es den Zuschauern deutlich in die Augen zu schrein, dass die Losung der modernen Bühne Geld, Geld, Geld heißt“ . 465 Ein anderer Autor wetterte gegen den „unausstehlich-wechselnden, geschmacklos aufdringlichen Annoncen- und ReklameVorhang“.466

Eine der ersten Berliner Bühnen, die auf diese Art der Werbung setzte, war das Wallner-Theater in den 1870er Jahren, wo „vor dem Vorhange ein nicht sehr umfangreiches Plakat herabgelassen [wurde], das eine Geschäftsreklame enthielt; die Entrüstung der Zuschauer hierüber war aber so groß, daß der Versuch nicht wiederholt werden durfte“. ${ }^{467}$ Dennoch verfügten bald die meisten Berliner Unterhaltungstheater über einen Reklamevorhang. Selbst Richard Schultz mochte nicht auf dieses Mittel verzichten. Als er 1898 das Metropol-Theater übernahm, veranschlagte er die Einnahmen durch die Verpachtung des Theatervorhangs auf 3000

\footnotetext{
463 Alfred Faust, Reklame-Theater, Die SCHAUbühne 1915, 1. Bd., S. 111-115, hier S. 112.

464 Morley, The Journal of a London Playgoer, S. 131 (Eintrag vom 29.12.1855).

465 Theatervorhänge als Anzeigetafeln, Der Kunstwart 6 (1892/93), Nr. 2, S. 189.

466 Arthur Seidl, Biedermeier in Decadence? Zur Psychologie des ,Überbrettl's', Die GesellSCHAFT 17 (1901), 2. Bd., S. 138-148, hier S. 146.

467 Neue Preussische Zeitung, 25.8. 1902.
} 
Mark. ${ }^{468}$ John Hollingshead hingegen entschied sich am Gaiety Theatre ganz bewusst gegen einen Reklamevorhang, um die Atmosphäre des Luxus nicht zu zerstören. ${ }^{469}$ Nach 1900 kam der Reklamevorhang dann ohnehin allmählich aus der Mode. An seine Stelle trat nun die „Diapositivreklame“, bei der vor, nach und zwischen den Vorstellungen Annoncen auf einen Vorhang projiziert wurden. ${ }^{470}$

Während es Reklame-Vorhänge und -projektionen im Theater heute nicht mehr gibt, hat sich eine andere Form weitgehend, wenn auch in geringerem Umfang, erhalten, nämlich die Reklame auf dem Theaterzettel und -programm. Diese war noch wesentlich einträglicher als der Reklamevorhang, Richard Schultz beispielsweise veranschlagte für die „Zettelpacht“ 9000 Mark. ${ }^{471}$ Wer ein beliebiges Programm des Metropol-Theaters aufklappte, musste schon zwei Mal hinsehen, um die Angaben mit den Namen der Schauspieler und den Titeln der einzelnen Bilder zu finden. Denn diese nahmen nicht einmal ein Sechstel des Platzes ein, während um sie herum Dutzende von Anzeigen zu finden waren - für Hotels wie das Adlon, das Impérial oder das Monopol, für Cafés wie das Victoria-Café oder für Gaststätten wie das Restaurant Hiller und die Weinstuben Lutter \& Wegener, die alle unweit des Metropol-Theaters lagen. Darüber hinaus enthielten die Programme Werbung für Waren wie Zigarren, Schirme oder Trikotagen (Abbildung 27). Auf einem Programmzettel des Gaiety Theatre war die Werbung etwas dezenter am linken und rechten Rand platziert, aber geworben wurde auch hier: für Autos, Getränke, Schuhe oder das Hotel Waldorf. Üblich war ebenfalls, dass das Publikum erfuhr, welche Modehäuser die Kostüme einer Aufführung beigesteuert hatten (Abbildung 28).

Die dritte und neueste Form von Reklame im Theater war die Werbung für bestimmte Produkte auf der Bühne als Teil eines Stückes - eine frühe Form von Product-Placement. Sorgt diese Praxis noch heute mitunter für Diskussionen, so konnte sie um 1900 einen wahren Theaterskandal auslösen. So etwa im Fall der Ausstattungsposse Berlin bleibt Berlin, die 1902 im Metropol-Theater aufgeführt wurde. Der Theaterkritiker des Berliner Couriers schrieb am folgenden Tag noch spürbar verärgert über „die Hervorhebung von Friseurläden, Putzgeschäften und allerlei Firmen“, die ihm das Gefühl vermittelte, „daß hier die Litfaßsäule dramatisirt ist und der Reclame-Vorhang auch während der Scene zudringlich auf der Bühne erscheint“.472 Das Fass zum Überlaufen brachte aber schließlich das Schlussballett Das Fest der Reklame, das zum Verdruss des Kritikers seinem Titel auf ganzer Linie gerecht wurde. Glaubt man seinem Bericht, war die Zuhörerschaft verärgert über die „harte Zumuthung, theueres Eintrittsgeld zu zahlen und bis Mitternacht auszuharren, nur um allerlei Geschäftsanzeigen anzusehen. Sie

\footnotetext{
468 Vgl. Aufstellung der Jahresspesen für das Metropol-Theater, LAB, A. Pr. Br. 030-05-3061.

469 Vgl. TREwin, Edwardian Theatre, S. 106.

470 Vgl. PANETH, Entwicklung der Reklame, S. 123, 127; Theatre Curtain, The ErA, 29.7.1911, S. 27; siehe auch NEVETT, Advertising in Britain, S.96; LAMBERTY, Reklame in Deutschland, S. $212 \mathrm{f}$.

471 Vgl. Aufstellung der Jahresspesen für das Metropol-Theater, LAB, A. Pr. Br. 030-05-3061.

472 BerLiner Courier, 24. 8. 1902.
} 


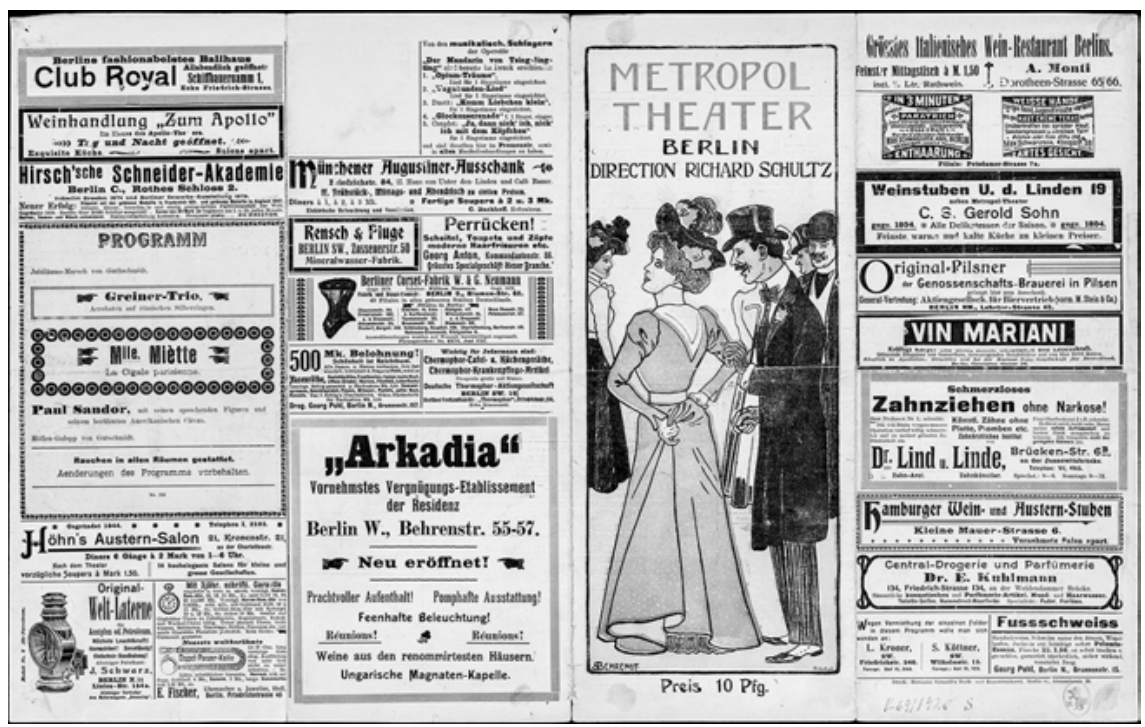

Abbildung 27: Programmheft des Metropol-Theaters zu der Jahresrevue Donnerwetter - tadellos! von 1908.

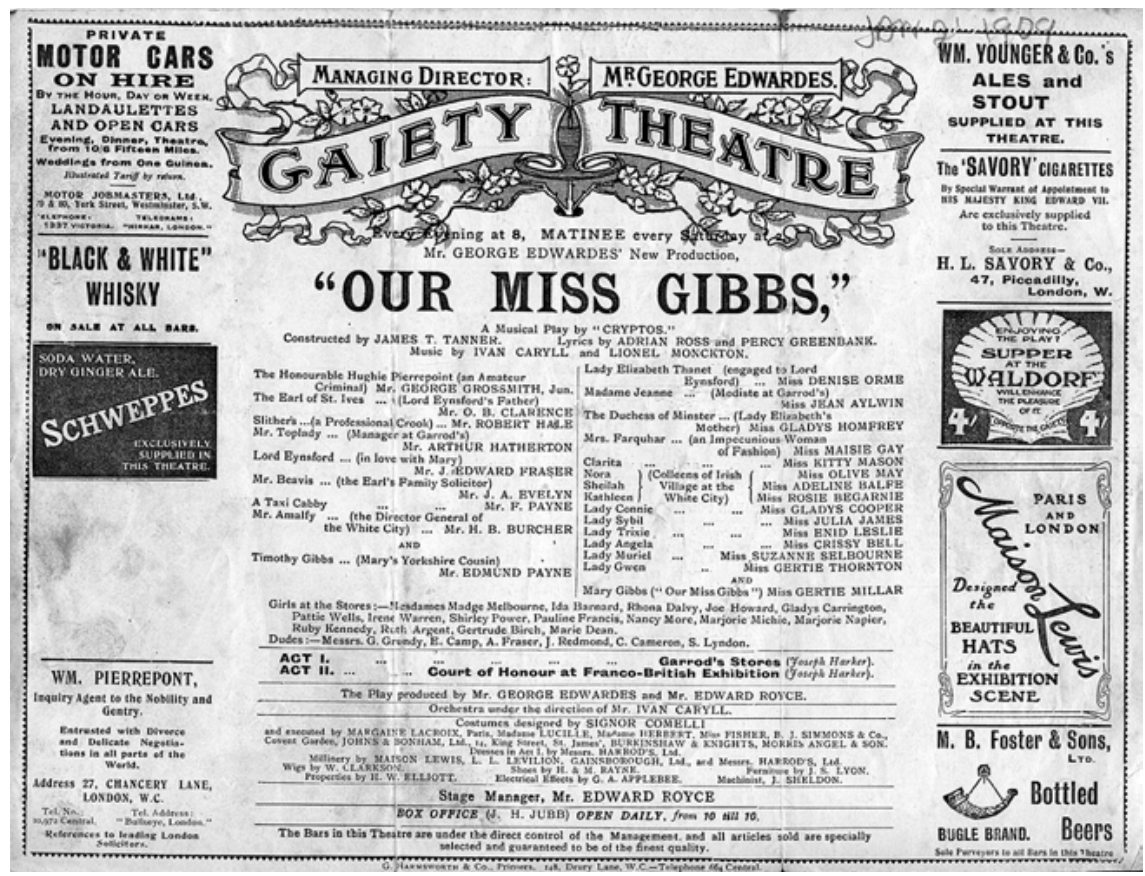

Abbildung 28: Programmheft des Gaiety Theatre zu der Musical Comedy Our Miss Gibbs von 1909. 
empörte sich aber schließlich aufs Heftigste, als die Tänzerinnen die Röcke hochhoben und die Firma ,Jandorf auch auf den Beinen sichtbar wurde, wie vorher auf den Hüten und Schirmen".473

Penibel zählte der Kritiker nahezu alle damals bekannten Formen von Reklame auf, angefangen bei Litfaßsäule und Zeitungsinseraten bis hin zu Reklamezettel und -vorhang. Am meisten ereiferte er sich aber über die Werbung auf den Körpern der Tänzerinnen, bei der die Kommerzialisierung von Weiblichkeit mit der Erotisierung der Ware verschwamm. Wenn er behauptete, die Zuschauer hätten verärgert reagiert, projizierte er jedoch sein eigenes Empfinden auf das Publikum. Denn seinem Kollegen vom Vorwärts zufolge war dieses mehrheitlich durchaus angetan von dem Ballett: „Einige altfränkische Pedanten zischten ob der Neuerung. Die Opposition wurde von der selbstlos am Gedeihen der Berliner Industrie uninteressierten Masse der Besucher in Grund und Boden applaudiert", meinte er ironisch. ${ }^{474}$ Andere Blätter wie die liberale Vossische Zeitung sprachen von einem „Skandälchen“. ${ }^{775}$ Dennoch entschied sich Richard Schultz dafür, das Finale von Berlin bleibt Berlin so abzuändern, dass die „anstößige Reklame“ entfiel - ein Beispiel dafür, wie sensibel die Theaterdirektionen auf das Verhalten ihres Publikums reagierten. ${ }^{476}$ Selbst wenn nur eine Minderheit ihr Missfallen an einer Szene äußerte, schien dies Anlass genug, diese zu überarbeiten oder zu streichen. Die Geschäftstheater konnten es sich nicht leisten, ihr Publikum zu verärgern.

Warum aber rief das Fest der Reklame bei manchen Kritikern und Zuschauern solche Empörung hervor? Erstens war damit eine neue Stufe der Werbung erreicht, die sich nun nicht mehr nur auf Programmzettel und Vorhang beschränkte, sondern die Bühne selbst eroberte. Dies erregte Widerstand wie bereits Jahrzehnte zuvor die Einführung des Reklamevorhangs. Zweitens war die Werbung und die Allianz mit dem Warenhauskonzern Jandorf ein unübersehbares Zeichen für die Kommerzialisierung des Theaters, die bildungsbürgerliche Zuschauer ablehnten. Und drittens sah sich die Werbung um 1900 als ein noch relativ neues Phänomen selbst der Kritik ausgesetzt. Ähnlich wie das Fest der Reklame wurde die stetig wachsende Präsenz von Reklame in der Großstadt kritisch aufgenommen, war sie doch ein anschaulicher Ausdruck sehr viel schwerer zu fassender sozioökonomischer Umwälzungen: dem Aufstieg des Einzelhandels, den Anfängen der Konsumgesellschaft und der Kommerzialisierung des öffentlichen Raumes. ${ }^{477}$ Das Fest der Reklame verstieß daher gleich auf mehrfache Weise gegen die Sensibilität des Bildungsbürgertums, das die „Ökonomisierung und Kommerzialisierung des Lebens“ ablehnte. ${ }^{478}$ Dass Schultz das Ballett nach den Unmuts-

473 Ebd.

474 VORWÄRTS, 26.8. 1902.

475 VOSSICHE ZEITUNG, 25. 8. 1902.

476 STAATSBÜrger ZeITUNG, 26. 8. 1902.

477 Vgl. Reinhardt, Von der Reklame zum Marketing, insbes. S.371; LAMBerty, Reklame in Deutschland, insbes. S. 13f.; KNOP, Werbung als Signum der Urbanität, S. 149f.

478 NipPerdeY, Deutsche Geschichte 1866-1918, 2. Bd., S. 590. 
äußerungen bei der Uraufführung strich, zeigt, dass es ihm nicht darum ging, sein Publikum zu provozieren oder einen Skandal heraufzubeschwören. Er griff die Reklame vielmehr deshalb auf, weil sie Geld brachte und weil sie etwas Neues war - und nach nichts strebte das Metropol-Theater mehr, als aktuell zu sein.

Eine subtilere, weniger Unmut erregende Form der Reklame im Bereich des Theaters war die Verpflichtung bekannter Schauspielerinnen und Schauspieler als Werbeträger. Wie ein deutscher Beobachter 1890 aus Paris berichtete, kam es dort häufig vor, dass Warenhäuser einer Schauspielerin kostenlose Kleider überließen, damit diese sie auf der Bühne trug: „Bei der Beliebtheit, welche das Theater besitzt, bei seiner Bedeutung als Zusammenkunftsort für die vornehmsten Stände der Gesellschaft muß diese wohl oder übel für eine Mode gewonnen werden, wel-

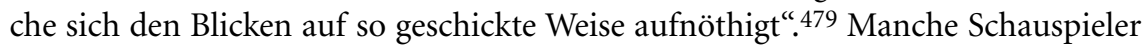
verwahrten sich allerdings gegen solche Angebote. Der Komiker Paul Morgan etwa beklagte sich darüber, mehrmals Briefe zugestellt bekommen zu haben, in denen er aufgefordert wurde, von der Bühne herab für ein Produkt zu werben. Obwohl er selbst sich gegen diese Praxis verwahrte, fand er sie jedoch überall bestätigt: „Heute ist die Bühnenreklame geradezu ein Faktor im Propagandawesen. Kluge Geschäftsleute suchen sich die geeignetsten Theater und die geschicktesten Künstler aus, mit denen sie in ,Geschäftsverbindung" treten “4 480

Zwischen dem späten 19. Jahrhundert und den späten zwanziger Jahren, aus denen dieses Zitat stammt, änderte sich daran kaum etwas. Noch verbreiteter als die Reklame von der Bühne herab war, dass bekannte Schauspieler ihr Gesicht und ihren Namen einem Produkt liehen. Der bekannteste deutsche Fall ist die nach der Metropol-Schauspielerin und Operetten-Diva benannte Massary-Zigarette, deren Werbung aus dem Stadtbild des Berlins der zwanziger Jahre kaum wegzudenken war: „Heute grüßt uns von allen Anschlagsäulen Berlins die Reklame der Massary-Zigarette“. ${ }^{481}$ Die Firma, die die Massary-Zigaretten herstellte, hoffte natürlich von dem Namen der bekannten Künstlerin zu profitieren. Die Konsumenten der Massary-Zigaretten wiederum erhielten dafür die Illusion, für die Dauer einiger Lungenzüge an der glamourösen Welt des Theaters zu partizipieren: „Ja, so besaß ich sie mindestens eine Viertelstunde lang. Eine vom Rang der Massary will in langsamer Andacht genossen sein", ließ der Schriftsteller Franz Hessel eine seiner Figuren philosophieren. ${ }^{482}$ Aus dem Zusammenhang gerissen wird die Zweideutigkeit dieses Kommentars noch deutlicher: Wer eine Massary-Zigarette ,besaß', so implizierte Hessel in Bezugnahme auf den viel beschworenen Sex-Appeal der Schauspielerin, besaß auch ein Stück weit das Original. Für die Darsteller schließlich bot die Reklame einen attraktiven Zuverdienst und überdies steigerte sie ihre Bekanntheit.

479 Silvester Frey, Der Luxus auf der Bühne, Die Gegenwart 37 (1890), Nr.25, S. 392f., hier S. 392.

480 Paul Morgan, Reklametheater und Theater-Reklame, DeR NEUE Weg 58 (1929), Nr. 7, S. 134.

481 RumPelstilzChen, Berliner Allerlei, S. $44 \mathrm{f}$.

482 Hessel, Von den Irrtümern der Liebenden, S. 103. 
Damit ist bereits ein weiterer Aspekt angeklungen: Das Theater und seine Angehörigen waren nicht nur Werbeträger, sie waren zugleich selbst Werbende. „Perhaps it is fairer to say that there is more advertisement in connexion with the theatrical art than any other, or, indeed, all the others put together", meinte ein britischer Beobachter 1910. ${ }^{483}$ „Es steht fest,“ notierte auch Walter Turszinsky, „daß das Theater unserer Tage ebensowenig wie jede andere künstlerische Unternehmung die Reklame entbehren kann“. ${ }^{484}$ In erster Linie warben die Bühnen mit Plakaten und durch Anzeigen in den großen Tageszeitungen, mitunter ließen sie sich aber auch publikumswirksame Werbegags einfallen wie das Suchlicht, das John Hollingshead auf dem Dach des Gaiety Theatre installieren ließ. Und nicht nur die Theater, auch die Darsteller warben. So verteilte ein britischer Schauspieler 191110000 Streichholzschachteln mit seinem Bild und der Aufforderung, der Darbietung seines neuesten Lieds im Prince of Wales Theatre beizuwohnen. 485

\section{Warenhaus}

„Uebrigens sind wir keineswegs sicher“, gab die Neue Preußische Zeitung im Nachklang des Skandälchens um das Fest der Reklame zu bedenken, „daß die lieben Berliner sich nicht auch an dergleichen gewöhnen werden“ - sie sollte recht behalten. ${ }^{486}$ Namen von Produkten und Firmen wurden in fast allen MetropolRevuen erwähnt, vor allem diejenigen von Kaufhäusern wie der ,Firma Jandorf im Fest der Reklame, bei der es sich um den Kaufhauskonzern A. Jandorf \& Co. handelte. Adolf Abraham Jandorf, der aus einfachen Verhältnissen stammte und seine Karriere als Leiter eines Textilgeschäfts in Berlin begann, war vor dem Ersten Weltkrieg einer der bedeutendsten Unternehmer der Stadt. ${ }^{487}$ Sein in den 1890er Jahren eröffnetes Warenhaus Jandorf am Belle-Alliance-Platz galt allgemein als das „Warenhaus des kleinen Mannes“. ${ }^{488}$ Das legt im Umkehrschluss ein weiteres Mal nahe, dass im Metropol-Theater nicht nur die gesellschaftliche Elite, sondern auch die Kundschaft dieses Kaufhauses verkehrte, die sich aus dem Kleinbürgertum und der besser gestellten Arbeiterschicht rekrutierte. Erst 1907 eröffnete Jandorf mit dem Kaufhaus des Westens das Flaggschiff seines Konzerns, das sich ganz an die oberen Schichten richtete. ${ }^{489}$

Das Fest der Reklame war nicht das erste Mal, dass der Name eines Warenhauses in einer Metropol-Revue fiel. Schon das Stück, mit dem Schultz seine Direktion im Metropol-Theater begonnen hatte, Im Paradies der Frauen von 1898,

\footnotetext{
483 SPENCE, Our Stage and Its Critics, S. 218.

484 Walter Turszinsky, Theater und Reklame, Die DeuTsche BüHnE 3 (1911), Nr. 16, S. 280-282, hier S. 280.

485 G. H. Elliott, A Chat about Advertising, The ErA, 7. 1. 1911, S. 28.

486 Neue Preussische Zeitung, 25. 8. 1902.

$487 \mathrm{Zu}$ Jandorf siehe Colze, Berliner Warenhäuser; Busch-PETERSEN, Adolf Jandorf.

488 Vgl. Colze, Berliner Warenhäuser, S. 12, 58; ähnlich GöHre, Das Warenhaus, S. 91.

489 Vgl. ebd., S. 20-32.
} 
enthielt ein Bild, das im Kaufhaus Wertheim spielte - ohne dass sich damals das Publikum daran sonderlich gestört hatte:

Wo ist wohl die Dame

Die Wertheim nicht kennt?

Es winkt schon der Name

Höchst chik und potent.

Wie heiß jedes Pröbchen

Die Herzen entflammt

Wie rauschen die Röbchen

Aus Seide und Sammt

In allen Nüancen

Nur haute nonvacante

Gibt er uns die Chancen

Zum höchsten succés

Für Liebesgefechte

Ist hier allemal

Das wahre, das echte,

das Hauptarsenal. ${ }^{490}$

Wurden in Berlin bleibt Berlin die Tänzerinnen zu Werbeträgerinnen im wörtlichen Sinn, stand in Das Paradies der Frauen die Figur der Konsumentin im Vordergrund. Die Handlung will es, dass die Frau des Teufels, verärgert aufgrund der Untreue ihres Gemahls und auf der Suche nach eigenen Liebesabenteuern, in einem Berliner Warenhaus landet, das hier in einer martialischen Sprache zum ,Arsenal' wird, in dem sich die Frau für ihre ,Liebesgefechte' ausrüstet. Zunächst als weibliche Sphäre charakterisiert, wird das Warenhaus zugleich, da Frau Teufel dort mit Verkäufer Isidor ihren zukünftigen Liebhaber trifft, als zwangloser Treffpunkt der Geschlechter vorgestellt, der Gelegenheit zum Flirt bietet.

In den Musical Comedies war das Warenhaus noch präsenter als in den Revuen. Angefangen bei The Shop Girl über The Girl from Kays und The Girl Behind the Counter bis zu Our Miss Gibbs gab es eine ganze Reihe von Stücken, die in Warenhäusern spielten, sodass sich regelrecht von einem Subgenre sprechen lässt. Befragt, woher die Idee für The Shop Girl stamme, teilte der Autor H. J. W. Dam dem Sketch mit:

It occurred to me, therefore, that, as many thousands of people do business at the large shops and stores in London, and taking into account the fact that people will readily pay to see on the stage what they can see in the streets for nothing, the stores formed an excellent sphere to make the basis of a musical piece. I was reasonably familiar with the Army and Navy Stores and Whiteley's, so I simply took a general store of this kind as a setting, and constructed a plot around ,The Shop Girl'491

Ausgangspunkt von The Shop Girl war also weder ein bestimmter Plot oder ein Charakter, sondern die Beobachtung, dass Kaufhäuser eine immer größere Rolle im täglichen Leben eines wachsenden Teils der Londoner Bevölkerung spielten. Der etwas abschätzige Kommentar des Autors, die Leute zahlten im Theater gutes Geld, um etwas zu sehen, das sie ebenso gut auf der Straße beobachten könnten,

490 Im Paradies der Frauen, 2. Bild, 1. Szene, LAB, A. Pr. Br. Rep. 30-05-02 Nr. 859.

491 The Shop-Girl at the Gaiety Theatre, THE SкETCH, 28. 11.1894, S. 215-217, hier S. 216. 
zeigt, dass das Publikum im Unterhaltungstheater nicht nur nach Eskapismus verlangte, sondern dass es seine eigene Umwelt auf der Bühne reproduziert sehen wollte.

Im Gegensatz zu Melodramen wie The Shop Girl and Her Master, The Shop Soiled Girl oder Das Warenhausfräulein, in denen das Warenhaus negativ gezeichnet wurde, entwarfen die Musical Comedies meist ein positives Bild. Sie zeichneten das Warenhaus als einen neuen urbanen Ort, an dem Angehörige aller Schichten und beiderlei Geschlechts aufeinandertrafen, sich auf einer Augenhöhe begegneten und die neue Welt des Konsums feierten. Ein typisches Merkmal war die Ausmalung der Warenfülle, die das Kaufhaus bereithält. Our Miss Gibbs vermittelte dies sowohl auf textlicher als auch auf performativer Ebene:

Garrods! Garrods! it's undisputed

You can go there for

All you care for!

Garrods! Garrods! Garrods! you will be suited,

Pay your money and take your choice!

For they will do your hair!

Up the revolving stair

Tickets for trips,

Railways or ships!

Shampoo or tub,

Feminine club!

Massage for either sex,

Bank where they cash you cheques!

Theatre stalls,

Brougham for calls

Ev'rything's found at Garrods!

And if a lady you would meet,

It's better here than in the street!

For while you choose a Paris skirt,

There's always time to flirt! 492

Wie in Im Paradies der Frauen wird das Warenhaus hier als ein weiblicher Raum (,feminine club') präsentiert, in dem es nicht nur alle erdenklichen Waren und Dienstleitungen gibt, sondern der überdies als sozialer Treffpunkt dient. Tatsächlich waren die Warenhäuser einer der wenigen Orte in den Metropolen der Jahrhundertwende, an denen sich Frauen aus den Mittelschichten alleine aufhalten konnten, ohne um ihre soziale Stellung fürchten zu müssen. ${ }^{493}$ Die Warenhäuser machten sich den Umstand zunutze, dass das Einkaufen zu den klassischen Pflichten der Hausfrau gehörte, und richteten ihre Räumlichkeiten und ihre Werbung ganz gezielt auf weibliche Kundinnen aus. Wenn dahinter auch primär ein ökonomisches Interesse stand, leisteten sie damit doch indirekt einen Beitrag zur Emanzipation, indem sie Frauen einen Raum in der Stadt boten, in dem diese

492 Our Miss Gibbs, 1. Akt, BL, MSS LCP 1909/3.

493 Vgl. Walkowitz, City of Dreadful Delight, S. 3, 21, 23; SCHLÖr, Nachts in der großen Stadt, S. 162-175; FranK, Stadtplanung im Geschlechterkampf, S. 111-115. 


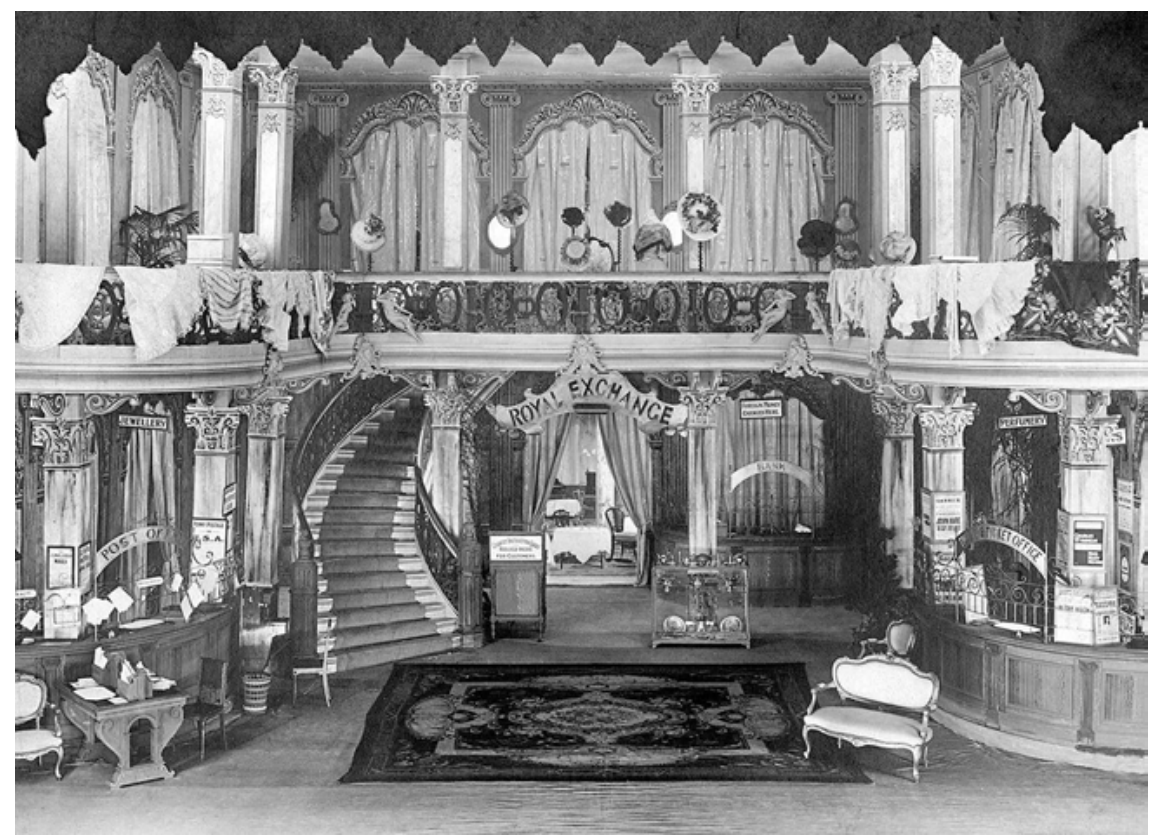

Abbildung 29: Der vom Warenhaus Harrods inspirierte, Garrods Department Store' in der Musical Comedy Our Miss Gibbs von 1909 - auf der rechten Seite der Schalter für Theaterkarten.

sich ohne Bedenken aufhalten konnten. ${ }^{494}$ Die Konzentration auf Frauen hatte aber nicht zur Folge, dass nicht auch Männer in den Warenhäusern einkauften. ${ }^{495}$ Wie die Zeile: ,There's always time to flirt!', andeutet, wurde es als ein heterosozialer Ort vorgestellt, an dem beide Geschlechter verkehrten.

Die Fülle der im Warenhaus erhältlichen Güter und die Atmosphäre des Wohlstandes und des Luxus, die Our Miss Gibbs auf der Ebene des Textes beschwor, vermittelte auch die Inszenierung (Abbildung 29). Das Bühnenbild zeigte ein säulenumstandenes Foyer im edwardianischen Stil, das sich ebenso in einem stattlichen Herrenhaus, einer Behörde oder einem Theater hätte befinden können. Linker Hand gab es ein kleines Post Office, neben dem die eine Treppe in den ersten Stock führte, wo auf einer Galerie zahlreiche Hüte ausgestellt waren. Rechts von ihr folgte das Büro der Bank, eine Parfümerie und die Theaterkasse. Davor ein bequemes Sofa, auf dem eine anspruchsvolle Kundin Platz nahm, um sich von der Schar der Verkäuferinnen die neuesten Moden vorführen zu lassen.

Ungewöhnlich für das Textbuch einer Musical Comedy enthält das Zensurexemplar von Our Miss Gibbs eine ausführliche Einführung, in der es heißt:

494 Vgl. McBride, A Woman's World; LEACH, Transformations in a Culture of Consumption; LAERMAns, Learning to Consume; NAVA, Modernity's Disavowal; RAPPAPORT, Acts of Consumption; dies., Halls of Temptation; dies., Shopping for Pleasure; BRIESEN, Warenhaus.

495 Vgl. Breward, The Hidden Consumer. 
The main feature of the scene is the luxury which makes shopping a matter of enjoyment and not ,fag. [...] All of these features are emphasised rather than the ordinary' shop character of the various departments which are not in any sense a photographic' reproduction of any one part of the Stores, but a ,composite' one conveying to the audience the idea of its being ,Harrod's' by certain recognisable points. ${ }^{496}$

Das klingt gar nicht nach den üblichen Regieanweisungen, sondern fast, als hätte die Reklameabteilung von Harrods den Text geschrieben - und möglicherweise war das auch der Fall. Ausführlich wird vorgegeben, wie der Aufenthalt im Warenhaus auf der Bühne zu inszenieren ist, nämlich nicht als ermüdende Last, sondern als Vergnügen. Am Schluss gibt der unbekannte Autor die Charade auf, wenn er statt von ,Garrods' explizit von Harrods schreibt. Ganz klar handelt es sich bei Our Miss Gibbs also um einen Londoner Beispiel für Product-Placement, durch das Harrods auf die großangelegten Zeitungskampagnen seines kurz vor der Uraufführung von Our Miss Gibbs eröffneten Konkurrenten Selfridges reagierte. ${ }^{497}$ Wie sich daran ablesen lässt, stand das Theater als Werbemedium zu dieser Zeit kaum hinter der Presse zurück. So brachte das Savoy Theatre im folgenden Jahr im Auftrag von Selfridges das Stück Selfrich's Annual Sale heraus. ${ }^{498}$

Manche Warenhauskonzerne waren sogar finanziell mit Theatern verflochten. Adolf Jandorf beispielsweise saß im Aufsichtsrat der Neues Operettentheater $\mathrm{GmbH}$, nachdem das Kaufhaus des Westens sich mit 20000 Mark an dieser beteiligt hatte. ${ }^{499}$ Das war kein reines Mäzenatentum, denn die Warenhäuser hatten ein lebhaftes ökonomisches Interesse an den Theatern. Wertheim am Leipziger Platz machte mit dem Verkauf von Theaterbilletts 1907 einen Umsatz von anderthalb Millionen Mark - selbst bei einem Jahresgesamtgewinn von 60 Millionen keine unbedeutende Summe. ${ }^{500}$ Und wie die oben zitierte Hymne auf Garrods und das Bühnenbild von Our Miss Gibbs zeigen, besaßen auch die Londoner Warenhäuser Theaterkassen. Im Gegenzug erhielten die Angestellten der Warenhäuser für bestimmte Vorstellungen von den Theatern verbilligte Billetts. ${ }^{501} \mathrm{Die}$ Angestellten von Selfridges waren so theaterbegeistert, dass sie eine eigene Laientheatergruppe gründeten. ${ }^{502}$ Und in Berlin wurde die Uraufführung von Das Warenhausfräulein von Angestellten des Warenhauses Tietz organisiert, nachdem der dort beschäftigte Autor Otto Reinhardt Popper seinen Kollegen aus seinem Stück vorgelesen hatte. ${ }^{503}$

Die Beziehung zwischen den Unterhaltungstheatern und den Warenhäusern war keine Einbahnstraße. Während die Theater das Warenhaus als Gegenstand

496 Our Miss Gibbs, 1. Akt, BL, MSS LCP 1909/3.

497 Vgl. RAPPAPORT, Shopping for Pleasure, S. 179.

498 Selfrich's Annual Sale, S. 15, BL, LCP 1910/26; siehe auch RAPPAPORT, Shopping for Pleasure, S. $204 \mathrm{f}$.

499 Vgl. Neues Operettentheater GmbH, LAB, A Pr. Br. Rep. 030-04-1990.

500 Vgl. GÖHre, Das Warenhaus, S. 48; siehe auch WienER, Das Warenhaus, S. 76.

501 Vgl. GöHre, Das Warenhaus, S. 78.

502 Vgl. Kaplan und Stowell, Theatre and Fashion, S. 183f.; RaPpaport, Shopping for Pleasure, S. 201; SANDERS, Consuming Fantasies, S. $77 \mathrm{f}$.

503 Vgl. Ein Hausdiener als Dramatiker, Berliner LoKalanZeiger, 14.3. 1908. 
und Schauplatz nutzten, lernte der Einzelhandel von ihnen, Waren ansprechend zu inszenieren. ${ }^{504}$ Am deutlichsten war dies bei der Gestaltung der Schaufenster, die mit den „Raffinessen der Theaterinszenierung“ konkurrierten. ${ }^{505}$ „Selfridge's window dressing struck the same note of showmanship, reproducing the boudoirs of famous ladies, borrowing from art masterpieces, copying the theatre," schreibt dessen Biograph. ${ }^{506}$ Vor der feierlichen Eröffnung seines Londoner Warenhauses ließ Selfridge alle Fenster wie die Bühne eines Theaters mit seidenen Vorhängen verhängen. ${ }^{507}$ Aber nicht nur die Vorhänge erinnerten an das Theater, auch die Lichtregie der Schaufensterbeleuchtung folgte den Konventionen der Bühnenbeleuchtung. ${ }^{508}$ Um die Passanten zum Verweilen vor den Schaufenstern und zum Betreten des Geschäftes zu animieren, ließen die Warenhausunternehmer, Ladenbesitzer und Dekorationsfachleute sich immer neue Tricks einfallen, die aus den Schaufenstern Miniaturtheater machten. So kamen vor der Jahrhundertwende bewegliche Figuren in Mode, die das Schaufenster mit Leben erfüllten. ${ }^{509}$ Sogar lebende Menschen, zum Beispiel Frauen beim Nähen oder Drehen von Zigaretten, wurden ausgestellt. ${ }^{510}$ Fehlten die Ideen oder die Mittel für solche Inszenierungen, konnte der Warenhaus- oder Ladeninhaber auf bezahlte „Schaufenster-Gaffer“ zurückgreifen, die, die Rolle des interessierten Konsumenten spielend, dieselbe Funktion erfüllten wie die Claque, die im Theater gegen Bezahlung für Applaus sorgte. ${ }^{511}$ Mitunter benutzten die Schaufensterdekorateure das Theater selbst als Rahmen, um etwa Abendgarderobe zu präsentieren. So empfahl ein Handbuch für Schaufensterreklame, das Schaufenster wie eine Theaterloge zu gestalten, in der dann die Mannequins platziert wurden. ${ }^{512}$ Manche Kaufhäuser besaßen überdies Säle, in denen sie Theatervorstellungen und Konzerte abhielten, um das Publikum anzulocken oder diesem den Aufenthalt im Warenhaus so angenehm wie möglich zu machen. ${ }^{513}$ Während die Theater Unterhaltung in ein Konsumgut transformierten, propagierten die Warenhäuser so das Shopping, das aus dem Einkaufen ein Vergnügen und eine Freizeitbeschäftigung machte.

Wenn die Theater die Handlung von Stücken im Warenhaus ansiedelten, ging es jedoch nicht immer um Einkaufen und Reklame, oft fungierte es als eine Metapher für größere Zusammenhänge, wie in diesem Lied aus der Jahresrevue Chauffeur - in's Metropol:

\footnotetext{
504 Vgl. Laermans, Learning to Consume, S. 92; NAVA, Modernity's Disavowal, S. 48.

505 Kiaulehn, Berlin, S. 33.

506 Pound, Selfridge, S. 106.

507 Vgl. RAPPAPORT, Shopping for Pleasure, S. 155.

508 Vgl. SCHIVELBUSCH, Lichtblicke, S. 143.

509 Berliner Schaufenster, ReKLAME 2 (1892), S. 185.

510 Vgl. Figuren, die wirklich leben, DAS MODERNE GESCHÄFT 5 (1913), Nr.20, S. 12; siehe auch REINHARDT, Von der Reklame zum Marketing, S. 274.

511 Vgl. ReINHARDT, Von der Reklame zum Marketing, S. $274 \mathrm{f}$.

512 EXNER, Moderne Schaufenster-Reklame, S. 41.

513 Vgl. Wiener, Das Warenhaus, S. 77; LANCASTER, The Department Store, S. 5; LeACH, Transformations in a Culture of Consumption, S. $325 \mathrm{f}$.
} 


$\begin{array}{ll}\text { Chor: } & \text { Wo geht Berlin heut ein und aus? } \\ & \text { Im Warenhaus! Im Warenhaus! } \\ & \text { Wo ist ein ewiger Saus und Braus? } \\ & \text { Im Warenhaus! Im Warenhaus! } \\ & \text { Wo sie die Leut' man Treppab- und Treppauf geh'n? } \\ & \text { Was ist dem kleinen Geschäftsmann ein Graus? } \\ & \text { Das Warenhaus! } \\ & \text { Das Warenhaus! } \\ \text { Kunde: } & \text { Politisches?! } \\ \text { Angestellter: } & \text { Rechts bitte! } \\ \text { Kunde: } & \text { Städtisches! } \\ \text { Angestellter: } & \text { Links bitte! } \\ \text { Kunde: } & \text { Dramatisches!? } \\ \text { Angestellter: } & \text { Hier bitte! } \\ \text { Kunde: } & \text { Literarisches! } \\ \text { Angestellter: } & \text { Da bitte! } \\ \text { Kunde: } & \text { Mode und Sport!? } \\ \text { Angestellter: } & \text { Ersten Stock muss ich bitten. } \\ \text { Kunde: } & \text { Gerichtssaal? } \\ \text { Angestellter: } & \text { Im zweiten! } \\ \text { Kunde: } & \text { Stadtklatsch! } \\ \text { Angestellter: } & \text { Im dritten. }\end{array}$

Berlin geht ein und aus im Warenhaus und wird hier zugleich selbst zum, Warenhaus Groß-Berlin', in dem alle Konsumenten die ihnen gemäße Ware finden: angefangen bei der Politik, über lokale Angelegenheiten, Theater, Literatur, Mode, Sport, sensationelle Gerichtsfälle bis zum Stadtklatsch. Wie die Metropole bot das Warenhaus einen „raschen und ununterbrochenen Wechsel äußerer und innerer Eindrücke".515

Das gilt auch für die Revue, die ebenfalls aus einem bunten Konglomerat unterschiedlicher Eindrücke und Bilder bestand, einem Gemisch aus Politik, Mode, Sport und Stadtklatsch. In seiner Besprechung der Revue Es liegt in der Luft von 1928 brachte Erich Kästner diese Ähnlichkeit auf den Punkt:

24 Bilder aus einem Warenhaus, diesem ausdrucksvollen Wahrzeichen der Großstadt. Ein Warenhaus hat alles, was man braucht. Und so kann der Autor alles, was er braucht, aus dem Milieu beziehen. Die Reste - Kaufwut der Frauen, die Kleptomanie, die Ping-Pong-Mode, die Erfolgsstücke der Saison, die Grammophonlieblinge, der Umtauschfimmel -, alles muß dran glauben. Von abgegebenen Hunden bis zur lesbischen Liebe, vom einfachen Ulk bis zur gesungenen Philosophie reicht das Fassungsvermögen des Spiels. ${ }^{516}$

Erneut scheint hier ein innerer Zusammenhang auf zwischen dem Warenhaus, der Großstadt und der Revue. Dennoch hatte sich der Blick auf den Massenkonsum spürbar eingetrübt. Im Unterschied zu den Stücken der Vorkriegszeit bot Es liegt in der Luft kein zukunftsoptimistisches Fest des Konsums. Die neue Sachlichkeit, die bereits das Titellied zum Motto der Revue erklärt hatte (,Es liegt in der Luft eine Sachlichkeit'), beherrschte auch die Darstellung des Massenkonsums: Am Ende treffen alle Kunden an der Kasse zusammen, um die erstandenen Waren

514 Chauffeur - in's Metropol!, 1. Bild, 1. Szene, TSFU, NL Freund 97/02/W174.

515 SiMMEL, Die Großstädte und das Geistesleben, S. 116.

516 KästNER, Gemischte Gefühle, S. 91. 
wieder umzutauschen. ${ }^{517}$ Schon in der 1923 uraufgeführten Operette Der Fürst von Pappenheim florierte das Warenhaus nicht mehr: „Keine Kunden, nichts zu tun. / Alle Hände müssen ruhn. / Ach, bald geht sie aus dem Leim / Die gute Firma Pappenheim“. 518 - „Oh, we sit and wait all day, / But no clients come our way!“, hieß es in der englischen Adaptation. ${ }^{519}$ In der Zwischenkriegszeit mit ihren konjunkturellen Auf und Abs verdunkelte sich der Blick auf den Konsum spürbar und das Genre der Warenhaus-Musical Comedy kam an sein Ende.

\section{Mode}

Noch enger als mit den Warenhäusern waren die Geschäftstheater mit der Modeindustrie verbunden. In der Ära vor Modeschauen und Hochglanzmagazinen bot das Theater den Modeschöpfern ein Forum, um ihre Produkte öffentlich vorzustellen und neue Trends zu lancieren. Große Teile des Publikums erwarteten dies geradezu von ihm, wie Charlotte Engel-Reimers kritisch anmerkte: „Auch in der kleinen Stadt wollen die Frau Amtsrichter und die Frau Apotheker an der ersten Liebhaberin die kommende Mode studieren". 520 Ihren Ursprung hatte die enge Verbindung von Theater- und Modeindustrie in Paris, der wichtigsten Modemetropole. ${ }^{521}$ Um die Jahrhundertwende aber war diese Praxis auch in Berlin und London bereits etabliert. Zwar ließen noch manche Theaterdirektoren bis ins frühe 20. Jahrhundert hinein die Kostüme in eigenen Werkstätten anfertigen, diese Praxis verschwand jedoch allmählich. ${ }^{522}$ Längst hatten sie erkannt, dass die Kleidung der Darsteller einen eigenen Reiz auf das Publikum ausübte. Wenn George Edwardes Frauen in den Mittelpunkt seiner Inszenierungen stellte, wollte er damit ebenso weibliche wie männliche Schaugelüste befriedigen, wie MacQueenPope schreibt: „He dressed them with perfection of taste, and thus attracted not only the men, to gaze at the girls, but the women, to gaze at their frocks ". ${ }^{23}$ Dabei vergaß er aber, dass die Bühne auch für Männer die Funktion eines Trendsetters erfüllte. Während die Schauspielerinnen die neuesten Kreationen der Bond Street trugen, traten die Schauspieler auf die Bühne, ,as if they had just walked in from Savile Row“. 524 In der Tat legte Edwardes größten Wert darauf, dass die Kostüme seiner Schauspielerinnen von den besten und bekanntesten Schneidern stammten. Seiner Biographin zufolge war er der erste Londoner Manager, der die Entwicklung der Mode genau beobachtete und in ihr „one of his strongest allies“

517 SChIfFer, Es liegt in der Luft, S. 153f.; siehe dazu Jelavich, Berlin Cabaret, S. 179; GrosCh, Revue und Medien; ders., Lieder vom Fahrstuhl, S. 190-197; Trageser, ,Es liegt in der Luft eine Sachlichkeit', S. 225-256.

518 ARNOLD und BACH, Der Fürst von Pappenheim, S. 3.

519 Toni, 1. Akt, BL, MSS LCP 1923/19.

520 ENGEL-Reimers, Die deutschen Bühnen und ihre Angehörigen, S. 505.

521 Vgl. Troy, The Theatre of Fashion; BerTschik, Mode und Metropole; WatzKa, Comme il faut.

522 Vgl. Stange, Das Bühnenkostüm, S. 32; Möhrmann, Die Herren zahlen die Kostüme.

523 MacQueen-Pope, Carriages at Eleven, S. 103.

524 Hyman, The Gaiety Years, S. 64; siehe auch Breward, The Hidden Consumer. 
sah. ${ }^{525}$ Vor allem die Warenhaus-Musical Comedies waren prädestiniert für Modevorführungen: „The effect of the fashion parade was superb“, bescheinigte Walter MacQueen-Pope etwa Our Miss Gibbs. ${ }^{526}$

Darüber hinaus sah sich Edwardes der Sorge um die Einkleidung der Schauspielerinnen enthoben. Er überließ sie kundigen Modeschöpfern, für deren Dienste er noch nicht einmal zahlen musste, da ihnen das Theater als Werbung diente. George Edwardes scheute sich auch nicht, selbst auf die Modehäuser zuzugehen. Als er die Inszenierung von The Merry Widow vorbereitete, brachte er seine Hauptdarstellerin Lily Elsie in die exklusive Maison Lucile der Modeschöpferin Lady Lucy Duff-Gordon am Hanover Square, wo sich die Londoner High Society einkleidete. Wie diese in ihren Memoiren schreibt, entwarf sie nicht nur die Kostüme für die Aufführung, sondern erteilte Elsie regelrecht Schauspielunterricht: „There was not a movement across the stage, not a single gesture of her part in The Merry Widow that we did not go through together" ${ }^{527}$ Erneut hatte Edwardes einen idealen Partner gefunden, denn die Zusammenarbeit war für beide Seiten ein großer Erfolg. Duff-Gordon sah in The Merry Widow „a personal triumph for me“. ${ }^{228}$ Dabei wusste sie sehr wohl, was sie dem Werbeträger Theater verdankte. Umgekehrt aber bescherten ihre Kreationen, vor allem der Merry Widow-Hut, dem Stück eine Aufmerksamkeit, die es anderenfalls wohl kaum gehabt hätte. Wie die Kritiker nicht müde wurden zu betonen, war jede Musical Comedy zugleich eine Modenschau: MacQueen-Pope sprach von einer „fashion parade“, William Archer bezeichnete sie als „animated fashion-plate“. 529

Zur selben Zeit wie Edwardes in London entdeckten auch die Berliner Theaterdirektoren die Modeindustrie als Verbündeten. Wie Theodor W. Adorno betont, waren die Revuen und Operetten „nicht nur Entkleidungs- sondern auch Kleidervorführungen“. ${ }^{530}$ Das gilt zuallererst für die Ausstattungsstücke und Jahresrevuen des Metropol-Theaters, das in jeder Hinsicht „Berlins Modetheater“ war. ${ }^{531}$ Im Paradies der Frauen spielte nicht bloß in einem Warenhaus, es machte Mode zugleich auf vielfältige Weise zum Thema, so etwa in einem spektakulären Ballet der Moden, bei dem 60 Tänzerinnen in sieben Szenen die wechselnden Moden des 19. Jahrhunderts vorführten. ${ }^{532}$ Diesem Thema blieb das Theater auch in den folgenden Stücken treu: in Donnerwetter - tadellos! wohnte das Publikum der ,Toilette der Berlinerin' bei, Hallo! Die große Revue zeigte ,Was die Modedame

525 BLOOM, Curtain Call, S. 98.

526 MaCQueEn-Pope, Gaiety, S. 424.

527 DufF-Gordon, Discretions \& Indiscretions, S. 102.

528 Ebd. S. 101.

529 MacQueEn-Pope, Gaiety, S. 424; Archer, The Theatrical ,World` of 1896, S. 301.

530 ADORNO, Leichte Musik, S. 33.

531 Berliner Abendblatt, 23.9. 1912.

532 Im Paradies der Damen, 2. Bild, 10. Szene, LAB, A. Pr. Br. Rep. 30-05-02 Nr. 859; siehe auch das Programm zur Eröffnung des Theaters, Stadtmuseum Berlin, Metropol-Theater, unkatalogisiert. 


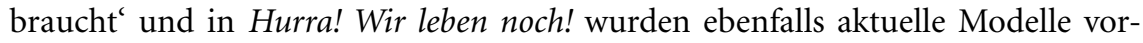
gestellt. ${ }^{533}$

Die Präsenz der Mode auf der Bühne verdankte sich zumindest teilweise dem Umstand, dass die Konfektionsbranche eine der wichtigsten Industrien Berlins war. Vor dem Ersten Weltkrieg setzte sie im Inland Fertigkleidung im Wert von 13 Millionen um und erwirtschaftete durch den Export weitere 10 Millionen Mark. ${ }^{534}$ Im Gegensatz zum Gaiety Theatre bezog das Metropol-Theater seine Kostüme allerdings nicht von einem der Berliner Modehäuser, sondern von einem Bühnenausstatter, sodass seine Bühne mitunter wie ein „Reklamesaal der Firma Baruch u. Co.“ wirkte. ${ }^{535}$ In Berlin war die Verbindung zwischen den Theatern und der Modeindustrie damit weniger stark ausgeprägt als in Paris oder London, zumindest war sie weniger unmittelbar. Dafür konnte die Berliner Modeindustrie gerade auf dem Gebiet des Theaters Erfolge verbuchen, lagen ihre Leistungen doch „weniger im Genre der Tages- und Abendmode im eigentlichen Sinn als vielmehr auf dem Gebiet des Bühnenkostüms. Hier war Berlin führend“. 536

Noch in einer weiteren Hinsicht war das Theater ein Mittler der Mode, denn wer die neuesten Modelle sehen wollte, der musste nicht unbedingt warten, bis sich der Vorhang öffnete. So schrieb etwa die Deutsche Tageszeitung über eine Premiere im Metropol-Theater: „Wieder grüßten uns Pariser und Wiener Moden modern, chik, als wollten sie wetteifern mit der glänzenden Konfektionsausstellung, die unter anderem da oben auf der Bühne in lebenden Modellen dahinschritt“ ${ }^{537}$ Der Zuschauerraum bot „ein Schauspiel, inszeniert vom Publikum für das Publikum “. 538 Kleidung war ein integraler Bestandteil der Selbstinszenierung des Publikums anlässlich der Premieren. In den Besprechungen der Metropol-Premieren ist immer wieder von „Toilettenprunk“ und „Toilettenluxus“ zu lesen. ${ }^{539}$ Das war in London nicht anders, wo die „leaders of rank and fashion“ sich einfanden zum „nightly carnival of gleaming shirt-fronts, of fashion and beauty“. ${ }^{440}$ Dass diese Aufführungen ihr eigenes Publikum anzogen, nutzten wiederum Modeschöpfer wie Paul Poiret aus, wenn sie ihren Models erlaubten, ihre Kreationen bei Theaterbesuchen zu tragen, sodass das Theater nicht nur auf der Bühne, sondern auch im Zuschauerraum der Modeindustrie zuarbeitete. ${ }^{541}$

533 Vgl. Donnerwetter - tadellos!, 3. Bild, 3. Szene, LAB, A Pr. Br. Rep. 30-05-02 Nr. 4214; Hallo! Die große Revue, 2. Bild, LAB, A Pr. Br. Rep. 30-05-02 Nr. 4559; Hurra! Wir leben noch!, 2. Bild, 5. Szene und 7. Szene, TSFU, NL Julius Freund 97/102/W184.

534 Vgl. Wagner, Die Mode in Berlin, S. 115; siehe auch Loeb, Berliner Konfektion; WestPHAL, Berliner Konfektion und Mode; DÄHN, Berlin Hausvogteiplatz; WAIDENSCHLAGER, Berliner Mode der zwanziger Jahre.

535 VORWÄRTS, 15.3. 1904; „Hugo Baruch u. Co.s Werke sind, glaube ich, am höchsten einzuschätzen“ schrieb Das KleInE JOURNAL, 12.3.1904; „Baruch war doch der eigentliche Sieger des Abends“, BerLiner Morgenpost, 13.3.1904.

536 Waidenschlager, Berliner Mode, S. 24.

537 Deutsche Tageszeitung, 18.9.1910.

538 BERLINER LOKAL-ANZEIGER, 27. 12. 1914.

539 Berliner Tageblatt, 6. 9. 1908; Berliner Lokal-Anzeiger, 27. 12.1914.

540 Forbes-Winslow, Daly's, S. 33; WiLson, Edwardian Theatre, S. 11.

541 Vgl. Troy, The Theatre of Fashion, S. 2. 
Wie die Warenhäuser lernten die Modedesigner im Gegenzug vom Theater, wie man Waren am besten dem Publikum präsentiert. Das gilt zu allererst für die Modenschau, von der Lucy Duff-Gordon beanspruchte, sie erfunden zu haben. Dabei nahm sie immer wieder Bezug auf die Bühne. So hoffte sie, ihre „dress parades“ wären „as entertaining to watch as a play“ und gestaltete den Raum, in dem sie stattfanden, wie ein Miniaturtheater mit Bühne und Vorhängen. ${ }^{542}$ Bis die „lebendigen Modelle“ nach Berlin kamen, dauerte es noch ein wenig; erst gegen 1908/09 folgte man hier dem Londoner und Pariser Vorbild und präsentierte die neuesten Modelle auf speziellen Bühnen, wie sie der Theaterarchitekt Oskar Kaufmann für einen Berliner Modesalon entwarf. ${ }^{543}$ Mitunter wurden auch die Theater selbst für die Vorführung von Mode genutzt. Der Verband der deutschen Mode-Industrie hielt beispielsweise 1922 im Metropol-Theater „eine großzügige Modenschau“ ab, die den Zweck hatte, „den hier weilenden Ausländern den Beweis des deutschen Modeschaffens zu erbringen, dadurch den Export zu heben und auch gleichzeitig dem grossen Publikum Gelegenheit zu bieten, sich dem Können unserer modeschaffenden Industrie zu überzeugen“. 544 Als Models dienten dabei „Frauen der Film- und Bühnenwelt, die ihre Kleidung gut zu tragen verstehen“ “545

Von ihrer Funktion als Modeschau profitierten auch die Theater selbst, erhielten sie so doch eine weitere Attraktion, für die sie nicht einmal bezahlten mussten, denn die Kosten trugen „die Konfektionsfirmen [...] aus Reklamegründen gern". ${ }^{446}$ Darüber hinaus bot die Mode aber auch Anknüpfungspunkte zu vielen anderen Themen: zu Berlin als modischer und moderner Stadt, zur Inszenierung von Geschlechterrollen und zu den auf der Bühne dieses Theaters so wichtigen jüdischen Charakteren, die sowohl als Angestellte als auch als Konsumenten vorkamen. ${ }^{547}$ Peter Jelavich sieht in der Mode das Schlüsselthema des MetropolTheaters, das alle anderen Themen übertraf oder sich einverleibte. ${ }^{548}$ Wie die Reklame oder das Warenhaus diente auch die Mode als ein Symbol, mit dem sich Abstraktes veranschaulichen ließ. Am Anfang von Donnerwetter - tadellos! beispielsweise musste sich in einer Szene, die den griechischen Mythos vom Urteil des Paris parodierte, die Göttin Venus von „Fräulein Chik“, der „Verkörperung hypermodernster Fraueneleganz“, sagen lassen:

Sie sind viel schöner, aber ich bin chicker!

Sie sind ein Bild von anno dazumal,

542 DufF-Gordon, Discretions \& Indiscretions, S. 68.

543 Vgl. Neue Berliner Kaufhäuser, Die PRAKTISCHE Berlinerin 1908, Nr. 2, S. 3-5; Bühne für Modevorführungen, Die Dame 51 (1924), Nr. 14, S. 5.

544 Brief des Verbandes der deutschen Mode-Industrie e.V. an das Polizei-Präsidium der Stadt Berlin, 28. 4. 1922, LAB, A. Pr. Br. Rep. 030-50-710.

545 Modenrevue, Berliner Börsen Courier, 4. 5. 1922; Varieté der Mode, Vossische ZeITUNG, 5.4. 1922.

546 Karl Neisser, Die Operette ist tot, es lebe die Operette, DiE SCENE 19 (1929), Nr. 2, S. 44.

547 Vgl. Im Paradies der Damen, 2. Bild, LAB, A. Pr. Br. Rep. 30-05-02 Nr. 859; Die Nacht von Berlin, 2. Bild, 4. Szene, LAB, A Pr. Br. Rep. 30-05-02 Nr. 5140; siehe dazu OтTE, Jewish Identities, S. 266-274.

548 Vgl. JelaVICH, Berlin Cabaret, S. 113. 
Doch ich bin das moderne Ideal!

[...]

Ich lieb's im Auto durch die Welt zu flieh'n

Und dufte daher manchmal nach Benzin! ${ }^{549}$

Natürlich entscheidet sich der ,moderne Mann` für Fräulein Chik und gegen die Venus, die daraufhin nach Berlin aufbricht, um sich mit der modernen Mode vertraut zu machen. Obwohl mit Fräulein Chik zunächst die Moderne über die Tradition und das Althergebrachte in der Person der Venus triumphiert, gelingt es dieser, nachdem sie erst einmal ihre Rückständigkeit anerkannt und die Moderne angenommen hat, am Ende doch, sich in der neuen Welt zurechtzufinden und ihre Stellung zu behaupten.

\section{Moden und Technik}

Mode hieß aber nicht Kleidermode und die Jahresrevuen behandelten keineswegs nur die jüngsten Kreationen der Haute Couture, sondern viele aktuelle Moden und Trends: Innovationen in Technik, Mobilität und Kommunikation oder neue Musikstile, Tänze und Vergnügungen, kurz gesagt: überhaupt alles, was schnell große Popularität entwickelte, um beinahe ebenso schnell von neuen Moden verdrängt zu werden. ${ }^{50}$ Mitunter gingen Mode und Moden fließend ineinander über, wenn sich wie in Hurra! Wir leben noch! eine Schneiderin an der Luftfahrt orientiert: „Aeroplane, leicht bewegt, / Wählt ich mir als Modell! / Die Frau, die solche Robe trägt, / Kommt hoch, doch fällt auch schnell!“551 Solche Anspielungen kamen um 1900 in vielen Stücken vor, denn die Erfolge der Luftfahrtpioniere wurden quer durch alle Medien diskutiert und lösten in weiten Teilen der Bevölkerung große Begeisterung, aber auch Ängste aus. ${ }^{552}$ In Frau Luna reisten drei Berliner in einem Ballon von der Erde zum Mond, in Neuestes! Allerneuestes! erreichte Serenissimus Berlin ebenfalls in einem Ballon, in Das muß man seh'n! trat ein Luftschiffer und in Donnerwetter - tadellos! Graf Zeppelin auf. ${ }^{553}$ Diese Invasion der Lüfte durch den Menschen provozierte in Hallo! Die große Revue den Widerstand des Windgottes Aeolus herauf, der sich von der zunehmenden Präsenz der Zeppeline, Ballone und Flugzeuge gestört fühlt. Er nimmt deshalb eine Luftschifferin gefangen, die sich allerdings wenig beeindruckt zeigt und dem König der Lüfte selbstbewusst seine Herrschaft streitig macht:

Das ist vielleicht früher mal so gewesen

Heut haben Hoheit ja nichts mehr zu sagen -

549 Donnerwetter - tadellos!, 1. Bild, 5. Szene, LAB, A Pr. Br. Rep. 30-05-02 Nr. 4214.

550 Vgl. KÖNIG, Neuheiten, Novitäten, Nouveautés.

${ }^{551}$ Hurra! Wir leben noch!, 2. Bild, 7. Szene, TSFU, NL Julius Freund 97/102/W184.

552 Vgl. Overr, Heralds of Modernity; Fritzsche, A Nation of Fliers; SIEgFried, Das Flugzeug; BERGHOFF, ,Dem Ziel der Menschheit entgegen:

553 Vgl. Venus auf Erden, LAB, A Pr. Br. Rep. 030-05-02 Nr. 384; Frau Luna, LAB, A Pr.Br. Rep. 030-05-02 Nr. 1128; Neuestes! Allerneuestes!, 1. Bild, LAB, A Pr. Br. Rep. 30-05-02 Nr. 2638; Das muß man seh'n!, 7. Bild, 3. Szene, LAB, A Pr. Br. Rep. 30-05-02 Nr. 3915; Donnerwetter - tadellos!, 4. Bild, 3. Szene, LAB, A Pr. Br. Rep. 30-05-02 Nr. 4214. 
Heut geht's Hoheit bedenklich an den Kragen!

Der Brummer, den Hoheit soeben sah'n,

Der heisst in der Technik Aeroplan.

Von den Brüdern Wright stammt die Prachtidee

Und verfertigt hat ihn die A. E. G. ${ }^{554}$

In der Begegnung zwischen dem König der Lüfte, der als Verkörperung der Natur, als griechischer Gott, als Monarch und als Mann als auf gleich vierfache Weise als aus der Zeit gefallen wirken soll, und der weiblichen, technikbewährten Luftschifferin, die die ,Eroberung der Lüfte'verkündet, spielte die Szene wiederum die Konfrontation zwischen Tradition und Moderne durch. Wie Venus in Donnerwetter - tadellos! erkennt Aeolus seine Rückständigkeit an und begleitet die Luftschifferin nach Berlin, wo er sich mit ihrer Hilfe zum modernen Mann mausert.

Ein ähnlicher Zusammenstoß war Gegenstand der Musical Comedy The Arcadians. In ihr erleidet James Smith, ein Londoner Gastronom mit einem Faible für Flugzeuge, eine Bruchlandung in einem weit entfernten, von der Zivilisation gänzlich unberührten Land namens Arkadien. Als dessen Bewohner des nahenden Flugzeugs gewahr werden, ergreifen sie in Panik die Flucht. ${ }^{555}$ Erneut wurde hier die Begegnung zwischen Tradition (in Form der unwissenden Arkadier) und Moderne (in Form des Flugzeuges) durchgespielt. Da sie noch nie ein Flugzeug gesehen haben, reagieren die Arkadier mit Furcht. Für das mit der modernen Technik vertraute Publikum jedoch hatte die Szene nichts Furchteinflößendes. Der Absturz, die übertrieben dargestellte Flucht und der auf die Bühne purzelnde Smith waren komisch inszeniert und riefen Gelächter hervor. Indem die Szene sich über die Furcht der Arkadier lustig machte, persiflierte sie zugleich die um 1900 verbreitete Technikfeindlichkeit. ${ }^{556}$ Wenn das Publikum sich in The Arcadians über die grundlos in Panik geratenden Arkadier amüsierte, lachte es auch über seine eigenen Ängste. Damit war das Stück auch in Berlin anschlussfähig, wo es 1912 als Schwindelmeier \& Co. im Metropol-Theater lief. ${ }^{557}$

Noch in den Revuen der Zwischenkriegszeit nahmen Innovationen wie Automobil, Fahrstuhl, Radio und Telefon eine zentrale Stellung ein. 558 Schön und Schick etwa baute „auf das Leitmotiv des Automobils“, das sich jedoch weitgehend darauf beschränkte, den Conférencier in Chauffeur-Uniform auftreten zu lassen. ${ }^{559}$ Generell war zu beobachten, dass das Theater Technik nun subtiler inszenierte als in der Vorkriegszeit. Viele Kritiker sahen in den Tanzgruppen - allen voran dem berühmtesten Ensemble der Zeit, den von Hermann Haller für den

554 Hallo! Die große Revue, 1. Bild, 1. Szene, LAB, A Pr. Br. Rep. 30-05-02 Nr. 4559.

555 The Arcadians, 1. Akt, BL, MSS LCP 1909/10.

556 Berghahn, ,Dem Ziel der Menschheit entgegen'; RIEGER, Technology and the Culture of Modernity, insbes. S.2-5; zu dieser Lesart des Stücks siehe auch PLATT, Musical Comedy, S. 49-53.

557 Vgl. Schwindelmeier \& Co., 1. Akt, 3. Szene, TSFU, NL Freund 97/02/w163.

558 Vgl. Grosch, ,Bilder, Radio, Telephon'; ders., Lieder vom Fahrstuhl, Automobil und anderen Nicht-Orten.

559 Monty Jacobs, ,Schön und Schick'. Hallers neue Revue im Theater des Admiralspalastes, Vossische ZeITUNG, 22. 8. 1928. 
Admiralspalast engagierten Tiller Girls - mit ihren gleichmäßigen, synchronisierten Bewegungen eine Metapher für Taylorismus und Fordismus, zwei Begriffe, die in der Zwischenkriegszeit für die zunehmende Rationalisierung in der Industrie standen. Immer wieder wurden die Tiller Girls als „Präzisionsmaschine“ oder „Bewegungsmaschinen“ beschrieben, als Produkt von Großstadt, Industrie und Moderne, „der Technik, der Präzision, der Masse, der Zahl“ ${ }^{560}$ Oder wie Siegfried Kracauer pointiert formulierte: „Den Beinen der Tillergirls entsprechen die Hände in der Fabrik“.561

$\mathrm{Zu}$ den technischen Innovationen, die um 1900 Wellen schlugen, gehörten, neben jenen aus dem Bereich der Mobilität, auch solche der Kommunikation und Unterhaltung, allen voran das Kino. Abermals zeigt sich, dass das Theater dem Kino keineswegs grundsätzlich feindlich gegenüberstand. Weit davon entfernt, die Bühne als Mittel im Kampf gegen einen Konkurrenten einzusetzen, finden sich Lieder wie das folgende aus der Jahresrevue Die Nacht von Berlin:

Mensch! - Sieh' Dir die Bilder an

Die man im Kientopp hat!

Mensch! - Da hast du Freude dran!

Das kriegst Du niemals satt!

Dort gondelt vorbei an Dir

Jede Sensation

Mit Harmonium und Klavier -

Und mit dem Grammophon!562

Entsprechend der geschäftlichen und künstlerischen Kooperation mit Oskar Messter verteufelte das Metropol-Theater den ,Kientopp' nicht, sondern forderte hier geradezu auf, sich die Bilder mit Grammophon-Begleitung anzusehen.

Ähnlich verhält es sich mit den beiden Operetten, die das Kino zum Thema machten. So behandelte die Operette Filmzauber von 1912 die Welt des Films zwar durchaus ironisch, wirkliche Kritik aber übte sie an denjenigen, die im Kino eine Gefahr für Moral und Sitten sahen. Viel lächerlicher als der Filmregisseur Adalbert Musenfett ist Euphemia Breitsprecher, die ihn dazu bekehren will, Filme zur sittlichen Besserung des Publikums zu drehen. ${ }^{563}$ Bei der Inszenierung kamen überdies, wie in einigen der Jahresrevuen, Filmaufnahmen zum Einsatz. Auch in im folgenden Jahr uraufgeführte Operette Die Kino-Königin, die in den USA spielte, wurden die Feinde des Films verspottet, hier der Fleischkonservendosenfabrikat, Temperenzler und Kino-Gegner Clutterbuck, der einer Filmdiva verfällt, heimlich gefilmt wird und so am Ende Widerwillens selbst zum Filmstar avanciert. 564

560 An und Aus. Die neue Revue im Admiralspalast, Vossische ZeItung, 19. 8. 1926; GIese, Girlkultur, S. 15.

561 Kracauer, Das Ornament der Masse, S. 54; zu den Tiller-Girls siehe auch Jansen, Glanzrevuen, S. 121-123; JelaviCH, Berlin Cabaret, S. 175-185; Fleig, Tanzmaschinen; LeHNE, Massenware Körper.

562 Die Nacht von Berlin, 2. Bild, 8. Szene, LAB, A Pr. Br. Rep. 30-05-02 Nr. 5140.

563 Vgl. Bernauer und SCHANZer, Filmzauber, S. 10-12.

564 Die Kino-Königin, TSFU, NL Freund 97/02/w175. 
Nach dem Ersten Weltkrieg machte das Theater dann verstärkt das Radio zum Thema. Die Revue London Calling von Noël Coward spielte schon in ihrem Titel auf das Radio an, denn mit, London calling' begannen die Sprecher der BBC ihre Ansagen, es diente aber auch inhaltlich als roter Faden. ${ }^{565}$ In Berlin hatten die Autoren der Haller-Revue Achtung! Welle 505 „das Radio, die Kunst ohne Augen als Zeitsymbol gewählt “ 566 Ähnlich wie im Fall des Kinos vor dem Krieg bediente sich das Theater des Radios also nicht nur aufgrund seines Neuigkeitswertes, sondern um etwas Zeittypisches aufzuzeigen. So verfolgte die Revue gleich zu Beginn „Kollos Tanzmelodie ,Du machst mir schlaflose Nächte $[\ldots]$ auf ihrer Wanderschaft ins Volk hinein [...], bis zu den Klampfen der Wandervögel und bis zum Männerquartett“. 567 Und sie zeigte, wie einst unüberwindbare räumliche Entfernungen immer mehr zusammenschmolzen, wenn das Radio mühelos Berlin mit der ganzen Welt verband: „Denn diese Urberliner Strippe, / Wenn Du's nicht hörst, Du ahnst es kaum, / Riskiert die allergrößte Lippe / Im ganzen Weltenraum". 568

Das Radio trug auch wesentlich zur Etablierung neuer Musikstile, Rhythmen und Tänze bei, ein Trend, der schon vor dem Ersten Weltkrieg mit einem „craze for the Tango" einsetzte. ${ }^{569}$ Die Theater griffen diese Mode schnell auf. Zunehmend begannen Komponisten, neue Rhythmen und Tänze in Operetten und Musical Comedies zu integrieren. Eine der ersten war The Sunshine Girl von 1912, in der George Grossmith und Phyllis Dare Tango tanzten und so diesen Tanz einem breiteren Publikum bekannt machten. ${ }^{570}$ Im folgenden Jahr kam die Revue Hullo, Tango heraus, die schon im Titel auf die Tango-Mode Bezug nahm. ${ }^{571}$ Die Berliner Bühnen zogen schnell nach. Das Metropol-Theater zeigte 1913 die Tango-Prinzessin mit Musik von Jean Gilbert. Abgesehen von dem Lied Ich tanz so gerne Tango setzte Gilbert aber überwiegend auf traditionelle Tänze wie den Walzer. ${ }^{572}$ Im selben Jahr schrieb Franz Lehár die Operette Die ideale Gattin, in der er ebenfalls den Tango verwendete und die er in überarbeiteter Form 1921 als Tango-Königin neu herausbrachte. ${ }^{573}$

565 London Calling, BL, MSS LCP 1923/22; siehe auch HoAre, Noël Coward, S. 177; Moore, André Charlot, S. 76-79.

566 Monty Jacobs, Hallers Revue ,Achtung! Welle 505` im Admiralspalast, Vossische Zertung, 20.8. 1925.

567 Ebd.

568 Haller et al., Achtung! Welle 505, 1. Lied.

569 MacQueEn-Pope, An Indiscreet Guide to Theatreland, S. 102; siehe auch Ritzel, ,Hätte der Kaiser Jazz getanzt...'; SCHRÖDER, Tanz- und Unterhaltungsmusik; HofFMANN, Aspekte zur Jazz-Rezeption; zu Großbritannien siehe Russell, Popular Music in England; PARsonage, The Evolution of Jazz in Britain.

570 Vgl. GänzL, The Encyclopedia, S. 1424; KNowles, The Wicked Waltz, S. 114 f.

571 Vgl. ebd.; Moore, André Charlot, S. 43; Parsonage, The Evolution of Jazz in Britain, S. 1215.

572 Vgl. Gilbert et al., Die Tango-Prinzessin; GÄnZl, The Encyclopedia, S. 1424.

573 Vgl. Brammer und Grưnwald, Die Tango-Königin; siehe auch GänzL, The Encyclopedia, S. 1424 . 
Auf Cakewalk, Onestep und Tango vor dem Weltkrieg folgten Foxtrott, Shimmy, Charleston und Blackbottom in den 1920er Jahren. Überhaupt war die Nachkriegszeit eine Ära der Tanzbegeisterung, manche Zeitgenossen machten sogar eine regelrechte „Tanzwut“ aus. ${ }^{574}$ Der Theaterkritiker Julius Bab kritisierte 1928 die „extreme Huldigung der Körperlichkeit“ und die so schnell wechselnden Tanzmoden: „Seit einem Jahrzehnt entstehen immerfort nicht nur neue Tänze, Tanzkünstler und Tanzschulen, sondern auch neue Theorien, ja förmliche Religionen des Tanzes in ganz Europa“. 575 Neben Radio und den aus dem Boden schießenden Tanzlokalen fungierte das populäre Musiktheater als Multiplikator. Die Operette diente „als ,Sammelbecken“ aller bis zum jeweiligen Erscheinen des Werkes vorhandenen Modetänze, wie Walzer, Cancan, Tango, Charleston und Foxtrott“. 576

Kaum zu trennen ist zwischen den Tänzen und der ihnen zugrunde liegenden Musik. Vor allem die Einführung des Jazz in Europa ging eng mit neuen Tanzstilen einher. Vertreter der jüngeren Generation, wie Emmerich Kálmán in Wien und Paul Abraham in Berlin, griffen ihn nicht nur instrumental auf, in ihren Operetten standen sogar Jazz-Bands auf der Bühne. ${ }^{577}$ Allerdings blieben sie letztlich doch überwiegend dem „vertrauten europäischen Klangbild“ treu. ${ }^{578}$ Ältere Komponisten wie Franz Lehár konnten mit dem Jazz oft wenig anfangen, dennoch waren dessen Operetten kaum weniger populär.

In Großbritannien war die Zurückhaltung bei dem Aufgreifen neuer musikalischer Formen noch größer. Der Theaterkritiker James Agate beispielsweise lehnte den Jazz zwar nicht rundweg, aber zumindest als Bestandteil englischer Musical Comedies ab. ${ }^{579}$ Andere machten die amerikanische Tanzmusik für ihren Untergang mitverantwortlich. ${ }^{580}$ Jüngere Komponisten wie Noël Coward und Ivor Novello benutzten manchmal Jazz-Elemente, waren insgesamt aber doch eher konservativ und der britischen Tradition verpflichtet: „The music was generally lyrical, lush, relying heavily on waltzes, although a jazz or blues number might creep in " ${ }^{581}$ Coward polemisierte auch musikalisch gegen die neuen Tänze und sehnte sich - nicht nur diesbezüglich - nach der trauten Großmutter-Zeit zurück:

Teach me to dance like Grandma used to dance,

I refuse to dance - Blues,

Black Bottoms, Charlestons, what wind blew them in.

Monkeys do them in zoos.

574 Sorge, Geschichte der Prostitution, S. 422; zu Großbritannien vgl. McKibBIN, Classes and Cultures, S. 390-418.

575 BAB, Das Theater der Gegenwart, S. 165.

576 Hoffmann, Aspekte zur Jazz-Rezeption, S. 81.

577 Vgl. Grúnwald et al., Die Blume von Hawaii; Grưnwald und LÖhner-BedA, Ball im Savoy; Hoffmann, Aspekte zur Jazz-Rezeption, S. 78f.; LareaU, Jonny's Jazz, S. 28-31.

578 JANSEN, Auf der Suche nach Zukunft, S. $54 \mathrm{f}$.

579 Vgl. Agate, Immoment Toys, S. 33f.

${ }^{580}$ Vgl. Short, Theatrical Cavalcade, S.162; Hyman, The Gaiety Years, S.191f.; Traubner, Operetta, S. 215.

581 GraY, Noël Corward, S. 52. 
Back in the past the dancing signified

Just a dignified glow.

They didn't have to be so strong

Though they revolved the whole night long.

Teach me to dance like Grandma used to dance

Sixty summers ago! 582

Dieses Lied schien eher die Haltung einer älteren Generation zum Ausdruck zu bringen, die den Vergnügungen der Jugend kopfschüttelnd gegenüberstand, als die eines gefeierten jungen Schauspielers und Autors, der zudem als Posterboy der ,Bright Young Things' galt. ${ }^{583}$ Doch verlieh Coward in vielen seiner Stücke dem Heimweh nach der Zeit vor dem großen Krieg, dem vermeintlich unschuldigen und unbeschwerten edwardianischen Zeitalter Ausdruck, in dem er seine Jugend verbracht hatte. Wie kaum eine andere Persönlichkeit verkörperte er die Zerrissenheit der Zwischenkriegszeit, das Schwanken zwischen Partystimmung und Pessimismus, Hedonismus und Hysterie. ${ }^{584}$

Auch in den Revuen mischte sich traditionelle europäische Tanzmusik mit neuen amerikanischen Elementen: Das Orchester des Admiralspalastes nannte sich Jazz-Symphonie-Orchester und in der Haller-Revue An und Aus stand die Paul-Godwin-Band auf der Bühne. ${ }^{585}$ Doch durchliefen die amerikanische Musik und die mit ihr verbunden Tanzstile einen Prozess der Akkulturation. Mit dem Original hatten sie danach oft nur noch wenig zu tun, wie Josephine Baker beobachtete: „Die Europäer haben den Charleston von den Negern tanzen sehen. Sie haben einen anderen erfunden; er gleicht dem ersten nicht, aber er ist auch sehr hübsch".586 Dank Josephine Baker und ihrer Revue Negre oder den Chocolate Kiddies konnte das Publikum in der Weimarer Zeit auch Shows besuchen, die nicht von Europäern, sondern von afroamerikanischen Künstlern konzipiert und aufgeführt wurden - wobei allerdings fraglich ist, inwiefern diese nicht doch am Ende dem europäischen Geschmack Rechnung trugen. ${ }^{587}$

Bei aller Anverwandlung des Neuen ließ aber auch das populäre Musiktheater in Deutschland unterschwellig ein Unbehagen gegenüber dem amerikanischen Einfluss erkennen. Wie Coward, der die neuen Tänze mit den Bewegungen von Affen im Zoo verglich, fühlte sich die Operette Ball im Savoy an hüpfende Kängurus erinnert:

Känguruh! Der neue Modetanz heißt Känguruh! O yes!

Känguruh! Man tanzt in ganz Europa Känguruh! O yes!

Ganz Paris ist von dem Tanz entzückt

582 This Year of Grace, LCP 1929/9; wiederabgedruckt in: CowArD, Play Parade, 2. Bd., S. 31.

583 Vgl. HOARE, Noël Coward, S. 114-127.

584 Diese widersprüchliche Haltung charakterisiert auch die Forschung; siehe PUGH, We Danced All Night; OverY, The Morbid Age.

585 Vgl. Kothes, Die theatralische Revue, S.74f.; SCHRÖDER, Tanz- und Unterhaltungsmusik, S. 295; HoffmanN, Aspekte zur Jazz-Rezeption, S. 82f.

586 BAKER, Memoiren, S. 45f.

587 Vgl. Ottomar Starke, Revue Negre, Vossische Zeitung, 6. 2. 1926; ,Neger Operette'. Die Chocolate Kiddies, Vossische Zeitung, 26.5.1925; Jelavich, Berlin Cabaret, S. 170-172; Nenno, Femininity; NAumanN, African American Performers; Hopkins, Louis Douglas. 
Und London ist damit verrückt!

Auch Berlin wird bald damit beglückt.

Und selbst die flotten Hottentotten

Trotten statt Black-Bottom

Känguruh! Der neue Modetanz heißt Känguruh! O yes! ${ }^{588}$

Diese Persiflage auf die wechselnden Tanzmoden, die zu immer neuen Kreationen führten, lässt sich als ironische Version von Julius Babs ernst gemeinter Kritik an der ,Tanzwut' lesen. Das Unterhaltungstheater assimilierte aus dem Wunsch heraus, das Publikum dort abzuholen, wo es dieses vermutete - in den Tanzlokalen -, neue Musikstile und Moden, aber es artikulierte zwischen den Zeilen zugleich ein Unbehagen an der Schnelllebigkeit der Zeit. Eben dies brachte Abrahams Song zum Ausdruck, wenn er die Hektik betonte, mit der ein Tanz den anderen ablöste, hin zu immer absurderen Formen wie dem ,Känguruh'. Wenn das Theater neue Tänze aufgriff, verlieh es dem Lebensgefühl der Zwischenkriegszeit Ausdruck, die als Phase verstärkter Beschleunigung und abrupten Wandels wahrgenommen wurde. Zugleich gab es sich den Anschein, mit der Zeit zu gehen, doch wirkte dies in seiner Atemlosigkeit, als fiele es ihm immer schwerer, mit den wechselnden Moden Schritt zu halten.

\section{Zwischenfazit}

Wie dieses Kapitel gezeigt hat, entwickelte sich das Theater in der langen Jahrhundertwende nicht nur selbst zu einem Geschäft, es stand auch in engem Kontakt zu anderen Gewerben wie den Warenhäusern und der Modeindustrie. Diese Kontakte gingen auf grundsätzliche Gemeinsamkeiten zurück: als GmbHs und Aktiengesellschaften unterschieden sich die Theaterbetriebe kaum von anderen Unternehmen; ,Theaterepidemie und ,Warenhausfieber' grassierten zeitgleich und bedingt durch innerstädtische Konzentrationsprozesse teilten sich Warenhäuser und Theater denselben städtischen Raum und damit auch denselben Konsumentenkreis. ${ }^{589}$ Beide verfolgten ein ähnliches Ziel, nämlich einen möglichst großen Kreis von Konsumenten zu erreichen und so ihren Gewinn zu maximieren.

Die Beziehungen konnten vielfältige Formen annehmen: Die Theater warben für Produkte und Unternehmen, Warenhäuser und Theaterateliers hielten Aktien an Theaterbetrieben, verkauften Billetts und bedienten sich bei der Inszenierung ihrer Waren der Strategien des Theaters. Das gilt ebenso für die Modeindustrie, die dem Theater die Modenschau abschaute sowie Bühne und Zuschauerraum als Laufsteg nutzte, wovon auch die Theater profitierten. Die wirtschaftlichen Beziehungen spielten sich also nicht dezent im Hintergrund ab. Vielmehr hatten sie einen unmittelbaren Einfluss auf das Geschehen auf der Bühne, die, angefangen mit der Einführung des Reklamevorhangs, nach der Mitte des 19. Jahrhunderts bis in die 1930er Jahre hinein ein wichtiges Werbemedium war.

588 GrÜNWALD und LÖHNER-BEDA, Ball im Savoy, S. 28.

589 JACOBSOHN, Das Theater der Reichshauptstadt, S. 23; ColzE, Berliner Warenhäuser, S. 8. 
Das Unterhaltungstheater nutzte das Warenhaus als Schauplatz und seine Angestellten als Charaktere, kleidete seine Schauspieler nach der neuesten Mode und teilte dem Publikum auf dem Programmzettel mit, von welchen Firmen es Kostüme und Ausstattung bezog. Bei manchen Schauspielern, Teilen des Publikums und vielen Kritikern sorgte dies immer wieder für Unmut. Letztlich konnten sie die Kommerzialisierung jedoch nicht aufhalten, die für die Theater ebenso wie für viele Schauspieler profitabel war. Auch viele Zuschauer erwarteten, von der Bühne über neue Trends unterrichtet zu werden. Mit der Klassifizierung dieser Inszenierungen als Werbung ist zugleich bereits angedeutet, dass Konsum nicht neutral oder gar kritisch, sondern weitgehend affirmativ inszeniert wurde. Die um 1900 verbreitete Feindschaft gegen Reklame und Warenhaus war allenfalls zwischen den Zeilen präsent - oder wenn sich Protest gegen die Werbung auf der Bühne regte. Die engen wirtschaftlichen Beziehungen zum Einzelhandel und zur Modeindustrie ließen andere Sichtweisen kaum zu. Allein das Melodrama bildet hier eine Ausnahme.

Trotzdem lässt sich die Präsenz von Reklame, Warenhaus und Mode auf der Bühne nicht allein durch wirtschaftliche Interessen erklären. Denn einerseits griff auch das Melodrama diese Themen auf, andererseits thematisierte das populäre Musiktheater auch Moden, bei denen es keinen ökonomischen Hintergrund gab. Ein noch wichtigeres Motiv war offensichtlich das Streben nach Aktualität. Indem das Theater aktuelle Phänomene auf die Bühne brachte, stellte es seine eigene Aktualität unter Beweis und damit seine gesellschaftliche Relevanz. Dass es gerade diese Phänomene herausgriff, lag daran, dass in ihnen die Moderne anschaulich und greifbar wurde. Da die Reklame für Kommerzialisierung und die Demokratisierung des Massenkonsums stand, diente sie als „eine Chiffre der Moderne“ überhaupt. ${ }^{590}$ Die Warenhäuser waren als „archetypal sites of modernity“ Orte, an denen die Umwälzungen der Moderne, allen voran die Geburtswehen der Konsumgesellschaft, genauso aber auch neue Entwürfe von Geschlechteridentitäten sichtbar wurden. ${ }^{591}$ Ähnliches gilt für die Mode, die geradezu als Synonym für die Moderne stand und die von Soziologen wie Werner Sombart und Georg Simmel als zentrales Phänomen ihrer Zeit behandelt wurde. ${ }^{592}$ Desgleichen verkörperten neue Medien, technische Innovationen und musikalische Stile Modernität. ${ }^{593}$ Im Gegensatz zu vielen Intellektuellen, die solche Entwicklungen kritisch beurteilten und den kulturellen Niedergang beschworen, vermittelte das Theater ein auffällig positives Bild dieser Phänomene und somit der Moderne selbst. Erst

590 LAMBERTY, Reklame in Deutschland, S. 36.

591 NAVA, Modernity's Disavowal, S. 46; siehe auch Spiekermann, Das Warenhaus.

592 Vgl. Sombart, Wirthschaft und Mode; Simmel, Philosophie der Mode, insbes. S. 9-11; siehe auch KÖNIG, Geschichte der Konsumgesellschaft, S. 388-390; KÖNIG, Konsumkultur, S. 150152; BerTSCHIK, Mode und Moderne, S. 7-12.

593 Vgl. Schweinitz (Hrsg.), Prolog vor dem Film, S. 146; DümLing, Symbol des Fortschritts; OverY, Heralds of Modernity; ähnlich RIEgER, Technology and the Culture of Modernity, S. 276 . 
in der Zwischenkriegszeit mischten sich - in Berlin wie in London - deutlichere Moll-Töne in die Repräsentation dieser Themen ein.

Die Bedeutung des Theaters wird noch dadurch unterstrichen, dass sich Warenhäuser und Modeindustrie bei der Präsentation ihrer Waren eng an ihm orientierten, wobei sie mitunter sogar einzelne Inszenierungsstrategien und Elemente übernahmen. Wer immer irgendetwas öffentlich aus- oder darstellte, suchte und fand im Theater ein Vorbild. Dass sie aber darüber hinaus das Theater als Werbemedium nutzten, zeigt, dass sie ihre Konsumenten im Theater vermuteten und welche gesellschaftliche Reichweite sie ihm zubilligten. Die Medien, die das Theater ablösten, knüpften daran an. So kann man im Reklamevorhang einen direkten Vorläufer des Werbespots sehen und im Fest der Reklame und Our Miss Gibbs erste Experimente im Product-Placement. Das 20. Jahrhundert entwickelte diese Formen weiter, schuf auf diesem Gebiet aber überraschend wenig Neues. 